Portland State University

PDXScholar

1978

\title{
Indications of feminist influence on contemporary social work practice
}

Clara Elizabeth Miller

Portland State University

Follow this and additional works at: https://pdxscholar.library.pdx.edu/open_access_etds

Part of the Feminist, Gender, and Sexuality Studies Commons, and the Social Work Commons Let us know how access to this document benefits you.

\section{Recommended Citation}

Miller, Clara Elizabeth, "Indications of feminist influence on contemporary social work practice" (1978). Dissertations and Theses. Paper 2773.

https://doi.org/10.15760/etd.2769

This Thesis is brought to you for free and open access. It has been accepted for inclusion in Dissertations and Theses by an authorized administrator of PDXScholar. Please contact us if we can make this document more accessible: pdxscholar@pdx.edu. 


\title{
INDICATIONS OF FEMINIST INFLUENCE ON \\ CONTEMPORARY SOCIAL WORK PRACTICE
}

\author{
by
}

CLARA ELIZABETH MILLER
A research practicum submitted in partial fulfillment
of the requirements for the degree of

MASTER OF SOCIAL WORK

Portland State University

1978 


\section{ACKNOWLEDGMENTS}

I am indebted to Lynn Thompson, my advisor, for guidance in completing this project. In addition, Nancy Koroloff and Susan Hines patiently assisted me with the statistical section; a number of faculty members at Portland State kindly helped me with development of the questionnaire. Without the active cooperation of the Oregon Chapter of the National Association of Social Workers, this study would not have been possible.

I am grateful for the support of my parents, Claire and James Miller, and my friends, Joan Lowe, Genie Miller, Angelique Rottweiler and Bougie d'Allumage. 
TABLE OF CONTENTS

PAGE

ACKNOWLEDGMENTS $\ldots \ldots \ldots \ldots \ldots \ldots \ldots \ldots \ldots \ldots \ldots \ldots \ldots \ldots . \ldots \ldots$

LIST OF TABLES $\ldots \ldots \ldots \ldots \ldots \ldots \ldots \ldots \ldots \ldots \ldots \ldots \ldots$

LIST OF FIGURES ........................ vii

\section{CHAPTER}

I INTRODUCTION $\ldots \ldots \ldots \ldots \ldots \ldots \ldots \ldots \ldots \ldots \ldots \ldots$

II REVIEW OF THE LITERATURE ............... 4

Preliminary Note on Terminology ....... 5

Psychological Implications of the Female Role ................

Problems Created By Restrictiveness of the Female Role

Socialized and Institutionalized

Limits to Women's Power

Mystification of Women's Experience

Feminist Critique of Traditional

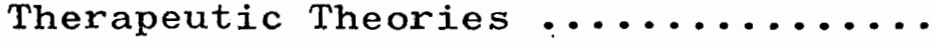

Psychoanalytic Theory of Female

Development

Feminist Reinterpretation of

Psychoanalytic Theory

Feminist Rejection of Psychoanalytic Theory

Feminist Critique of Ego Psychology

Feminist Critique of Theories of

Marital Therapy

Feminist Critique of Other Therapeutic Theories

Feminist Critique of Therapeutic

Setting and Relationship 
PAGE

The Role of Social Work in the

Feminist Critique............. 34

Feminist Therapeutic Strategy ...... 45

The Consciousness Raising Model

Authority in the Therapeutic

Relationship

Interpretation in a Social Context

Women's Negative Self Image

Passivity and the Expression of

Anger

Identity and Personal Relationships

Learning to Value Strengths

Special Techniques and Services

Developed by Feminists

Implications for Research

RESEARCH METHOD $\ldots \ldots \ldots \ldots \ldots \ldots \ldots \ldots . \ldots 1$

Population ............... 82

Selecting the Sample

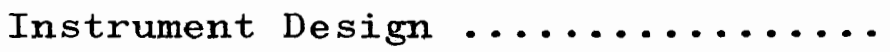

Cover Letter and Strategic

Considerations

Demographic Questions

Case Descriptions

Feminist Beliefs

Involvement in Feminist Activities

Questionnaire Administration ..... 97

IV RESULTS $\ldots \ldots \ldots \ldots \ldots \ldots \ldots \ldots \ldots \ldots \ldots$

Method of Tabulating Scores ...... 99

Feminist Commitment and Intervention 100

Commitment to Feminism

Preference for Feminist Intervention Strategies

Influence of Stage of Life

Differences Related to Type of Intervention 
PAGE

Commitment and Intervention

Strategies.................. 112

Measures of Correlation

Three Groups of Feminists

Demographic Associations ........... 122

Age

Sex

City Size

Date of Last Degree

School Attended

Practice Setting

Ethnic Background

Practice Orientation

Difference Between Feminist Commitment and Practice ............. 133

Pattern of Influence on Practice .... 137

Adoption Limited by Traditionally Prescribed Methods Adoption Limited by Traditional

Role Responsibilities

Limited Acceptance of Feminist Interventions

Influences in Adoption of Feminist Interventions

Questions for Further Study

Implications for Theories of Social Change 


\section{LIST OF TABLES}

TABLE

PAGE

I Difference Between the Original Sample

Group and the Non-Respondents Group..... 100

II Means of Sample Group Responses to Questions

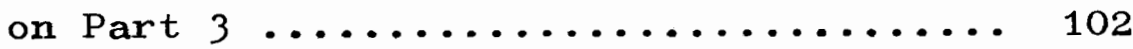

III Mean Scores by Cases .................. 108

IV Scores on Part $2 F$ and on Part 3 for the

Three Groups of Feminist Respondents ... 119

V Age of Respondents .................. 123

VI Mean Scores on Part 2F, Part 3 and Part 4

by Age and Sex ....................... 124

VII Responses to Part 2F Related to City Size .. 125

VIII Date of Last Degree Related to Scores on

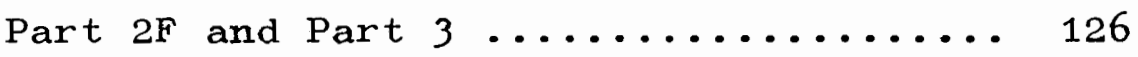

IX Practice Orientation Related to Date of

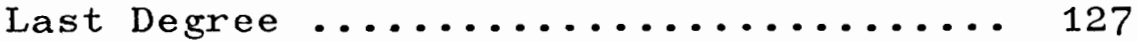

X Distribution of Practice Orientations ..... 130

XI Relation Between Practice Orientation and

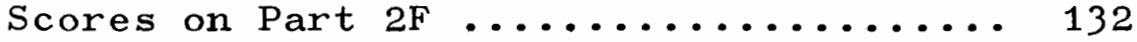

XII Comparison of Mean Scores on Cases in Part

$2 F$ for Group 1, Group 3 and the Samp1e

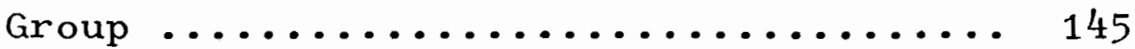




\section{LIST OF FIGURES}

FIGURE

PAGE

1. Pattern of Responses to Part 3 and Part 4 .. 101

2. Pattern of Response to Case 1 in Part 2

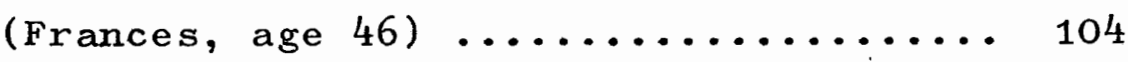

3. Pattern of Response to Case 2 in Part 2

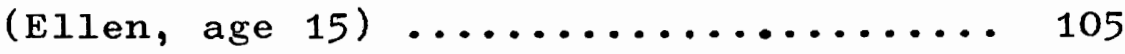

4. Pattern of Response to Case 3 in Part 2

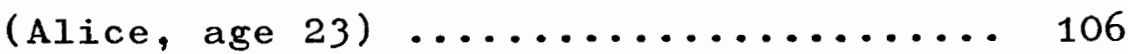

5. Comparison of Mean Response Patterns

by Case and Intervention Strategy ..... 109

6. Joint Frequency Table for the Correlation

of Scores on Part 3 with Scores on

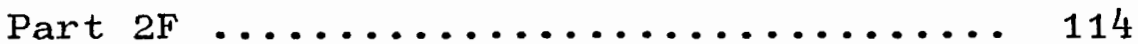

7. Joint Frequency Table for the Correlation

of Scores on Part 4 with Scores on

Part $2 F \ldots \ldots \ldots \ldots \ldots \ldots \ldots \ldots \ldots \ldots \ldots \ldots \ldots \ldots \ldots \ldots \ldots \ldots \ldots$

8. Joint Frequency Table for the Correlation

of Scores on Part 3 with Scores on

Part 4

116 


\section{CHAPTER I}

\section{INTRODUCTION}

Looking at the influence the feminist movement has had on social work practice is an interest that developed for me as much as a result of my own experience in questioning and thinking through the feminist analysis, as of my own -- eventual - judgment that it was, in the main, both valid and useful. I remember that, for a long time, I had no comprehension of what the feminists were talking about. When Betty Friedan/spoke at my college in 1962 , my only reaction was that I was not going to be a suburban housewife, so nothing she said applied to me. It was only when I began to meet other women who took feminism seriously, and affirmed to me that understanding would open doors yet unimagined, that I myself began to take it seriously. And taking it seriously was just the beginning of the process, in a consciousness raising group, with friends, and alone, of understanding, fitting it to my own life, and revising my cognitive map of the world.

As a social work student, I began to encounter some excellent analyses of conditions for women within the profession, and of the effect on clients of social 
work's traditional methods. I realized that a particular effort was being made to demonstrate the seriousness and validity of the feminist analysis to social workers, given added weight because its proponents were social workers themselves.

The analysis of traditional social work methods presented by feminist social workers is a special application of the assessment of concepts that social work shares, as a common theoretical base, with other professions in the field of mental health and the larger social welfare system of our society. This common theoretical base is principally grounded in the psychoanalytic model of what normal development for men and women should look like. In addition, this perspective emphasizes the individual source and nature of problems that may result in deviations from normal development. Recommended solutions also tend to emphasize individual change.

Feminists have questioned both the model of what is normal for women (and men), and the explanation for deviations from the norm. They assert that this interpretive theory is itself an ideological tool that contributes to maintaining women in inferior roles.

Alternative models of women's developmental potential have been presented, together with articulated personal and societal strategies that would facilitate attainment of that potential. There is, generally, an empha- 
sis on the need for women to become conscious of the social forces that shape the contours of their lives (at least as much as of their internal dynamics) in order to effect change on a personal and societal level. It is this criticism of traditional theory and methods, and the advocacy of new approaches that feminists have tried to present to social workers and to other professionals in mental health and other social services. The feminist goal has been to convince social workers and others to modify their beliefs and practice in order to be more helpful (as the feminists believe) to women. In this study of the beliefs and practice of social workers in Oregon, I attempt to find out to what extent, ten years after the "rebirth of feminism," they have adopted feminist beliefs and recommendations for practice. 
CHAPTER II

\section{REVIEW OF THE LITERATURE}

The "second wave" of feminism has been characterized by a thorough appraisal of the factors in social organization that serve to oppress women. In particular, feminism in recent times has focused on the internalized oppression inherent in society's role prescriptions for women. This focus reflects the assessment that removing the more obvious legal restrictions against women was only the first part of the struggle -- in fact for many years oppression was consolidated because women, due to the legal victory, thought they were equal, and therefore ascribed failure and role conflict to personal problems. Jo Freeman explains this new concern:

There is more to oppression than discrimination and more to the condition of women than whether or not they want to be free of the home. All societies have many ways to keep people in their places.... Women have been striving to break free of these bonds for many hundreds of years and once again are gathering their strength for another try. It will take more than a few changes in the legal system to significantly change the condition of women, although those changes will be reflective of more profound changes taking place in society.... It is the more basic means of social control that will have to be attacked as women look into their lives and dissect the many factors that made them what they are. The dam of social control 
now has many cracks in it. It has held women back for years, but it is about to break under the strain (1973: 147).

It was this broadened understanding of women's oppression, focused on "the more basic means of social control," that prompted the resurgent women's movement to examine the mental health and other social services of this society, and to bring its developing analysis to bear on their theory and practice.

\section{PRELIMINARY NOTE ON TERMINOLOGY}

Although this paper is a study of the implications of women's psychological problems for mental health and other social services in this society, it becomes necessary to refer repeatedly to the reputed social origins of these problems. How to characterize this, indeed, how to analyze it, would be ample subject for another paper. A few observations on the state of the analysis, however, are appropriate to explain the meaning of some of the terms to be used in this paper and the reasons for their adoption.

The place of women in the social structure has been compared to that of blacks by Gunnar Myrdal. In his Appendix 5 to An American Dilemma, he states:

In every society there are at least two groups of people, besides the Negroes, who are characterized by high social visibility expressed in physical appearance, dress and patterns of be- 
havior, and who have been "suppressed." We refer to women and children (1944: 1073).

Myrdal elaborates on the similar basis of the differential social treatment of blacks and women, finding its roots in what he calls paternalism. Modern feminism refers to this "pre-industrial scheme of life" as "patriarchy." Myrdal notes that, like blacks!, women's place is in a cast order which is "fundamentally a system of disabilities" forced on one group by another. He follows the parallel with the black caste status to show that the status has been rationalized on similar (often biblical) grounds, that many women have come to believe in the rationale, and that the deprivations in the economic, political and social sphere (though different from those faced by blacks) are upheld "by law, or by social convention and the pressure of public opinion" (1944: 1077). While Myrdal shies at calling women (or blacks) a "minority group" because he believes this terminology imputes too much impermanence to their status, Hacker used this sociological concept in an essay written in 1951 to elucidate a number of facets of women's peculiar status. By Louis Wirth's definition of a minority group, she found women lack the subjective component of consciousness of themselves as objects of collective discrimination, although they clearly meet the objective criterion of receiving differential and unequal treatment. 
She suggested that an outside observer would accord women minority group status, however, and went on to detail the psychological consequences and social causes of this tendency to ignorance of minority status (1976: 156-170). In her further analysis of the position of women, Hacker both applied classic sociological concepts to clarify aspects/of women's position, and pointed out how many were ill-adapted for analyzing this overlooked phenomenon. The concept of social distance, for example, is not useful unless modified as she suggests (1976: 161163).

Other theorists have struggled to analyze and define women's position. Millet's survey of available explanatory concepts in the social sciences, which laid the groundwork for current research, resulted in her coining the phrase, "a status category with political implications," to describe women's situation (1971: 2358). A review of current sociological research and theory building is given by Huber, who notes that "An adequate theory must emerge from many disciplines" (1976: 697). She finds that the concept of "sex stratification" has been useful to recent sociological researchers, but considers the term provisional, depending on the outcome of research. She defines the problem: "what is needed is a theory of 'sex stratification to explain women's apparently subordinate position in every era and in all societies" 
(1976: 696).

Feminists concur with Myrdal's observation, in connection with analyzing the position of blacks, that to speak merely of "discrimination" against women is to be unduly| influenced by a traditional American credo (Myrdal, 1944: 1035-1064), since this defines only one aspect of "woman's place." They tend to use terms with admittedly moral implications such as sexism (to refer to prejudice against women (Huber, 1976:686)), or oppression, to refer to the complex of institutionalized differential treatment, and socialized role prescriptions for women's behavior and men's interaction with them (Cox, 1976: 152). With Myrdal, they would assert that there is no terminology that could convey this reality without inherent value loading (invented terminology would acquire it). That the complex of social controls referred to by the term "oppression" is not yet clearly analyzed and understood does not mean that this term is merely jargon, since the realities it is currently used to describe will, when further understood, be described in value laden terminology also. Myrdal expresses the necessity for using such terminology:

The value-laden terms have a meaning and represent a theoretical approach because the theoretical approach itself is determined by the valuations inherent in the governing ethos of the society. When this is seen clearly, and when those valuations are made explicit and, consequently, the terms are defined in rela- 
tion to the valuations, then, and only then, are we in the position to use the terms freely without constantly endangering the theoretical analysis by permitting the biases to slip in (1944: 1064).

In this paper, then, the term oppression will be used with the understanding that it refers to the as yet imperfectly understood complex "system of disabilities" forced on women by custom and the self-interest of the dominant social group. This system includes both institutional controls and socialized behavior. While the term "oppression" implies a value judgment (i.e. that this situation is unjust) it is asserted that any other descriptive term available would also imply a value judgment, though perhaps one of a different sort Feminists do assert the injustice of woman's situation, and thus the use of this term is representative of the theoretical approach that is here described, and the ethos out of which it arises.

\section{PSYCHOLOGICAL IMPLICATIONS OF THE FEMALE ROLE}

The women's movement has pressed for reform and redefinition of mental health and other social services generally as a result of its developing understanding of what causes psychic pain and social damage to women in this society. This understanding is chiefly socioeconomic, or broadly environmental in nature, unlike traditional intrapsychic or biologically determined 
explanations. With the current influence of field theory, structural analysis, and general systems theories, this focus is not unique to the women's movement. What is unique is the relationship feminists explore between one aspect of the social structure which is generally overlooked by other systems proponents -- sex oppression - to the situation of women.

Problems Created by Restrictiveness of the Female Role

Innumerable articles have detailed "The Stereotype of Femininity" (Klein, 1975: 19-30) to which women have been encouraged to conform throughout their lives. Increasingly, this feminine role is being seen as inadequate for people, women included.

The role involves numerous restrictions on the choice of a life's work for all women; regardless of particular talents, all are consigned to being wives and mothers. For women whose interests lie outside this realm there is role conflict. The conflict may be resolved by exaggerated conformity to the female role (Mundy, 1975: 198). Since the role includes expectations of helplessness and passivity, this may create more problems than it solves. Holroyd (1976: 26) and Fodor (1974: 132-168) point to the importance that these limitations on women's behavior have (along with helplessness and dependency) in the etiology of phobias 
(agoraphobia, in particular). Women who move too far out of the accepted sphere may be subject to severe social censure, as are lesbian women (Abbott and Love, 1971: 609-615) and others. As a woman continues to rebel, she may encounter a range of other social sanctions. Phyllis Chesler describes the way that psychological intervention has become one form of sanction against deviant women. According to Chesler, this has been one of the earlier and milder institutional efforts to restrain a woman's behavior. Chesler states that deviant women are likely to be termed mad, and given oút-patient psychotherapy at first. Then, if found incorrigible, they are likely to be remanded to more stringent authority, such as a mental hospital (1972: 27-59).

The female role does not provide for a woman's expectable lifetime. Pauline Bart's study of depression in oldex women shows that women who had been most involved as mothers, most identified with this core aspect of the female role, became very depressed when their children left home. They still had a possible twenty or thirty years to live, but Bart found they had developed few interests upon which to structure their lives or to base their sense of personal identity, after the children had gone (1971: 183-186). Women's sexual attractiveness, as is commonly pointed out, is considered in this culture to cease when she is no longer 
young (Hubbard, 1976: 32).

The role, furthermore, is inherently contradictory. Some feminists point to this as a double bind situation (Kaschak, 1976: 61). Women are to be sexy, yet virginal; strong (for the housework and other trials), yet weak; subordinate, yet challenging; smart enough to get a man, yet good at hiding their intelligence; capable of achieving at school, but not at work (Rice and Rice, 1973: 193).

Even women who fulfill the sex role and report themselves as satisfied, tend to be less satisfied than the men who, in some respects at least, share the same circumstances through marriage (Bernard, 1971: 26-32). Housewives, in particular, constitute a population that is significantly more at risk for developing neurosis than the population of working women (Bernard, 1971: 47-49). Numerous studies confirm that women who work are psychologically healthier (see, for example, Powell, $1977: 414)$

Socialized and Institutionalized Limits to Women's Power

People do not come to fill such an unsatisfying role by choice or chance, feminists assert. In expe tation of their growing up to fill one or another $s$ type of femininity, women experience a very differ early socialization process than do men. In gir] 
pendency is fostered by encouraging clinging, "charming" behaviors (Bardwick and Douvan, 1971: 226-228). Direct aggression is sharply discouraged, as are mere activity, creative games (rather than repetitive playing house), testing and developing their bodies (Brownmiller, 1976: 451). Often girls have a period of relative freedom until about the fifth grade, when tolerance ends. Girls who persist in pursuing boys' options may do so "not from unsureness of feminine identity, but from a knowledge of it and its implications" (Chodorow, 1971: 285). Still, they are not permitted to pursue their choice, and are socially coerced, not only by authority figures, but also by their peers (Chodorow, 1971: 284-286). Girls are socialized to the more oblique forms of aggression, particularly the forms of pro-social aggression described by Shirley Bernard: enforcing the norms of the group (Bernard, 1971: 190).

Chesler sees this behavior of competitiveness with other women as developing out of a socially denied need for companionship with them:

The female "policing" phenomena is rooted in an anguish of powerlessness.... Psychologically and politically in male society, one woman's "success" is usually purchased at another woman's expense. The successful woman today cannot protect (or instruct or "incorporate") other women into a non-biologically based image of power or individuality. There are too few "successful" women to accomplish this by interpersonal social example (1972: 274). 
In isolation from egalitarian relationships with other women, girls come to value other relationships. These tend to be between people of unequal power, namely between daughter and parents, between husband and wife, or between mother and children. They tend to be characterized by the expectation that the woman involved will work toward satisfying the needs of the others.

As a result, women learn to put others' needs before their own. Bardwick and Douvan describe the developmental phenomenon:

Some girls defer consciously, with tongue in cheek, but the majority, who were never significantly aggressive, active, or independent, internalize the norms and come to value themselves as they are desired by others. The only change from childhood is that the most important source of esteem is no longer the parents but the heterosexual partner (1971: 230, 231).

Both Chesler (1972: 295) and Miller (1976: 71, 72) see this relationship to a specific group of others as the basis of a woman's ego identity. Miller also shows the positive potential of this characteristic preference for "relatedness" that women have developed in this culture $(1976: 60-75)$

The female role is less valued than the male role, and is subordinated to the male role in this culture. Natalie Shainess surveyed the modern literary and social scientific sketches of relations between the sexes to conclude that men have taken for granted their superior 
position, their centrality, and have assumed that they are the standard by which the rest is measured (1969: 77-97). Several social scientists have pointed out that women resemble a minority group, with the exception that they lack a sense of consciousness of their shared status (Hacker, 1976: 156-170; Myrdal, 1944: 1073-1078; Bem and Bem, 1976: 180-190) .

Bardwick and Douvan describe the process by which, at adolescence, while Erik Erikson's boys are establishing a sense of identity, girls are learing ambivalence:

The essence of the derogation lies in the evolution of the masculine as the yardstick against which everything is measured.... Ambivalence is clearly seen in the simultaneous enjoyment of one's feminine identity, qualities, goals, and achievements and the perception of them as less important, meaningful, or satisfying than those of men. Girls envy boys; boys do not envy girls (1971: 234).

More than devaluation, but reinforcing it, is the daily experience of an institutionally elaborated "system of disabilities" (Myrdal's term). Miller and Mothner detail the psychological consequences of this arrangement, both for. the dominant (since they are tied together) and the subordinate group. Subordinates tend to learn to dissimulate in order to survive. They absorb some dominant group rationales (especially if there are no alternative intellectual explanations available) for their position. Still they have experiences of themselves and their irrational relationship to the dominant 
group that conflict with the official version, and develop increased inner tension as a result. When members of the subordinate group begin to question the situation, they move ipso facto into open conflict with the dominant group (which defends its position because it consistently underestimates the true cost of maintaining it). Conflict continues on a covert level at other times, and tends to have certain constant characteristics: there is no real resolution or satisfaction because "the real objectives, the factors that create the unequal situation are never attacked" (1971: 772). Besides, the social norm for relationships between people involves the type of relations the dominant group has with the subordinates: routine destructive treatment of others (1971: $768-75)$.

Marecek analyzes the relationship of three models of "powerlessness" to depression. These models are defined by epidemeological statistics, studies of life stress, and Seligman's theory of "learned helplessness." Marecek concludes that the three complementary models indicate that women, due to their lesser power (which is both institutionally and cognitively based) are more at risk for developing depression. Marecek notes that "Nonemployed wives with young children may experience the most severe sense of powerlessness" due to the need of their children for constant care, their isolation from 
other adults, and their probable lack of control over family finances $(1975 b: 4,5)$.

Wetzel sees socialization for dependency (when the environment does not support that dependency) as leading to a sense of powerlessness and depression. She also points out that women's environment does not support independence either, because of women's lack of institutional power, and therefore also leads to depression $(1976 b: 10-15)$.

Mystification of Women's Experience

Overlying this very real derogation of women's power and opportunity, feminists assert, are the myths of femininity. Members of oppressed groups often come to believe in their own inferiority, both because the dominant group convinces them, and because they need an explanation of their inferior status in society (Allport, 1954: 142-162). Women are especially vulnerable to these myths since they live isolated from each other in separate families and in closer and more constant proximity to representatives of the dominant group. The myths vary greatly in scope. Betty Friedan, for example, describes the uncanny hold of the myths surrounding the suburban housewife: from stories and vignettes in women's magazines to Freudian pronouncements about how women can be normal and happy (the function of Freudian theory as mystification is 
explored further below). Anthropologists have traced myths of female evil throughout almost all known societies (Ortner, 1974: 67-87).

Much of the work on mystification of experience by culture and ideology has been done by women influenced by the radical psychology movement. They define mystification of experience as social explanations which are misleading on many levels (Brooks, 1973: 339-345; Hermes, 1972: 29-34). They examine the many ways in which substitute and misleading explanations of experience may distract women (and men) from attacking what they analyze as the real roots of the problem, and to fail to see the problems they have in common with others (Kashak, 1976: 63; Wyckoff, 1971: 182-184). For example, a woman influenced by the women's magazines surveyed by Friedan might look for the causes of her unhappiness in problems with her husband, rather than in her lack of meaningful work (and fail to see that her neighbor has the same problem).

A common thesis of the women's movement in recent years has been the necessity for "reclaiming our bodies." This indicates the extent to which feminists feel their most intimate experience has been "mystified," and unavailable to them. Ignorance of their bodies, and devaluation of their physical selves, as well as distorted beliefs about body function and appearance come from the influence 
of myths of the dominant culture (Rush, 1974: 55-57; Wyckoff, 1977).

FEMINIST CRITIQUE OF TRADITIONAL THERAPEUTIC THEORIES

Feminists have criticized traditional therapeutic intervention in terms of the structuring of relationship between therapist and client, and in relation to its overt interpretive concepts. Not all feminists criticize the traditional methods for the same reasons: some attempt to criticize in order to reject them. Yet all would agree that traditional therapies have been consonant with and reinforcing of women's oppression, and there is widely shared agreement on the broad outlines of how this has occurred.

Feminists have focused their criticism of the traditional interpretive constructs on psychoanalytic theory, which they regard as basic to modern ego psychology. Some feminists have analyzed other approaches (as will be noted below); however the terms in which other therapeutic approaches are analyzed are derived from the concepts developed to undertake the criticism of psychoanalytic theory.

Psychoanalytic Theory of Female Development

Feminists criticize psychoanalytic theory for positing the biological (and hence permanent) inferiority of 
women. In Freud's description of female development, girls and boys both take their mother as their first primary object. He theorizes that, upon seeing a boy's penis, a little girl "acknowledges the fact [sic] of her castration, and with it, too, the superiority of the male and her own inferiority" (Freud, 1974b: 54). The little girl develops "penis envy." Abnormal development occurs when the little girl continues in active strivings to gain her desires: Freud called this the masculinity complex. Alternatively, she might abandon the whole enterprise and become relatively asexual. Freud posits the "normal" resolution of this dilemma as abandoning the active striving for passive desires. The little girl becomes attached to her father through passive libidinal drives in hopes of obtaining a penis from him. These hopes, which finally mutate into a desire for his child (preferably male) are finally transferred to a desire for a child from her husband. Freud adds that women, therefore, do not need to sublimate their desires to the same degree as do boys, and thus, their resolution of the oedipal period does not result in as strong a superego formation (Freud, 1974c: 113). Therefore they have less sense of justice and mora1ity (Freud, 1974a: 36). Further, in the process of changing object identification from mother to father (as well as in change of erotic area from clitoris to vagina) their sexuality is likely to be repressed and lost to them. 
This developmental picture emphasizes the normality of female passivity. Only as a mother caring for her children does Freud grant that a woman is normal in her expression of active drives.

Feminist Reinterpretation of Psychoanalytic Theory

This model of female development was criticized almost from the start (although this criticism did not stem its influence to any great degree). This criticism has generally taken two relatively distinct forms: reinterpretation, or rejection of all or part. Horney early pointed out that the Freudian theory mirrored in abstract language what little boys commonly thought about little girls $(1973 \mathrm{a}: 8,9)$, and proceeded to use some of Freud's basic methods and insights to develop her own theories about women (1967).

Chodorow acknowledges Freud's misogeny, but feels some of his insights are valid and can be used to clarify the errors in his theory of female development. She points out that Freud's theory of biologically determined inferiority for women contradicts one of his basic percepts, that the way a person internally represents his or her biology is a developmental product, and may be shaped by considerations other than biology (such as culture). Further, she points out that Freud injected teleological concerns: the idea that the aim of sex is procreation seems to have 
deterred him from his original thesis that there is nothing inevitable about sexual object choice. Finally, penis envy is not treated as something that needs to be explained, contrary to Freud's principle that all traumas need explaining, but is taken as self evident (1977a). Chodorow joins other feminists in interpreting what Freud describes as the result of family structure, a social and cultural phenomenon, itself|a result of the social oppression of women. Chodorow, whose own theories relate mainly to the pre-oedipal period, sees that the little girl's early attachment to her mother is overly encouraged by the mother; the daughter fails to develop autonomy, particularly in the context of the nuclear family (1974: 58-65).

Most feminists reinterpret girls' development during the oedipal stage in terms of power. Clara Thompson pointed out that (besides not being a castrated boy) the girl wanted not the boy's or father's penis but his power (1973: 52-57). Kronsky finds that partial identification with male figures ("penis envy") is normal and fairly widespread in this society because men have more power and opportunity, and, like Thompson, she finds that these identifications fade rapidly when a woman is encouraged to develop her own power (1971: 91-95). Along with her emphasis that Freud overlooked the fundamental existential situation, Simone de Beauvoir analyzes 
the many ways a woman comes to appreciate her real social inferiority, and states that this, rather than the series of events postulated by Freud, is the basis of her development (1974: 42-58). Shulamith Firestone echoes this in her more recent attempt to reinterpret all Freudian theory in terms of gender-differentiated power (1970: 53-58). Millet, similarly, makes a very detailed analysis of the way Freud's intrapsychic explanations obscure and substitute for sociological analysis (1970: 176-202).

Mitchell takes a slightly different tack. She validates Freud's discovery of the unconscious (and its methods of reaching conclusions) along with his emphasis on infantile sexuality (1974:5-29), as does Chodorow. Mitche11, however, states that the oedipal situation is the point in development for a boy or girl when certain ideological structures become part of the unconscious. In this culture, those ideological structures relate to the exchange of women (in the marriage institution), and therefore this critical point of entry into society has the form described by Freud as the oedipal situation (1974: 377-381). With this proviso to save the concept of the unconscious, Mitchell emphasizes that what Freud has described is one mechanism of female oppression, and that its particular character is social and not biological. Breaking the hold of patriarchal culture, she states, is the task of feminism. When 
this has been done:

$$
\begin{aligned}
& \text {...some other expression of the entry into } \\
& \text { culture than the implications for the uncon- } \\
& \text { scious of the exchange of women will have to } \\
& \text { be found for non-patriarchal society (1975: } \\
& 415 \text { ). }
\end{aligned}
$$

\section{Feminist Rejection of Psychoanalytic Theory}

Other feminists, such as Naomi Weisstein, point to the problems in Freudian theory and in the theses of his followers to demonstrate that psychology knows next to nothing about women. Weisstein abandons the psychological focus for a social psychological approach:

...it is obvious that a study of human behavior requires, first and foremost, a study of the social contexts within which people move, of the expectations about how they will behave, and of the authority that tells them who they are and what they are supposed to do (1971: 219).

Other feminists reject only certain parts of the psychoanalytic position. One of the most commonly rejected aspects is Freud's theory of the vaginal orgasm. Feminists, supported by Masters' and Johnson's research (1966: 66,67$)$, reject the idea that a woman must abandon one erotic zone for another. Koedt's essay, "The Myth of the Vaginal Orgasm," emphasizes the contribution of this myth to maintaining women in ignorance of their bodies, and how this served men's sexual and political interests (1970: 204-206). Many feminists object to Freud's characterization 
of women as having less developed moral sense than men. They point out that men's development has led to dehumanizing competition and near-destruction of the planet.| They also observe that male-oriented psychology has neglected to recognize that:

...their own concept of full development is still generally tied to an image of men. They thus overlook the psychological value of those processes in which only (or especially) women have engaged (Miller, 1973: 387).

Women have, for example, more "male" skills than is generjally recognized by psychology texts, but they also posselss "an awareness of the intricate interstices of human relationships rather than the manipulation of things" (Miller, 1973: 388). At the same time, feminists acknowledge women tend to be passive, too dependent on servi|ng others' needs rather than advancing towards meeting their own, and accepting of male standards of behavior, including competitiveness and devaluation of women (Miller, 1976: 10-12, 94). These less desirable characteristics, along with the strengths, are seen as deriving from women's particular position of powerlessness,| rather than the "normal" development of the feminine |character (Miller, 1976: 124).

Feminists also reject Freud's concept that passivity is woman's normal route to satisfaction, while competition with men is evidence of penis envy and the masculine protest. Many refutations of this thesis 
could be cited (including a number of the studies described above in relation to the female role). Particularly interesting, perhaps, is psychoanalyst Ruth Moulton's statement that the passivity thesis is one of "the inaccuracies that necessarily accompanies a phallocentric view of women" (1973: 240). She adds:

Many women achieve a sense of complete fulfillment when they are actively investing their intelligence and talents in pursuits that were formerly regarded as masculine prerogatives. The acceptance of narrow concepts of normal sexual function unnecessarily limits the development of individual activity patterns and may cause women to forfeit a great deal of what might become valuable and attractive feminine effectiveness. Activity has primary satisfactions apart from competition with men (1973: 257,258 ).

There is, then, no particular area of life from which a "normal" woman is debarred.

Feminist Critique of Ego Psychology

With the development of ego psychology, emphasis shifted.from focus on resolution of genitally determined id drives to the socially defined functions of the ego in dealing with reality. "Adjustment" to reality thus became the new standard of normality. Feminists join with radical therapists (who assert "therapy is change not adjustment") in attacking the adjustment principle. Firestone summarizes:

Meanwhile, Freudianism itself had undergone deep internal changes. Emphasis had shifted from the original psychoanalytic theory to 
clinical practice... The term that perhaps best characterizes this neo-Freudian revisionism is "adjustment." But adjustment to what?

The underlying assumption is that one must accept the reality in which one finds oneself. But what happens if one is a woman, a black, or a member of any especially unfortunate class of society? ... One must abandon all attempts at self-definition or determination (1970: 71, 72).

Adjustment to reality, for women, meant adjustment to the female role. Many argued, as did Gordon Hamilton, that adjustment did not involve persuading the client to accept unjust, deprivational conditions. Rather, the focus was to be on understanding reality: accepting it or not was up to the client (1951: 237-270). At the same time, however, ego psychologists and those who used concepts of ego psychology in their work (Iike Gordon Hamilton) rejected social action focused on economic and cultural conditions as part of the therapeutic process. Wetzel observes that thereby "Hamilton rejects a vision of a real world that includes not only what is, but also what can be, and the facilitation of its development" (1976b: 13, 14). The problem with such an orientation is, feminists assert, that in the absence of alternatives to the social norm, which this approach facilitates, women have little or no choice but to accept the reality they know. Noting that therapists have often dismissed women's resigned complaints about the "reality" of the female role as due to secondary gain, rather than 
taking them seriously, Brodsky says:

Such therapists probably do not understand that without role models or encouragement from the environment, these women have no real choice in not accepting the only reality they have been indoctrinated to believe about the capacities of their sex (1973: 27).

Brodsky also points out that therapists' acceptance of the female role as the norm to which women should adjust had adverse consequences for women who had comfortably transcended it:

Therapists have been guilty of producing iatrogenic disorders in women who felt comfortable in what they were doing until the therapist suggested that they were selfish, unreasonable, or pointed out how no one expected them to accomplish so much and they would be loved and accepted without this unrealistic drive to compete (1973: 28).

In uncritically taking the current cultural standard as the standard of normality of adjustment, the feminists claim, therapists ignored the pathogenic situation the role implied, and the healthful creativity of those who moved beyond it.

\section{Feminist Critique of Theories of Marital Therapy}

Marital therapy has been one very popular development of ego psychology and sociological systems theory which has had a profound effect on women. The principles of this therapy have had ostensibly solid empirical support, which is now being questioned by feminists. They question the use of stability as a criterion of success 
(a marriage may be stable for many reasons, not all of which are taken into account or controlled for). In the area of marriage research, self report data has been found to be particularly contaminated by conventionality. Feminists criticize the models on which the studies and therapy are based. Most employ Parsonian expressive (this is the wife)/instrumental (the husband) role models of marriage as a social institution to the neglect of other approaches available even before the feminist critique, such as Burgess' model of "companionship marriage" (1953: 417-469). Feminists point out that women inevitably perform many instrumental functions in child rearing and that giving the woman responsibility for all expressive functions in the family inevitably puts a strain on her and on the system itself which is not even conducive to system maintenance:

The wife is responsible for the quality of the relationship yet the role prescriptions limit her to unilateral activity. Consequently it should come as no surprise to observe that wives in fact adopt a strategy of insight cum accommodation -- a line of action that may be pursued unilaterally, that requires no mutual adaptation, raises no conflicts, ensures harmony -- and of course characterizes relationships of inequality (Laws, 1971: 489).

Occasionally therapists state the man's and woman's functions are worthy of equal respect, but this idealistic view glosses over, not only the interactional dynamic described by Laws, but also the difference in power 
between husband and wife (the wife has less control over material resources and fewer options), and the fact that the wife's function is not accorded equal respect in the larger society (Laws, 1971: 490-493).

Thus, in marital therapy, the wife assumes the traditional role, encouraged in this by therapists who have not given due regard to the pitfalls of this way of living. In particular, the woman's tendency to see her relationship roles as more important than her self-actualization is reinforced. Criticism of this aspect of the theory is widespread. For example, female psychologists, responding to an APA survey:

...criticized a wide variety of therapist attitudes or behaviors that force them into a kinship role: suggesting that getting married would solve problems, that a woman's attitude toward having children is a sign of her emotional maturity, that child rearing and a child's problems are primarily the mother's responsibility in family therapy, that a husband's needs are primary; or simply being insensitive to the woman's career, work and role diversity, (quoted in Holroyd, 1976: 24).

Therapists have, then, ironically, also reproached women for not developing an adequate sense of self and self worth, or stressed the components of female masochism (Miller, 1976: 48-59).

Feminist Critique of other Therapeutic Theories

Any therapeutic approach that (1) prescribes roles and functions for women that are not applicable to men, 
or that (2) ignores women's social context in applying its therapeutic concepts and procedures is criticized by feminists. These are the main points developed in their criticism of Freud and applied to other therapeutic systems. Feminist criticism of Jung's psychology, for example, has centered on the idea that the mythic content of the anima does not fit women's experience (de Castillejo, 1973:77). To limit women to being "earth" while men are "spirit" inevitably implies a power differential between them, although this contradicts one of the overt tenets of the theory.

While feminists have used gestalt techniques, as well as techniques from other branches of the humanist movement in psychology, they question the pervasive assumption of "personal responsibility":

Everything is not my projection and there are many things over which I have little control no matter how clear and sane and together and responsible I become. It is dangerous to women to have these blame trips laid on them. Women have been taking personal responsibility too long for difficulties in their lives whose roots are social. It is time we put some of the responsibility where it belongs, on the oppressive political-economic system (Rush, 1974: 48).

Further, they point to the emphasis on "doing your own thing" as destructive of community sharing and responsibility for the individual member. Rush comments: "As I see it, this attitude is a perfect philosophy for a capitalistic society and a laissez faire economic system" 
(1974: 49).

Behavior therapy is criticized, not on the grounds of prescribing role behavior (Lazarus, 1974: 217-229), although it may be criticized on the grounds of prescribing, but for ignoring the social context of the behaviors it seeks to treat. This is illustrated by the feminist treatment of the behavioral technique of assertiveness training described below.

Feminist Critique of Therapeutic Setting and Relationship

Feminist criticism of traditional therapies also is aimed at the therapist/client relationship and the setting of therapy. Phyllis Chesler sees the nature of both asylums (where poor people get therapy) and private therapy (for the middle class) as "patriarchal." Asylums are patriarchal in that the patients have few rights, and get little emotional support from anyone.

At their worst, mental asylums are families bureaucratized; the degradation and disenfranchisement of self, experienced by the biologically owned child (patient, woman) takes place in the anonymous and therefore guiltless embrace of strange fathers and mothers.... Perhaps one of the reasons women embark and reembark on "psychiatric careers" more than do men is because they feel, quite horribly, at "home" within them. Also to the extent to which all women have been poorly nurtured as female children, and are refused "mothering" by men as female adults, they might be eager for, or at least willing to settle for, periodic bouts of ersatz "mothering" which they receive as patients (Chesler: 1972: 56,57).

Besides, female patients are supervised by other women 
who are nearly powerless in the hospital hierarchy, another replication of the family situation.

Private therapy has similar characteristics. The woman is subordinated to the (usually male) expert who will tell her what to do (for her own good):

For most women (the middle-class-oriented) psychotherapeutic encounter is just one more instance of an unequal relationship, just one more opportunity to be rewarded for expressing distress and to be "helped" by being (expertly) dominated. Both psychotherapy and white middle-class marriage isolate women from each other; both emphasize individual rather than collective solutions to women's unhappiness; both are based on a woman's helplessness and dependence on a stronger male authority figure; both may, in fact, be viewed as reenactments of a little girl's relation to her father in patriarchal society (1972: 121)

The woman is encouraged to talk, but not to make any major attempt to change her situation; the situation may well, however, turn out to be her fault.

Finally, the therapist's position as an expert is ultimately confusing, adding to the woman's uncertainty about where she stands. The therapist does not make personal communications, or, resting on the assumption that his theory is "scientific," make statements about his values. This prompted one woman's "Letter to her Psychiatrist":

I was operating under a false premise, namely that we could have an honest exchange of ideas. Instead, I have had to guess where you stand from things you imply, rather than have real feedback on which to defend my accusations. I also see that 
there are very real reasons why you would want to withhold information from me, and also channel things into a direction which would and did work against me as a woman (Miller, 1971: 140).

In a time when the validity of the theories upon which the therapist's authority is based is being questioned, feminists are demanding disclosure of therapeutic values.

THE ROLE OF SOCIAL WORK IN THE FEMINIST CRITIQUE

Social work, as a profession, has begun to react to this new definition of what women's problems are and to the criticisms of traditional approaches to treatment. Janice Wood Wetzel, a social worker, notes that "In reality, social workers provide a preponderance of all psychosocial treatment. Social work attitudes and behavior are, therefore, not only relevant, but also of great impact and concern". (1976b: 12).

As a first step, the women's movement has sparked a new awareness of the status of women in the profession. Women in social work, like educator Diane Kravetz, have revived interest in the historical background of women in social work. Kravetz determined that women had been especially important in the early years of social work, a position facilitated by social work's connection with middle class charity work, and the perception of its role as an extension of woman's mothering role. When, in the $1950^{\prime} \mathrm{s}$, men were increasingly recruited into the 
field, they generally took different types of jobs; as administrators, planners, group workers, theoreticians (Kravetz, 1976b: 412-424). Thus, women social workers: ...did not reject the assumptions underlying the sexual division of labor in society; sex role socialization effectively controlled their professional behavior and goals (Kravetz, 1976b: 422).

Therefore, besides the discrimination they encountered in their personal lives, discrimination became more of a part of their professional experience as we11:

Women social workers did not recognize the ways in which sexism affects society's determination of occupational prestige, nor did they realize that a significant rise in discrimination against women would accompany an increase in the proportion of male social workers (1976b: 422).

At present, women in social work have fewer administrative positions, lower salaries (even after taking account of the costs of taking time out for families, traditionally the woman's responsibility), publish fewer articles in journals, obtain fewer D.S.W. degrees: down to $24 \%$ from the $85 \%$ that prevailed when the degree was first granted (Kravetz, 1976b: 424). Other observers have noted the trends and statistics Kravetz presents, and proffer various explanations for them. Chafetz points to role conflicts, and devaluation of women's efforts (1972: 14-17). Williams, Ho and Fiedler focus on evaluation processes:

The perception of competence on the part of 
decision makers in the organization may be a significant problem for women. Since most decision-makers are men, could it be that men feel more secure in choosing to promote other men and are simply less able to evaluate women adequately? Or is competence in general poorly evaluated and do objective standards actually not play a major part in making such decisions? (1974: 466).

Scotch, somewhat at a loss to explain why women did not protest about unequal treatment in the field, wonders whether women never expected promotions and better salaries (and therefore did not get them: a self fulfilling prophecy), whether they were ninterested in administration or felt there was no real power there, whether their sense of professionalism silenced the few who would have protested, or whether they lacked peer support (1971: 10)

In any case, the record of such clear discrimination in a "woman's profession" suggests that social workers, like other women workers, did not have a developed consciousness of women's issues before the women's movement. In fact, Mary Schwartz, writing in 1974 , surveyed articles in Social Work for the preceding eight years, looking for discussions of sex as a factor in social work practice. She found four articles: two dealt with practice issues and two with the status of women in the field; all had been published from 1971 to 1973, after the first impact of the women's movement had occurred (1974: 177-183). Schwartz noted 
social work had been sensitive to the concerns of women (child welfare, etc.), but that this is not the same as considering the implications of sex role for oneself or for one's client:

Many writers either write with unisex labels, or, when they do give the sex of the client group, they fail to develop the significance of that information. A small number of articles indicate behavioral differences, but neglect to develop reasons for those differences. Realistically, one does not live in the unisex world that many social work writers construct. Social workers, their clients as well, are either male or female. They deal with specialized sex role pressures as they confront their client's problems and try to develop solutions for those problems. In the construction of new roles, social workers and clients have had to deal with both the available male or female support systems, and the acceptable, defined behaviors of sexism in this culture (1974: 184).

Following Schwartz's article, however, more attention has been given to sex role issues and sex discrimination in social work journals and by social workers writing in other formats. Several writers have pointed to the connection between the conditions under which social workers are trained and practice and their work with clients. Kravetz, for example, states, "Women social workers share a common experience with women clients as victims of discrimination based on sex" (1976c: 160).

Besides the conditions of practice and their implications for awareness of the issues of women's liberation there is the issue of social work theory and the content 
of social work education. Kravetz (1976a) believes that "distortions and false statements are notable in the theories taught in human growth, behavior, and psychopathology courses" where the curriculum is structured around the intrapsychic theories of Freud, Erikson, and others. Walstedt, in a survey of a number of prominent intrapsychic theorists, concludes that they have little to offer for understanding women $(1976: 8,9)$. Wetzel quotes Rhonda S. Connaway's statement that the tendency to view such conditions as depression intrapsychically instead of socio-culturally, is in itself discriminatory against women (1976b: 12).

Feminist social workers have insisted that social work needs an expanded view of the client's problems, one which includes, specifically, the concept of sex role oppression. They add that this is not enough: social workers need to become aware of their own attitudes, the situation of women in their own profession, and how these influence their conceptions of the potential of women and their work with women clients (Kravetz, 1976c: 160).

Incorporating an analysis of the oppression of women into social work theory will, feminists assert, strengthen social work as a field:

The reintegration and application of the principle that social and psychological factors interact to affect the individual's wellbeing could lead to renewed viability for the social work profession. The women's libera- 
tion movement, with its emphasis on egalitarian prinicples, environmental change, and resocialization of men and women has provided the impetus (Wetzel: 1976b: 15).

Moreover, Kravetz states that the socioeconomic explanation as a basis of social work intervention is part of the "best" social work tradition:

Finally, women clients must be encouraged to be aware of environmental constraints and to use that awareness to discover new solutions for defined problems. This is not a radical statement; it is an accepted social work function, i.e. to increase options and opportunities of clients (1976c: 167).

Thus, feminists assert that including an awareness of the social and psychological implications of the female role is iconsonant| with some of the most innovative conceptual theorizing in social work. Kravetz herself cites the .work of Pincus and Minahan as laying out a framework for practice which could fit and be enriched by feminist concerns. For example, Pincus and Minahan state that among the legitimate functions of social work are making linkages between people and societal resource systems, and contributing to making public policy (1973: 64-68). Feminists' concern with the absence of critical sex role analysis in psychodynamic theories is one aspect of a problem that has troubled social work theorists for years. Many have pointed to the way the focus of casework narrowed from the 1920 's onward, when it first encountered psychoanalytic theory. Scott Briar has called this the "retreat to therapy" (1968: 7). 
Redefinition of social casework as treating individual

"illness" influenced group work and community organizing as well. It involved a significant value shift, as well as a shift in focus; the tacit assumption in treating only individual illness is that the social order is at least as good as can be expected; therefore only individuals need change (Borenzweig, 1971: 16). This narrowed focus was, ultimately, a political phenomenon. After describing the salient events in the transition, Borenzweig concludes:

Concern with sexual behavior and the unconscious led to the neglect of balancing psychological theories, particularly those concerned with the more rational cognitive processes of the mind. Finally, the repudiation of social reform caused by the political climate of the 1920's reinforced a preoccupation with the individual psyche. The conclusion one draws from this historical analysis is that the social work profession must be acutely sensitive to the political forces that influence the scientific judgment of the validity of a treatment theory (1971: 16).

The Briar and Borenzweig criticisms have been addressed most adequately by the systems framework theorists, like Pincus and Minahan (cited above), and Carol Meyer. Meyer's approach is self-consciously oriented to responding to the defects of the traditional psychosocial perspective, and systematically accounting for the influence of social institutions on individual identity:

In the linear psychosocial framework, problems are assessed along the range of psychological to 
social phenomena, with one emphasis being greater than the other in some cases. Actually, knowledge of psychological phenomena has been more unified and compelling so that in the linear approach, attention to the social part of the framework has been almost peripheral. In comparing knowledge and action possibilities of the psychological and social polarities, it has been no contest; the pivotal. construct has remained psychological. No amount of pressure could "put the social back in social casework" because the power of the knowledge of the individual was overwhelming and therefore determined practice techniques (1973: 48).

Further, Meyer notes that her "eco/systems perspective," ] which she believes should retain parts of ego psychology, opens the way for a reintegration of theoretical bases for casework, group work, and community organization, which had become completely impossible while casework practice was equated with psychotherapy (Meyer, 1976: 130-151). Both aspects of Meyer's view are congenial with the feminist focus: once individual problems of women are linked to social institutions, roles, and the economy, it becomes possible to intervene on a number of levels coherently to attack the same problem area. Kravetz, for example, specifically points to the "antiwoman values of social welfare policies" in AFDC (1976c: 165). Further examples of the implications of the feminist analysis for remoulding existing service networks and creating new ones will be examined below.

As Borenzweig suggests, and Bart (1974) and others confirm, the adoption of conceptual frameworks is 
politically influenced, and feminist analysis, for all the scientific studies it has sparked and will encourage, and for all of its basic theoretical congruence with current reconceptualizations of social work practice, remains controversial. Some aspects of the analysis have revolutionary implications (abolishing family structure for example); others are more reformist. Meyer notes the limitations of social work as a profession in espousing radical causes: "All professions exist for purposes defined by the society and social work is perhaps the one most responsive to the social mandate" (1973: 31$)$. In her essay "Signals from an Illustrious Past," Kendall attempts to draw the line for the profession between reform, which is an acceptable professional concern, and revolution (which is not) through an analysis of the history of social work's concern with socioeconomic determinants of social problems. She emerges with two standards of acceptable reformist concern: that social workers be competent, with a valid theory, and that they "maintain a basic solidarity with the field" (1977: 334). It would seem that much feminist theory meets the first criterion, insofar as it has a firm basis in research and is brought to bear by appropriately trained social workers. The second test is, by its nature, an overtly political one, but one that is openended. Although social work does not significantly 
control the political climate, social workers do have a hand in influencing it, like any other group, and are particularly likely to have influence in the area of mental health and other social services. Therefore, whether a plan meets the criterion of "solidarity with the field" is at least partly the result of the educational and policy-influencing efforts of social workers who have taken upon themselves the responsibility for changing professional practice. In fact, this kind of effort has been recognized for some time as a legitimate function of social work.

Social workers may have a special responsibility for undertaking educational and political work in the case of women's liberation. For one thing, sexual discrimination is clear in the very institutions in which social workers serve, and has direct effects on women social workers. Second, as Miller and Mothner argue, social workers and other behavioral scientists have supported the rationalizations of what is "normal," although they did not create the problem. Their professional contribution to elucidating the destructive effects of inequality would be particularly appropriate (1971: 775). Rice and Rice, acknowledging the implications for therapeutic practice, point to the need to train new therapists, the need for professionals to be open proponents of alternative life styles and "community agents of social change" 
(1973: 194).

There is some evidence that social workers are beginning to take on this obligation.| For example, in oregon, the state chapter of N.A.S.W. has a special Women's Issues Committee, which meets monthly and works to advance feminist causes in the profession and the community. The Chapter recently sponsored a one-day workshop, "designed to help the individual to identify sexism and sex role stereotyping" (Foster and Reed, 1978). Other chapters of N.A.S.W. have similar committees with similar concerns. In fact, in a survey of feminist therapists in three cities on the West Coast, Thomas found that most of the therapists who identify themselves as "feminist therapists" are social workers. (1975: 103, 104).

Social workers have also contributed to developing new styles of practice, and new services to meet the needs of women. These will be explored below, as part of the examination of feminist practice modalities (which includes other helping professions besides social work). The scope of social work interest in feminist theory is, however, quite broad, as a brief overview of specific social work contributions indicates. Social workers have been involved in integrating consciousness of sex role oppression into their work with individuals (Schwartz, 1974), and avoiding sex role stereotyping (Harris and Lucas, 1976). This concern has led some to participate 
in groups of therapists working to define a specific group of appropriate interventions for women (Radov, et al., 1977), or to combine techniques of consciousness raising with group therapy processes (Eastman, 1973; Kravetz, 1976c). Others have worked using assertiveness training as a feminist tool (Berlin, 1976; Brockway, 1976). Social workers have organized to provide services for special women's problems such as abortion (Young et al., 1973), rape (Abarbanel, 1976), lesbians (Chafetz, 1976), middle-aged housewives (Klass and Redfern, 1976), and women getting out of prison (Kestenbaum, 1976). Most descriptions of these efforts show that social workers are not just meeting newly identified needs in the old ways, but that they take into account, from their inception, the effects of sex role oppression on the women served. There is, therefore, reason to expect that these new departures in practice will have a coherent impact (Lacerte, 1976: 660).

\section{FEMINIST THERAPEUTIC STRATEGY}

The feminist influence on therapeutic work has resulted in a modified theoretical system, and in a reconstructed model for a therapeutic relationship. Both aspects of this change are important in the feminist value system (although there has been more empirical support for the change in conceptual framework), and 
had their origins in the consciousness raising experience of the late sixties and early seventies.

The Consciousness Raising Model

Consciousness raising groups grew as part of the political struggle of the feminist movement. In the consciousness raising group, women talked about aspects of their lives with other women in a permissive, equalitarian atmosphere. Pam Allen describes what happened in four stages: opening up (the beginning process of any new group), followed by sharing personal experiences, then analyzing and abstracting from these experiences (1973: 271-279). The analyzing, and abstracting stages emphasize the political connection of the consciousness raising group: the women attempted to use their own experience as a base for analyzing their own oppression, to go beyond their own experience. Finally, they attempted to fit their discrete analyses into a total picture of societal oppression (this is what Allen means by "abstracting"). Thus, the process in consciousness raising was to start with shared personal experiences, and from that, work towards generalizing to the experience of all women in order to define a feminist political perspective. Dreifus, in describing how a consciousness raising group should function, is succinct on this point: "Remember above everything else; the primary goal of consciousness raising is political. Always frame one's personal 
experiences within a political context" (1973: 26). This process emphasized the psychological effects of oppreission since this was the main constituent of the raw data. Besides creating their own feminist consciousness, the women in the groups reported a "process of deeply personal attitude change":

Most women find this experience both irreversible and contagious. Once one has gone through such a "resocialization," one's view of oneself and the world is never the same again, whether or not there is further active participation in the movement (Freeman, 1975: 118).

The change the women experienced was related to their discovering their own strengths, getting support from other women, and realization that many problems they had thought were theirs alone were common problems, subject to common concern and action.

As women began reporting intense personal changes, the strength and type of these changes began to be tested by sympathetic researchers (who had access to the groups). In general, studies show positive changes in self concept, increased autonomy and self knowledge. Participants re-. port to researchers that they feel they are less passive, and have stronger, more supportive relationships with other women (Eastman, 1973: 178-180; Follingstad, et al., 1977: 223-230; Kirsh, 1974: 326-332; Kravetz, 1976a: 66-68). Sympathetic therapists also became interested in using this new tool in therapy with women (Brodsky, 
1973: 24-29; Kirsh, 1974: 326-354; Eastman, 1973L 180). Consciousness raising, however, was not immediately adaptable to the therapeutic situation. Personal change was never its central focus (although this was considered to be important (Kravetz, 19.76a: 68)), and it tended to concentrate on what is wrong with society more than on the convolutions of individual problems. The groups were leaderless: women members prized the concept of the equality of all group members, and the idea that the group, alone, should define its goals. Firally, in the consciousness raising model, individual solutions are suspect, and fundamentally, considered to be a delusion. Since the problems concern all women, all who recognize those problems share an obligation to work for their resolution, and the social resolution is considered to be the only one that will really have the effect of resolving the individual's problem (Wolman, 1976: 274). In practice however, not all consciousness raising group members engaged in social action, and what action they did engage in tended to be local and limited by the resources of the participants (Freeman, 1975: 118,119). Obviously, a method which limits the role of the expert, and values political analysis and action cannot be directly assimilated by the mental health system. Still, elements of the consciousness raising model are continually proposed for incorporation. 
When utilized in therapeutic frameworks, the focus inevitably is different. The focus is on the people who are and feel powerless, rather than on the other side of the equation: the powerful ones who maintain institutional controls. In the therapeutic focus, there is an effort to help women see what power they have and how to use it in their individual lives (rather than, for example, appealing to the powerful to be more humanitarian). Yet consciousness of social influences on the woman's situation remains central. There is general agreement that permits "acceptance of the 'patient's' symptom as an appropriate response to an inappropriate situation" (Chase, 1977: 20).

Authority in the Therapeutic Relationship

One of the most persistent issues for feminists is the authority or the expertise of the therapist, and how this should be handled. There is wide agreement that the therapist should "demystify his or her role, and the function of therapy" (Rush, 1973: 129). The therapist is personally open and accessible (Kaschak, 1976: 62,63), and does not claim more authority than competence and knowledge allow. Besides, competence and knowledge are shared openly with the client. Chase says:

...the strategy among a new group of feminists has been to dismantle the professional/ patient hierarchy, to discount formal accre- 
ditation, and to reconstruct the therapeutic situation on a basis of mutuality. The therapist is no longer high priest of the psychosexual, and there is corresponding change in terminology -- "Dr." and "patient" replaced by "helper" and "client" (1977: 20).

Coordinate with the demystification of the therapist's role, there is emphasis on the validity of the client's experience (Marecek, 1975a: 6). Berlin sees encouraging and valuing the woman's experience as basic to helping a woman move to decide what she wants for herself (1976: 497). Lerman sees the issue as specifically related to increasing the client's personal power:

The assumption of competence goes hand in hand with the assumption of personal power. The therapist constantly attempts to help the woman client validate her own experience rather than to undercut this process through the use of the authority position. Women have been trained not to believe that they can have any psychological power, that is, power to determine their own values, needs, actions, and thoughts. Instead, they frequently accept the "fact" that others possess the power to determine these things for them (1976: 18).

The issue of authority in the structure of the therapeutic relationship is thus closely related to the feminist assessment of what psychic problems women have as a result of oppression. Their central assertion is that women are living out a social role that limits their control over their lives, and exposes them to devaluation by others. They find that therapy can only be effective if, by its very structure, it encourages women to trans- 
cend the traditional role limitations and begin to take control over what will happen to them:

Formal theories do not tell us the whole story about psychotherapy. To understand how power operates in psychotherapy, process is a more important focus than theory (Marecek, 1975b: 9).

Marecek cites studies showing that the personal characteristics of the therapist and the relationship between therapist and client are perhaps the most important ingredients in determining the outcome of therapy: "In theory, patterns of interaction established between the therapist and client serve as a model for the client's behavior outside therapy." She concludes that an experience in therapy of being subordinate will not "increase the client's social power in everyday life regardless of the therapist's intentions" (Marecek, 1975b: 9).

Many feminists have come to advocate that the client and therapist agree on a contract about what the client wants to work on. This minimizes the power of the therapist's hidden agenda, and sets up a framework for the therapist to explain her (or his) priorities during the process of negotiating the contract. This is a way of dealing with the therapist's values, and their inevitable influence on therapy, that is most likely to have meaning to the client (Dejanikus and Pollner, 1974: 10-12; Marecek, 1975a: 7).

A further reason for the emphasis on equalizing 
power and validating the woman's own experience is the fact that women are highly sensitive to the opinions of people in authority and "can be expected to read into most remarks of the therapist the negative selfevaluations which they most fear" (Kronsky, 1971: 92). This is especially likely when the therapist is an authority figure. Thus, the woman will be unlikely to bring up problems she knows she is not supposed to have: among which are problems with her role as a woman. The equalization of power is necessary to begin to neutralize the sensitivity that would inhibit discussion of the very problems feminists are concerned to bring into focus.

Interpretation in a Social Context

Acknowledging the less commonly accepted aspects of one's personal experience is an important component of any therapeutic experience. Feminists urge that therapists be especially aware of the problems women develop that are due to their status as women. They are, however, divided about how far-reaching such effects are, and, thus, about how much to rely on traditional therapies and work to accommodate them to their new insights.

Some feminists, like Naomi Weisstein, assert that the most important factors in behavior are (relatively 
current) social context and consciously accessible socialization experiences. They assert that factors such as the subconscious, personality "traits," and biology have little to do with social behavior (and they question the existence of the subconscious, etc.). They believe that dealing with the woman's' current and expectable social environment is the most relevant focus of therapeutic intervention (Weisstein, 1971: 221, 222).

While feminists do not assert that women and men are the same, and in fact, assert the opposite, because of the different socialization and social conditions they experience, they do regard as suspect any studies that tend to show significant sex differences to be the result of biological differences (Marecek, 1975a: 4,5). They assert, for example, that researcher bias can be demonstrated to have affected interpretation of results of experiments with both animals and humans, that the reasoning is falacious, and the methodology inadequate (because significant variables are not controlled). Further, research with animals is held inadequate for predicting social behavior in humans (and this, in their view, includes sex role related behavior) because humans, due to culture, have a capacity for an infinite variety of responses to a given stimulus. Examination of research and "counter" research has called into question such presumed biological differences as more aggres- 
siveness in the male ("Aggressiveness is clearly a behavioral complex, not a sex-linked gene," Bleir, 1976: 71), thoeries of sexual, moral and cognitive development (studies summarized in Bleir, 1976, and collected in Sherman 1971, and Unger and Denmark, 1975).

Some feminists, however, find the early experiences before socialization, as it is commonly understood, can occur, to be an important factor in determining differences between the sexes, and important to understanding women. Chodorow asserts that, as modern boys and girls are brought up, gender is part of identity and is not properly a "role" that is taught and learned consciously:
A person is not just personifying a gender category. We cannot step out of our gender role: we do not exist apart from being gender so we have to see the social organization of gender and our being gendered as a totality: they only gain meaning one from the other. Thus a feminist theory needs to include the fact that we are psychologically gendered and wants to argue that gender and sexuality are created socially -- not biologically -- and demands a theory that explains gender as so- cially created (1976).

Other feminists are uncertain whether sex oppression extends into the earliest years, yet still feel the early years are important in considering a woman's psychological situation. They tend to accept the traditional ways of understanding the effects of these early years on the woman's subsequent life, although they subject these interpretations to a feminist standard (that 
is, that they should not involve particular limits or norms for women and women's achievement that could not be applied to men as well). Thus, Hannah Lerman (who, in 1976, was chairwoman of the Feminist Therapy Committee of the Association of Women in Psychology and the Committee for Women of the Division of Psychotherapy of the American Psychological Association, and defines herself as a feminist therapist) states that the feminist insight "cuts accross the usual categories of therapy -- whether Gestalt, behavioral, eclectic, or even psychoanalytic concepts" and that therapists of many persuasions can "share this common philosophy and even a common language" (Lerman, 1976: 17).

Among the consequences of sex oppression that most feminists have urged therapists to consider are more negative self image, tendency to be dependent and passive, defining the self by relations to others, aversion to conflict and repressed anger, ignorance of social, economic and political realities, and ignorance of their own strengths. They argue that these problems can be significantly alleviated through helping a woman become aware of the social context of her oppression: how she learned through sex role socialization, to behave in this way, and how institutional controls perpetuate this learned behavior. 
Women's Negative Self Image

Miller points out that a woman who accepts the dominant group's view of her, necessarily accepts a view of herself as inferior and dependent. This alone discourages a woman from recognizing and clarifying her own needs (1976: 13-15). She adds:

When, however, we can think only in terms given by the dominant culture and when that culture not only does not attend to our own experiences but specifically denies and devalues them, we are left with no way of conceptualizing our lives. Under these circumstances, a woman is often left with a global, undefined sense that she must be wrong (1976:57).

Marecek supports this contention, adding that the role of the therapist is to question women's sense of their limited options and their negative attitude toward themselves (1975a: 6). The therapist leads the woman to realize that this is what she was taught, and that this is misleading. Lerman adds:

I have found that most women believe deep down that they are crazy, that is, that their intuitions, their thoughts, their feelings and their needs are crazy. Indeed, in a world in which sensitivity to emotional nuances is discouraged, the expression of feelings downgraded, and rationality upheld as the supreme ideal, women are crazy in a sense. Directly or indirectly, men as well as other women are fond of telling them just that in subtle and not-so-subtle ways. When a therapist helps a woman distinguish more clearly the inside from the outside [i.e. the internal message from the distorted cultural message] there. i.s frequently the equivalent of a sigh of relief (1976: 18, 19). 
Passivity and the Expression of Anger

Passivity and dependency may be habits of response produced by a woman's socialization; they are certainly maintained by institutional arrangements that afford women little control over their lives, and thus women fail to develop or use their potential for constructive anger or assertive action. As described above, feminists attempt to structure the therapeutic relationship so that a woman is encouraged to be less passive. They also attempt to elicit a woman's anger at the constrictions of the social role. Being limited in her possibilities for development is presumed to elicit anger in a woman, but fear of the consequences of anger may lead to disregarding and forgetting it along with self assertion, and to adopting other more covert ways of getting her needs met. Mundy lists evidence of suppressed anger: disengagement from action (to avoid anger-provoking situations), attacking non-feminine women and children, physical disorders, sexual activity disorders, and social disorders (phobias, dependence as a demand, selfsacrifice), and recommends that the therapist "tease out the general passive-active behavior pattern" that has replaced the direct expression of anger (Mundy, 1975: 199-210) .

Helping a woman to feel justified in expressing 
anger at unjust social conditions and expectations has been a major focus of feminist writing about therapy. The consciousness raising groups regarded anger as appropriate and rewarded members who expressed it. Similarly, feminists believe women in therapy have repressed their anger, and therapeutic intervention needs to help a woman find out what she is really angry about. Repressed anger is considered to be the basis of the "largely unconscious, self-destructive and ambivalent strategies of the oppressed in their passive aggressive rebellions against their oppressors" (Edwards, et al., 1975: 18, 19). Feminists urge therapists to:

...help women see the self-destructive consequences of their strategies and help them rechannel the energies which they ordinarily direct against themselves and eachother to the more appropriate target. That is, to help women transform their unconscious, covert slave rebellion to conscious open warfare against the persons and institutions which work to enslave them (Edwards, et al., 1975: $18,19)$.

This involves focusing the woman's awareness on her social environment, on the aspects of sex oppression that affect her life. Kronsky notes that women will at first be very reticent about expressing anger, and stresses that it is important to avoid any interpretations that emphasize the negative aspects of the anger (at least at first); otherwise the anger itself is likely to be repressed again (1971: 92-95). Helping to elicit a woman's anger in this way is not traditional therapeutic practice 
(where anger may more often be regarded as a symptom of personal pathology). Lerman says:

Feeling anger and dealing with it seem to me to be an essential part of feminist therapy. The experience of anger is one of the things that the feminist therapist has to validate because few others will. In much of our society, one of the things people find most difficult to deal with is anger. There are myriad ways available to discount the feeling and the person feeling it. Owning one's own anger is, for women, an important -- perhaps even an essential -- step toward personal power.... Its power scares the woman who is beginning to experience it as much as it scares and offends others. The point eventually is to help a woman channel it so it can work for her rather than repress it or deny it (1976: 19).

Mueller and Leidig put special emphasis on the role of the therapist which, unlike that of the consciousness raising group, does not end with the eliciting of anger at appropriate targets:

The trap into which we therapists must not fall is that of believing our work is complete once we have helped our clients realize the depth of their anger. We also have an obligation to provide help in working through the rage and gaining control of some of the factors that feed it. As a long-term state, rage is difficult to live with and unpleasant to feel. It is often counterproductive ... (1976: 22).

They identify five steps in the process of helping women deal with anger: helping the woman recognize her anger, showing her there are valid external reasons for it, helping her identify the source of her anger and the specific aspect that makes her angry, validating the 
woman's expression of anger and her setting out to gain control over some areas of her life she feels angry about, and finally, helping her to "mellow out" after she has faced her rage. They point out that there are different strategies for different situations: assertiveness skills (to be discussed further below) are effective only in interpersonal relationships when the other party is able to respond differentially, depending on how the claim is stated. In situations of institutional discrimination, only a social action strategy is appropriate; if the threat is physical, then self defense, escape, and still other strategies would be most appropriate. Thus, dealing with a woman's anger may involve the therapist in helping her to engage in a variety of non-psychological responses to gain control of her life (1976: 26-29).

Miller elaborates hex theory that conflict is essential to personal growth. Growth requires engagement with difference, but within a system of inequality, difference and conflict are denied in order to support structures of dominance (1976: 13-15). It is the suppressed, covert conflict characteristic of systems of inequality that is most destructive (see Mundy's list, above). As women move toward equality, they will deal with the anger and conflict generated by the system, but as they become aware of the causes of their problems, they may 
be able to understand, resolve them in productive ways, and use the experience for growth (1976: 126-132).

Identity and Personal Relationships

As noted above, feminists stress that women are socialized to define themselves in relation to other people, rather than in their own terms. They are someone's daughter, wife or mother rather than being valued for personal skills and contributions. Kronsky stresses the importance of the therapist's trying to see the woman as "a whole person, functioning in many areas and striving for fulfillment in many directions," despite the fact that the woman herself may be adapted to defining herself as the sum of her relationships (1971: 95).

Miller uses her clinical experience to support her contention that because women are encouraged to define themselves by their relationships and to put their energies into relationships, they neglect important developmental tasks. Many psychological needs are not easy to grasp and define, and require the opportunity to try out various possibilities and resolutions. Women are not encouraged to do this, do not develop a sense of themselves, and thus, after some years, cannot choose whether to serve or not to serve. The process of beginning to find out how to have an identity apart from the family may be very threatening: many women fear this is aban- 
doning the husband and children who had been the central focus of their lives. In any case, Miller regards self definition as a long process for many women (1976: 6874).

Berlin is similarly concerned to help a woman gain a new definition of herself. She recommends helping the woman to construct a clear, individualized standard of personal value by reference to her own strengths, desires, and satisfactions. She feels this is the first concern of therapy with women, and a continuing effort throughout the therapeutic process. Berlin recommends training in self awareness to increase the woman's ability to know and support herself (1976: 492-495). This awareness, rather than anger, as in the Mueller and Leidig model, is the basis for taking action and taking control of her life. Berlin teaches assertiveness skills as part of this process, and emphasizes helping the woman plan for change and for learning whatever skills and strategies are necessary. Once again, the therapist may be involved in helping a woman learn to undertake a number of non-psychological tasks, although they may be undertaken for psychological goals.

Rush emphasizes the need to include body awareness as part of a new self awareness. She points to the socialization of women to view their bodies as sources of approval from others rather than as a source of perso- 
nal power (1973: 54-57). She proposes a series of physical awareness exercizes to help a woman realize how she has been feeling about different parts of her body, and how she handles her body in relationships with other women and with men (1973: 54-57, 139-185).

Almost all feminists suggest that therapists help women to find new sources of pleasure and validation of themselves as individuals, to replace that which they once received from family relationships. Lerman (1976: 19) and Rush (1973: 1-57; 1974: 38) both stress the importance of self nurturance. Rush (1973: 117-155) and Miller (1976: 136) emphasize the importance of gaining support from other women in their efforts.

Learning to Value Strengths

Feminists also stress the positive qualities that women possess, but may have undervalued because they are not recognized or valued by the dominant culture. They reject the idea that men are the standard, and that women should try to develop men's characteristics, abandoning their own wholesale. This concept, like so many others, also grew out of the consciousness raising movement (Kravetz, 1976a: 68). Lerman advocates validating women's sensitivity to emotional nuances and ability to express a greater range of feeling (1976: 19). Kaschak points out that many women have ignored or downgraded parts of 
themselves that are not socially valued; therapy should permit reintegration of the experiences of the socially accepted and the socially denied self (1976: 62). Miller emphasizes this split in women as related to a splitting of awareness of human potential:

We have seen that as society emphasizes and values some aspects of the total range of human potentials more than others, the valued aspects are associated closely with and limited to the dominant group's domain. Certain other elements are relegated to suboridnates. Although these may be necessary parts of human experience, they are not the ones valued by that particular society (1976: 21).

As particular strengths of women's culture, Miller points to women's ability to concern themselves with others' needs, to cooperate, and to realize that doing anything in the context of relatedness to others is a major source of meaning in life: "Women may be able to integrate the need for relationship and personal strength and find more and better ways to use affiliation to enhance strength -and strength to enhance affiliation" (Miller, 1976: 96).

Special Techniques and Services Developed by Feminists

There are special techniques and services defined as particularly useful by feminists. These include working with groups of women, teaching assertiveness skills, and developing new services for women as new issues and needs are identified.

Work with groups of women has been a major focus 
of feminists doing therapy. In view of their concern for the differences of power and authority between the individual therapist and client, the group model has definite advantages:

In the group setting, therapists can de-emphasize their leadership posture and encourage group members to take responsibility for several functions usually undertaken by the therapist (Marecek, 1975a: 8).

In therapy groups for women, the ideas generated by the consciousness raising model are most directly applicable. There can be common discussion of problems women share in group treatment, with the direct realization that these problems are common problems (Berlin, 1976: 492-496).

Wolman has reported on two outpatient groups for women only that she organized (along with two different co-leaders). She points out that the participants in these groups defined themselves as patients, and were not oriented toward women's liberation (although they agreed to participate in the woman-only group, they would not have joined a consciousness raising group). Wolman states that the woman-only group conveys several covert messages that she feels are important to women in therapy: women exist as persons in their own right apart from men; it is permissible and desirable for women to bond strongly to each other rather than being defined chiefly by their bonds to men; women are worth- 
while and have valuable gifts to offer each other; men have no monopoly on power or goodness (1976: 274). Wolman states further that the all-woman group avaoids the covert male dominance of mixed therapy groups, and facilitates women's bringin up problems they experience as women. In the presence of men, they might decide not to mention such things. Feminists are very concerned to structure the therapeutic experience so that these very problems are more likely to emerge.

Wolman encouraged the women in her groups to get to know each other outside the group, as well as within it. Noting that the women tended to be socially isolated, she states:

We believe that in addition to exploring their individual problems in a sympathetic group setting, women need to learn anew to depend on and value each other. Such interdependence eases problems of isolation and anomie and also teaches people to be dependable and to value themselves (1976: 174).

The groups passed through the classic stages of group work (initial phase of sharing and focusing in on problems, middle phase of developmental work, and final phase of clarifying, generalizing and consolidating gains) reaching the second phase more quickly than most Wolman has worked with (1976: 276, 277).

The therapists shared their own perceptions of sexism with the group as it developed, and gave advice 
on how to fight it:

Such intrapsychic wounds of sexism as fear of assertiveness, the tendency to define oneself as a wife, mother, girlfriend, or sex object rather than as a person, masochism and deference to men, hatred of other women and concommittent seif hatred, and repression of one's ability to think can be put in context, shared in the group, and healed (1976: 277).

As a result of the group experience, a support system formed among the group members in the less disturbed group (though rot in the smaller group of ex-hospital patients). This support system provided additional material for discussion during group time, and operated for at least several years after the termination of the group.

Besides such benefits, as would be expected from the consciousness raising model, Wolman reports specifically traditional therapeutic benefits: that the women were able to relive their dependent fantasies, work through their rage about not receiving enough nurturance and learn true autonomy in the group setting (1976:277).

Other feminists working with groups have also emphasized the possibility of combining therapeutic effectiveness and group supportiveness. Hogie Wyckoff, who uses a problem-solving model within a Transactional Analysis framework, emphasizes the value of loving cooperation in gaining awareness and moving towards action for social 
change (Wyckoff, 1977).

Assertiveness training is another method extensively advocated by feminists. After examining the links between actual or perceived powerlessness and the development of depression, Marecek points out that assertiveness training is one of just two recent clinical treatments specifically designed to increase the client's personal power (the second is a less formulated but compatible therapy emerging from Seligman's (1975) learned helplessness theory). Assertiveness training was not developed by feminists: it was developed originally by Wolpe in 1958 (Butler, 1976: 57, 58), and not all practitioners are feminist. However, feminists have adopted the technique and modified it to fit the feminist view.

Feminists have been critical of those who develop assertiveness training groups for women outside a feminist context. They fear that women will use their assertiveness against safe targets (traditionally, as noted above, the safe target has been other women). Further, they see that assertiveness can be used not to change the system of male privilege, but to enable the woman, who is "one down" by definition, learn to function more effectively in these adverse circumstances:

As long as women value a male-oriented culture and are motivated to seek techniques which will make them more proficient in using sur- 
rogate power to become better oppressors along the way to getting what they personally want, assertiveness training will continue to lack goals geared toward effecting societal changes.... Assertiveness training will have real meaning only when its implementation brings it into direct confrontation with male attitudes and behavior that are inimical to women (Schneidt, 1977: 87).

There is, perhaps some question about how effective developing personal assertiveness is for anyone without institutional change. Brockway reports assertiveness training groups for professional women. At the end of the training, anxiety associated with assertiveness was reduced for the women, but they continued to consider themselves unassertive (though they had tested as assertive when they joined the group, and more so when the training was done). Brockway hypothesized that they had equated assertiveness with professionalism, and their conclusion they were not assertive merely reflected the fact that doors to professional power had remained closed to them (Brockway, 1976: 505).

On the other hand, feminists urge that, when assertiveness is taught within a political framework, it can increase a woman's political and personal effectiveness. For one thing, if she learns assertiveness within this framework, a woman will be able to distinguish institutional oppression (where assertiveness is minimally effective and social action the remedy of choice) from the 
arbitrary interpersonal oppression where assertiveness can be effective. Further, they emphasize, when assertiveness is presented in a feminist framework, a woman realizes that she has a choice to be assertive or not, and that this opens a new awareness of her own needs and rights (because it is possible to attain more of them) :

Lack of assertiveness is often a reaction to our socialization, and becomming assertive can be one way of coping with society and of gaining the strength and awareness to change it. Assertiveness training can help us be aware of how we allow ourselves to be oppressed and help us choose not to let this happen, to some extent. Assertiveness training isn't going to get rid of sexism, capitalism, racism, ageism, etc., but it can help us cope within these systems and choose not simply to accept them (Neil and Woolfe, 1976: 11).

The Montana Assertiveness Training Collective for Women which conducts assertiveness training sessions for women and for mixed groups asserts (perhaps simplistically) that "Assertiveness training constantly stresses the feminist concept of power: power as ability, as control over one's self, but not over others" (1977: 25).

Various formulations of assertiveness training have been adapted to women's particular socialization experiences (Phelps and Austin, 1975: 19-118). Jakubowski has developed a four stage cognitive behavioral approach, (distinguishing assertion from aggression and non-assertion from politeness; with behavior rehearsal) two inter- ; 
mediary steps: developing a belief system to support assertive behavior and developing skills to deal with excessive emotions that may interfere with assertive behavior. The belief system includes tenets about one's equality with other people (and theirs with oneself). Emotions to be confronted include fears of looking foolish and expressing anger (1976: 2-6).

New services, often called "alternative services" have been developed by feminists to meet newly identified needs of women. They are generally locally conceived, organized and funded. Often they have grown out of the social vision of a consciousness raising group (Freeman, 1975: 119). These services reflect the selfhelp idea of the early women's movement: women would help themselves and each other because they realized they had a common problem, and only they understood what it really was. They rejected the idea that someone who did not have the problem could charitably help the less fortunate who did (Rush, 1973: 135-137). As more women began to use the new services, they often came to be funded or set up by traditional agencies and government. As social values change, the society makes provision for supporting those who attempt to realize those values. Slowly, and not without problems, these services are being integrated with established mental health and other social service systems (Bayes, et al., 1977: 78; Liss, 1974: 14). 
The new services tend to concentrate on growthoriented therapy or on more substantive assistance such as educational and vocational assistance for women making major life changes. The Women in Mental Health Project conducted a survey of fifty alternative self-help support systems in ten states. They found that the services have a number of common characteristics. Organization tend to be collective, non-hierarchical. If professionals are involved in the organization, they give up their customary authority; instead they are considered part of the staff, with perhaps a special skill, but not special privileges. Often they have rejected the treatment methodologies they were taught. There is some evidence that as government funding plays more of a role, and as these services are integrated into established service networks, the role of the professional may change and the methodology of service may be formalized.

Many clients of alternative services might be diagnosed as depressed in a traditional system, but this has been considered irrelevant in the alternative structure: "depression and methods of treatment are inner-directed and many of the alternative services were attempting to tie women's difficulties to social and political factors that govern behavior" (1976: 21-27).

$$
\text { Myrna Weissman (1975) and Pincus, et al. (1974) }
$$

cite their experiences at the New Haven Women's Educa- 
cational and Counseling center to show that help according to this model may be therapeutic. Weissman, in a controlled test, found that a sample group of women who received services from the Educational and Counseling. Center did not become patients, despite their havịng the same mood disturbance as the control group. Women who visited the Educational and Counseling Center attributed their improvement to the practical help and support they received. Weissman concludes: "It may be that the direct assistance offered by the Center may have helped to hasten their adaptation and prevented the development of their symptoms into a full blown depressive syndrome and avoided the necessity of psychiatric treatment" (1976: 15). Davis, from her experience as a prevention worker, (1977), and the Women in Mental Health Project (1976: 26) reached similar conclusions.

Many centers are established for women who have been subjected to violence (by husbands or others) or who are making particularly painful transitions in their lives and need a place to stay in a supportive atmosphere. These combine growth counseling with substantive services. The Elizabeth Stone House in Boston (1976:2-4), and the Bradley-Angle House in Portland are examples of such services for women. Both are collectively run, with residents taking their share of responsibility for running the house and making decisions. Therapy is task-centered, 
supportive, and oriented toward helping women make sense of their lives in the context of sex oppression in society (Tinker, 1976).

Further attempts to identify problems of women may be expected, with efforts to set up new services to meet the identified needs, or to expand existing services. Several feminist issues are being defined that have clear implications for mental health and other social service agencies. These include women's sexuality, rape and physical violence, lesbianism, and the social re-inte gration of institutionalized women. A variety of service approaches to these problems have been recommended by feminists, and experimentation with ways to deal with the problems is continuing.

Concern with women's sexuality has been a special feminist focus for some time. The feminists emphasize that sexual functioning is connected to all parts of a woman's experience, and in particular, to how she feels about her relationships and her body (this emphasis is compatible with the Masters and Johnson (1970: 222-226, 315) view of the importance of relationship and self concept in sexual functioning). Feminists contend that it is therapeutic for women to identify some of the negative and conflicting judgments they encounter in relation to their sexuality (Faunce and Phipps-Yonas, 1978: 
83-95). Problems are created by society "still telling women how they should feel" about themselves -- whether the message is to be sexually inhibited or free (Hubbard, 1976: 31). Rush stresses helping a woman to understand her own sexual response (that she turns herself on) and to experiment transcending the limits she imposes on her body (Rush, 1973: 159-184). This feminist approach may be based on behavioral techniques or on gestalt awareness exercizes, but in both instances, there is concern to help women sense the social origin and character of their feelings about their bodies and intimate relationships.

Feminist concern with traumatic experiences like rape and physical. violence is also longstanding. Feminists have consistently exposed interventions that involve subtly "blaming the victim," pointing instead to cultural views of women and men's socialization (Brownmiller, 1976: 1-342). They have developed guidelines for helping a woman get through the initial shock of being subjected to violence, to move to a balanced sense of her own and external responsibility. From there, she can begin to take as much control of events as is possible (Mueller and Leidig, 1976: 26-29). Feminists have sparked the creation of services for rape victims either within their own networks or in established institutions. Abarbanel describes the complex process of educating 
staff in traditional institutions to deal sensitively with rape victims (1976: 479). Silverman describes how the male counselor in such institutions can be helpful (1977: 91-96).

Feminists are working to gain a better understanding of the situation of women subjected to violence from their husbands. Clearly, the phenomenon makes sense only within the context of women's lack of financial and psychological resources, need for social approval (gained through being married), and lack of legal and other alternatives (Schuyler, 1976). The homes for battered women and improved legal recourse are part of the developing feminist response (Martin, 1976: 87-147; Schuyler, 1976: 480).

Feminists have been concerned with normalizing the lesbian's experience and "helping lesbians grow stronger in their lesbianism, in discovering their own power, and in realizing the role society has in 'problems' which are considered intrapsychic" (Wandrei, 1975: 2-4). Feminists have advocated helping the lesbian accept her sexuality without guilt. If she is ambivalent, they feel that encouraging her to explore and make choices based on needs and wishes as well as on an assessment of "reality" is important (Chafetz, 1974: 721). Feminists are also most concerned to help a woman explore all facets of her needs to form relationships with other women, whether 
these relationships are sexual or not (Radov, et al., 1977: 509).

Feminists have identified the re-entry into society of women who have been institutionalized -- whether in hospitals or prisons -- to be a special (and extreme) instance of women's problems in moving out of restrictive environments into fuller participation in society. The special needs of these women are being identified. Services have focused on normalizing the women's problems, pointing out their relationship to the problems all women face and teaching respect for personal strengths. There is an attempt to open doors to new experiences in work a and personal growth previously denied by the society, and to give very practical re-socialization experiences (Kestenbaum, 1976: 77-83).

This review of feminist recommendations for therapeutic intervention with women has been written -- for the sake of clarity about the subject matter -- as though the process were unidirectional (i.e. from the movement to the therapists) and in the past. In actual fact, there are, of course, influences in both directions. Although some feminists reject the idea of therapy altogether (A Redstocking Sister, 1971: 121-126), asserting that consciousness raising and participating in the movement are all that is necessary, most accept therapy and supportive institutions as part of the social structure that can be 
helpful to women, and must become more helpful in the future. Feminists who are concerned with therapeutic issues are involved in the continual political process of redefining the goals of the movement, which, in turn, have implications for the development of therapeutic practice. And yet, the most decisive direction for change is inevitably from the political to the therapeutic. Not only does the political movement define the direction in which women can move, but it has impact on society that permits the development and utilization of new approaches in social institutions. Social work, for example, will not move in a feminist direction in its professional practice unless this becomes more politically acceptable.

Despite its concern with therapeutic issues, the focus of the feminist movement as a whole remains broadly social, with improvements in mental health and other social welfare services for women seen as just one aspect of the necessary social change. Thus, the feminist movement affirms the need for "individual solutions" without espousing a policy of individual solutions as a means to or as a substitute for social change. This society-wide change remains the primary focus. Chase summarizes the recurrent -- as it was the original -- influence of political concerns on therapeutic practice:

It is the movement which engendered feminist therapy, and it is the goals of the movement 
that it must seek to obtain.

Therefore, feminist therapy rejects patriarchy and tries to alleviate the suffering it causes. Its explanations never ignore the sexist underpinning of female alienation. Furthermore, it contains within its practice the image of a new political/sexual order and it recognizes no cure but a society-wide cure. Its accomplishments are always incomplete but no less necessary for that (1977: 22).

\section{Implications for Research}

The feminist concept of the psychic consequences of women's place in this society has clear implications for reform of traditional concepts of therapy and social services, and the adoption of new strategies. The critique and recommendations rest on an empirical base, which is expanding. In addition, and in consequence, feminists are becoming more precise in criticizing the old and defining a new model for social and personal intervention. As demonstrated in this review, the analysis is becoming quite comprehensive and detailed.

To what degree any of this is actually being applied, especially in the established service networks, has not been systematically investigated. Early surveys of professionals -- social workers, psychologists, guidance counselors, etc. - - tended to be oriented towards finding evidence of sex prejudice (cf. Broverman, 1970, and Donahue, 1975). More recent surveys indicate that such prejudices are lessening (Engelhard, et al., 1976). In 
any case, the feminist critique of mental health and other social service systems of treatment of women goes beyond finding prejedice, as demonstrated by the incisive critique of the limitations of current theory itself to clarify women's problems and prescribe solutions. The feminist critique concludes that changes in the ways of understanding and dealing with women's problems are essential for intervention to be helpful.

As reviewed above, the changes feminists recommend center on restructuring the therapeutic relationship and providing new services as women's needs are identified. Particularly, they are concerned with exploring the influence of women's socialization and social context on the development of their problems. Therapeutic intervention, they assert, is properly directed at helping women to understand these influences. This is the first step in helping women to deal with them.

Testing for how widely these recommendations have been adopted in practice among Oregon social workers is the focus of the research to be described in the rest of this paper. Using the feminist orientation, as presented above, for understanding and resolving women's problems, an instrument was constructed to assess how likely social workers would be to employ feminist recommended interventions. Design of the instrument and of the research are described in the following section. 


\section{RESEARCH METHOD}

The research was undertaken, generally, to determine how likely members of the National Association of Social Workers in Oregon are to employ therapeutic interventions based on the feminist conceptual framework that emerges from the literature review. Specifically, there was an expectation that there would prove to be a relationship between how likely the social workers would be to employ feminist interventions and the degree of their ideological commitment to the women's liberation movement. This ideological commitment/was presumed to be composed of agreement with women's liberation beliefs, and participation in activities to advance the feminist cause.

Secondarily, there was interest in examining selected demographic variables, e.g. age, sex, theoretical orientation in practice, etc., assuming that there would be variation in response to feminist issues due to these factors. There was no attempt to assess "bias" of the social workers against women in this research. Rather, the interest was in whether the workers were likely to use the kinds of interventions feminists 
say they believe will help women.

\section{POPULATION}

The population selected for this research was the membership of the Oregon Chapter of N.A.S.W. This was the population of social workers most accessible to the author, and social workers were of particular interest, not only because of the author's participation in the field, but also because, as noted above, social workers deliver more therapeutic services to women than any other professional group. Thus, due to the extent of their influence, it seemed very important to assess what orientation social workers would take towards the issues raised by the women's liberation movement. Further, as detailed above, the relevance of the feminist critique and recommendations for improved services to women have been relatively well publicized in social work 1iterature.

The particular population of social workers selected is both representative and significant. The N.A.S.W. membership represents some of the social workers who are most self-consciously identified with their profession, its advancement, and well being, and among those most likely to influence its future course. Though small, it is assumed the Oregon chapter has a membership that can be considered representative of both the urban and small 
town milieux of the United States. The membership is acquainted with women's issues, not only through the national media, but also through the activities of the Women's Issues Committee.

Selecting the Sample

The research sample was composed of 100 members of the Oregon Chapter of N.A.S.W. This represented a 15\% random sample of all the members of the Oregon Chapter (al1 members of the chapter -- whether retired, students, B.A. members, etc. -- were included in the population from which the sample was selected). The population was stratified into five groups to insure proportional geographic representation of members. The groups were: Portland and its suburbs, Salem, Eugene, other communities in Western Oregon, and Eastern Oregon. Some researchers into feminist issues have reported variation in sample data based on size of city. Professionals working in cities larger than 25,000 have been reported to be significantly more likely to be sensitive to feminist issues in their relationships with clients (Donohue, 1975: 10).

\section{INSTRUMENT DESIGN}

A questionnaire and cover letter were designed to be mailed to the sample group to test how likely members of the group would be to use feminist interventions in 
their practice.

Cover Letter and Strategic Considerations

The cover letter did not state the particular subject of the research. It merely stated that the author had "decided to do research on issues in social work treatment in Oregon." No further mention was made of the subject of the research in the letter, in order to avoid, as much as possible, contamination of the results due to ideological arousal (as this phenomenon was described in the study by Goldschmidt, et al., 1974). Attempts to minimize such contamination generally characterize research in this area (cf. research summarized in Donahue, 1975: 1-9; Goldschmidt, et al., 1974: 603,604).

The questionnaire itself was six pages in length. It contained four parts, arranged so that the explicit references to women's liberation issues appeared in the two final sections (see Appendix). This ordering was adopted in an effort to minimize the contamination of the results.

It is unlikely that these minimal efforts to avoid contamination were very successful. For example, two of the non-respondents contacted during the telephone follow-up (described below) mentioned they were aware of "what you're trying to get at." This had been accepted from the start as a likely occurrence.. There appeared 
to be no way to control for this effect in this small research effort. Besides, the questionnaire was already too long ( six pages) and it seemed likely that the mailed return rate would drop drastically if significantly more questions were added. Otherwise, questions to confuse the issue, and another scale (such as the Crowne Marlow Social Desirability Scale) could have been interpolated with the feminist questions.

Each of the four parts of the questionnaire was oriented to one specific aspect of the research. Part One contained demographic questions (age, sex, etc., to be detailed below) that were of secondary interest in the research. Part Two consisted of three case descriptions followed by six possible interventions (three oriented toward the feminist theoretical framework, three toward the traditional). Respondents were asked to indicate how likely they would be to use each intervention on a five-point Likert scale. Part Three encompassed the feminist beliefs assessment. Extent of agreement or disagreement with the twelve propositions was indicated on a five-point Likert scale. Finally, in Part Four, respondents were asked to check if they had participated in up to six designated activities in support of the women's movement, and to list other activities they had engaged in (if there were others) in its support. 
Demographic Questions

Part One of the questionnaire was designed to collect relevant demographic data on respondents. As noted above, previous studies have indicated that the size of the city in which the subject practices may be correlated with the likelihood of adopting feminist responses.

Sex was considered to be a significant variable.

It was expected that women social workers would be more ideologically committed to feminist issues than men. Furthermore, it was thought that the likelihood of women social workers employing the feminist perspective, in their practice would be greater than it would be for men. Numerous studies have confirmed the significance of this variable (Bernard, 1975: 165-169). Age may also be related. In general, studies have shown that younger people are more likely to be sympathetic to women's liberation, but the relationship is somewhat complex. Older women, for example, may be sympathetic (Bernard, 1975: 165-169).

Age could be considered to be a factor in indicating degree of exposure to feminist issues; for example, older people might not have had much personal contact with feminist concerns. On the other hand, given. the typically broad age variation among students in social work education, the year of last educational degree completed was considered to be an indicator of 
equal or greater importance.

It was thought that social workers who have completed their educational degree more recently would have had greater opportunity to be exposed, through the educational process, to feminist issues, and their professional practice would reflect this exposure. Reorientation of the social work curriculum to include content regarding women's issues has been relatively recent. On the other hand, it was assumed that social workers (particularly caseworkers) who received their last degrees in the 1950's and the 1960's would reflect an ego psychology orientation to practice, and hence a more traditional view of the female role, and social work intervention.

Information about ethnic background was requested since the various ethnic groups have had distinct and different relationships to the women's movement. Besides, the traditional place of women has also been significantly different in the different ethnic groups.

In addition there was some question about whether place of employment might have an effect on responses, due to the tradition in social work of more innovative practice occurring in private agencies. A box was provided for respondents to check if they were employed in an "alternative" agency. These respondents, it was thought, would be more liberal and provide a further check on feminist responses. Also, alternative agencies often offer 
special services for women (often developed by consciousness raising groups, as noted above), and have espoused generally radical treatment approaches, operated collectively, and de-emphasized professionalism (all factors that would conceivably predispose them to accept feminist ideas).

Finally, respondents were requested to check what theoretical orientations they used in their practice. Because the number of people who attempt to integrate two or more different orientations has increased in recent years, respondents were asked to check "all that apply" from a group of twenty. This group was, substantially, the group a previous study found to be the most common orientations among West Coast therapists (Thomas, 1977: 101). Since certain therapeutic orientations have been considered particularly antithetical to feminist tenets (as described above), this was considered to be a variable that might be significantly correllated with frequency of feminist response.

Case Descriptions

Three case presentations, each followed by six possible treatment interventions, formed Part Two of the questionnaire. The cases were created to reflect a variety of women's life situations and problems. Frances, 46 , is facing the end of her daily responsibilities 
as a mother and despairing of what to do with the rest of her life. Ellen, 15, is confused about how to reconcile what whe wants with what reality seems to offer her. Finally, Alice, 23, is trying to combine motherhood with a job, and deal with marital difficulties (see Appendix). All of these cases pose problems typical of those with which feminists have been concerned. The cases were representative of developmental problems -- difficulties in transition from one stage of life to the next -rather than more severe pathological states. In this context, the issues posed by the cases emerged more clearly, it was thought. Many social psychologists and feminists themselves would question the centrality of environmental problems in the development of schizophrenia, for example.

No effort was made to include feminist recommendations for restructuring the therapeutic relationship as part of the questionnaire material, since these issues were considered more difficult to assess in a written, self-report format. Equalizing power between a client and therapist, for example, is always a matter of degree, and, more important in the present context, is usually accomplished in accordance with the particular opportunities for doing this afforded by different approaches. Thus, this question would be posed differently for psychodyanmic therapy, gestalt therapy, behavioral therapy, 
and any kind of group work

Following each case presentation were six possible treatment interventions. Respondents were asked to circle, on a scale of one to five (Very Unlikely to Very Likely), how likely they would be to employ each of them. To avoid confusion, respondents were advised that "The range of interventions listed is not meant to be comprehensive, nor does the order in which they appear indicate a sequential treatment plan."

Three of the six interventions following each case represented feminist options. These options emphasized the personal consequences of social role prescriptions, anger against the female role, recognizing undervalued personal strengths, and transcending sex role limitations. These emerge from the review of literature as major components of the feminist approach.

In the case of Frances, the feminist interventions focused on helping her to regain a sense of herself apart from traditional role relationships, recognizing the appropriateness of her anger and fear to her situation, and helping her to value the strength and skill she had developed in her years as a mother. Much of the work elucidating Frances' situation has been done by Bart (1971), as explained in the literature review. Interventions in Ellen's case emphasized dealing with social pressure to be feminine. This pressure to 
develop feminine behaviors generally intensifies with adolescence (Freeman, 1976: 139). Other interventions included the possibility of explofing ways of transcending the traditional role prescriptions, and recognizing the appropriateness of her anger that her options seemed too limited.

Alice's case represents the most common example of feminist rhetoric. Interventions aimed at dealing with Alice's passive acceptance of a harmful social role. They included teaching assertiveness, showing Alice that the role behaviors she had learned involve a loss of her own power, and attempting to stimulate anger at this situation that could be channelled into energy for growth to transcend it.

Traditional intervention options were not designed to compete directly with the feminist options: there was no design to score one against the other. In general, the traditional options were designed to represent a range of appropriate therapeutic strategies (although, given the diversity of current therapeutic methods, there was no effort to be comprehensive in this offering). Most were oriented towards possible intrapsychic dynamics of the cases presented. In only one instance, an intervention was offered that was not considered to be acceptable to feminists under any conditions. This intervention 
was offered as the fifth possibility in the case of Alice and read as follows:

Stimulating her awareness that the world of work may be too much for her, causing her inferiority feelings, and that she would be more fulfilled caring for her young children.

This was designed to reflect the traditional view, as explicated by Helene Deutsch and others, that women can find fulfillment only as wives and mothers (Williams, 1977). Since this view has been so vigorously attacked by the feminist movement from its inception, it seemed wise to include it as an option, to see how likely its use would be.

The other traditional interventions, while not specifically feminist in character, and open to attack from feminists if used alone, are among the range of interventions a feminist might consider. They are not necessarily antithetical to feminist beliefs, in and of themselves:

In the case of Frances, involving her in volunteer work might be the best that could be done, but much feminist research indicates that volunteer work, as it is generally taken up by women, does not provide the sense of self and self-worth that a woman needs to develop a good self-image (as explained above). Similarly, drug therapy is not a treatment of choice (and certainly not as a substitute for other forms of 
intervention in this case), although it might be necessary in some cases. Feminists would deny that Frances' complaints were mainly physiological, and would be concerned that drugs would produce an artificial sense of well-being, further deteriing the woman from making the kinds of changes in her social situation that are necessary. Finally, the third traditional intervention involves exploring Frances' supposed anger towards her children. Some feminists would question whether Frances' dreams should be understood as indicating anger towards her children. If they interpret dreams at all, feminists might infer that the dreams indicate Frances' concern for her own fate: since Frances had never expressed concern for herself directly, perhaps the symbolic expression of her own impending psychic death (due to losing) her identity as a mother) is appropriately expressed in the imagery of catastrophies befalling her children, through whom she has lived her life.

In the case of Ellen, feminists would question some forms of intervention based on the idea that Ellen was "acting out" instinctual impulses. They would deal first with the social context of her problems. Similarly, feminists would point to the contribution others in the the social order make to Ellen's problems, urging her not to take responsibility for those contributions. They would consider Ellen responsible for how she reacts to 
others only when Ellen knows what her options really are (although they would not necessarily consider Ellen responsible for the range of the options). Finally, the feminists assert that since the therapist needs to make a specific educational contribution to therapy for the client's health, empathic listening is not enough by itself in this instance; Ellen will not successfully resolve her socially-determined problems of finding direction in life if, in therapy, social conditions are not dealt with.

In the case of Alice, some feminists would question whether her difficulties were primarily developmental, and would tend to regard them as situational instead. Furthermore, feminists would hesitate to define Alice in primarily relational terms, as would tend to be the case if therapy were to be focused on her need to improve her relationship with Dale (her husband) and the children.

This section of the questionnaire was pre-tested in two stages. First, three faculty members from the School of Social Work at Portland State University read the three cases, and the three traditional intervention choices for each one. They agreed that the cases seemed realistic, and that the interventions offered were among the appropriate interventions a practitioner could choose in dealing with the cases. In two instances, they made 
suggestions which resulted in modification of an intervention and a case description.

In the second stage, one feminist faculty member of the School of Social Work and two feminist faculty members from other departments at Portland State University (who also teach courses in the Women's Studies Program) were presented with the cases, and both the traditional and feminist interventions. They agreed that the cases were realistic, that the feminist interventions were valid, and that they could distinguish between feminist and traditional interventions. They were also helpful in suggesting improvements in the format of this section.

\section{Feminist Beliefs}

Part Three of the questionnaire was an ideology scale, developed for a study of college women by Goldschmidt, et al. (1974). The scale was used subsequently by Marecek and Frash, who stated:

...scores on the scale were extremely po-
tent predictors of behavioral support of the
women's movement. Furthermore, several theo-
retical predictions about the demographic back-
ground, life experiences and psychological dis-
positions associated with support for women's
liberation were empirically verified using the
scale. Thus, there is some evidence for the
validity of the Sympathy for Women's Libera-
tion Scale (1977: 133).

The scale consists of twelve items. Seven relate to issues like abortion, day care and sex discrimination in employment, which are prominent among the seven goals 
stated in the N.O.W. Bill of Rights (Yates, 1975: 45). The remaining five questions revolve not around the question of women's rights but around a redefinition of women's social role in the family, which is the prime concern of the more radical feminists - both the cultural and political wings of this group (Cox, 1976: 436-438). This scale is therefore, relatively comprehensive of ideological issues raised by various branches of the women's movement.

\section{Involvement in Feminist Activities}

Part Four was a check list to assess the degree of respondent involvement in the movement. It, too, was developed as part of the study by Goldschmidt, et al. Respondents were asked to check if they had given verbal support, attended meetings, demonstrated, etc., in support of women's liberation. There was one open-ended question asking respondents to describe any other supportive activity they had engaged in. Criteria for judging "involvement" are, however, less than clear. In the 1974 Goldschmidt study, a respondent was considered to be involved if one item was checked, because very few respondents checked any items at all.

These two scales from the Goldschmidt study were included as measures of respondents' exposure and committment to the feminist viewpoint. 


\section{QUESTIONNAIRE ADMINISTRATION}

Questionnaires were mailed to the sample group on February 15, 1978, with the request that members respond by March 1 .

Fifty members responded with usable returns. One return was sufficiently incomplete as to be unusable. Nine additional questionnaires were returned uncompleted because members were ill, out of the country, or felt themselves unqualified to reply. In mid-March, 1978, a randomly selected sample of the forty remaining nonrespondents was chosen. Thirteen members were included in this sample. They were contacted by telephone, and questioned about problems they might have had with the questionnaire. If there were none, the member was requested to complete the questionnaire within the following week (if the questionnaire had been lost, or misplaced, another copy was supplied). Ten members so contacted agreed to complete the questionnaire and returned it. They generally stated that they had meant to return the questionnaire before, but had been busy, had misplaced their copy, etc. Three of the members so contacted did not return questionnaires. One member reported feelings of anger and defensiveness upon attempting to complete the original questionnaire; the member expressed disappointment that only feminist attitudes were being 
researched. No request was made of this member to try a second time to complete the questionnaire. Two other members refused to complete the questionnaire, stating that they were too busy to take time for any questionnaire. When it was suggested that the subject of the questionnaire was controversial, and thus might be cause for refusal, they stated that this was not a factor in their decision not to respond. 


\section{CHAPTER IV}

\section{RESULTS}

Data were collected relating to the three interconnected research concerns: how likely Oregon members of N.A.S.W. were to use feminist interventions, whether there was a relationship between the likelihood of choosing feminist interventions and commitment to feminism, and finally, whether any of several demographic variables was correlated with the likelihood of employing feminist interventions.

\section{METHOD OF TABULATING SCORES}

In the following section, scores of all 60 respondents have been grouped together. Upon comparing the scores of the original group of respondents (50) with the sample group of non-respondents (10), there were found to be no significant differences, with the exception that the non-respondent group tended to have lower scores on the feminist section of Part 2 (referred to hereafter as Part 2F), and to be more oriented towards psychodynamic theories in practice orientation. These differences between groups are presented in Table I. The differences are significant (as calculated by t test 
TABLE I

DIFFERENCES BETWEEN THE ORIGINAL SAMPLE GROUP AND THE NON-RESPONDENTS GROUP

\begin{tabular}{|c|c|c|}
\hline & $\begin{array}{c}\text { Mean } \\
\text { Score } \\
\text { Part 2F }\end{array}$ & $\begin{array}{c}\text { Psychodynamic } \\
\text { Practice } \\
\text { Orientation }\end{array}$ \\
\hline $\begin{array}{l}\text { Sample Group } \\
(N=50)\end{array}$ & 33.33 & $52 \%$ \\
$\begin{array}{l}\text { Non-Respondents } \\
(N=10)\end{array}$ & 29.44 & $100 \%$ \\
\hline
\end{tabular}

of differences between means) at the 0.05 level.

These differences, while important, were not considered to distinguish the two samples so dramatically that separate analysis of results was warranted. In attempting to generalize results obtained from the analysis of the combined samples to the population, however, it is worth taking into account the possibility that the sample group may be more oriented toward utilizing feminist interventions, and less oriented toward psychodynamic theories than the population.

\section{FEMINIST COMMITMENT AND INTERVENTION}

\section{Commitment to Feminism}

Scores of respondents on Part 3 (beliefs) and on Part 4 (activism) indicate that the sample group has a strong tendency to subscribe to feminist beliefs, and to 
back this up with some action in support of these beliefs. Figure 1, below, shows the pattern of response to Part 3 and Part 4.

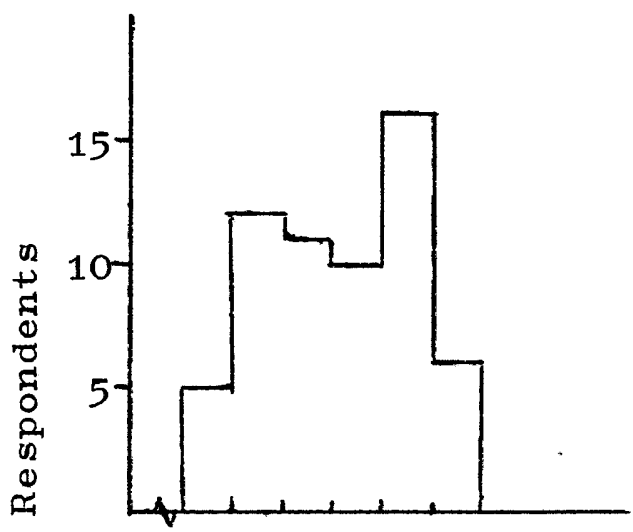

Scores on Part 3

Mean: 49.08

SD : 8.71

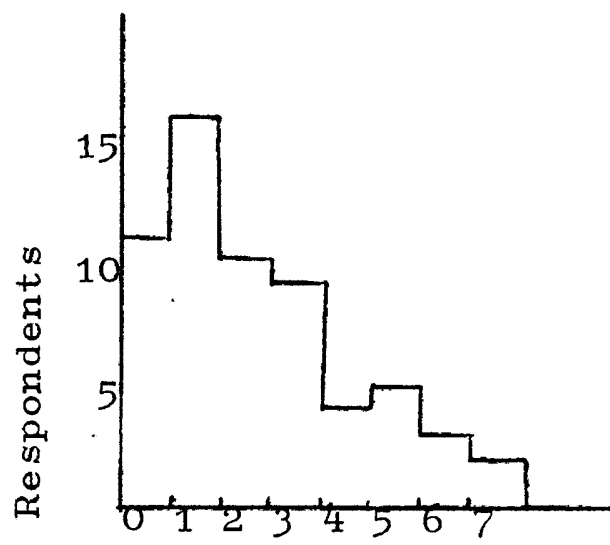

Scores on Part 4

Mean: 2.26

Figure 1. Pattern of responses to Part 3 and Pari 4

Response to Part 3 shows a marked feminist orientation (mean score: 49.09). This is in contrast to the scores on the same scale obtained in the 1974 study by Goldschmidt, et al., where the means of the four sample groups ranged from 32.66 to 37.90 (1974: 605). On the other hand, the pattern of response was similar. Like the Goldschmidt study, means for propositions $5,6,7$ and 12 were among the lowest. These propositions relate mainly to redefining women's social role. Only one of the four highest rated propositions in the Goldschmidt study was highly rated by the sample group, however (this 
is proposition 8). Table II shows the means for each proposition in Part 3 for the sample group.

TABLE II

MEANS OF SAMPLE GROUP RESPONSES

TO QUESTIONS ON PART 3

\begin{tabular}{|c|c|c|}
\hline $\begin{array}{l}\text { Question } \\
\text { Number }\end{array}$ & Issue & Mean \\
\hline 3 & equal pay. & 4.93 \\
\hline 8 & equal pay & 4.87 \\
\hline 10 & career & 4.60 \\
\hline 11 & housework & 4.55 \\
\hline 9 & job rights & 4.50 \\
\hline 1 & abortion & 4.07 \\
\hline 2 & day care & 3.90 \\
\hline 6 & abortion & 3.87 \\
\hline 7 & day care & 3.83 \\
\hline 4 & Motherhood & 3.77 \\
\hline 1 & parenting & 3.75 \\
\hline 5 & attractive & 2.38 \\
\hline
\end{tabular}

Similarly high scores, relative to the Goldschmidt study, were obtained for Part 4. Almost all respondents $(82 \%)$ had given at least verbal support to the women's liberation movement: when just one item in Part 4 was checked it was always - with one exception - that the 
respondent had given verbal support. (The second item checked varied, although it was often "attended meetings"). The sample mean in Part 4 is 2.26 .

\section{Preference for Feminist Intervention Strategies}

Respondents showed a slight preference for feminist intervention strategies over the traditional interventions offered. The in Figures 2, 3 and 4 show the means for each intervention, and the pattern of response. This pattern of response is of particular interest because responses varied so widely, often approaching in their pattern that of a normal curve (see the graphs of interventions 1, 2 and 5 for Case 1; interventions 1, 2, 4. and 5 for Case 2; interventions 2,3 and 4 in Case 3), rather than centering on any one strategy.

Overall totals for feminist and traditional responses have means of 32.37 (the range is 23-45) out of a possible 15-45), and 27.32 (range is 19-39). When averaged to indicate the overall likelihood of feminist response to any one intervention, the mean falls between 3 (neither likely nor unlikely) and 4 (likely), at 3.60 . The averaged mean for the traditional response is 3.04 . Of particular interest is the overwhelming rejection of intervention 5 in Case 3 as a strategy. This involved the rationale for convincing Alice that her troubles arose from not adopting a traditional role. As 


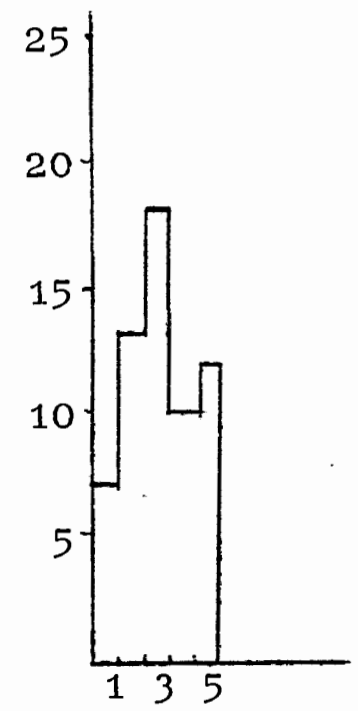

Intervention 1 (working through anger)

Mean: 3.12

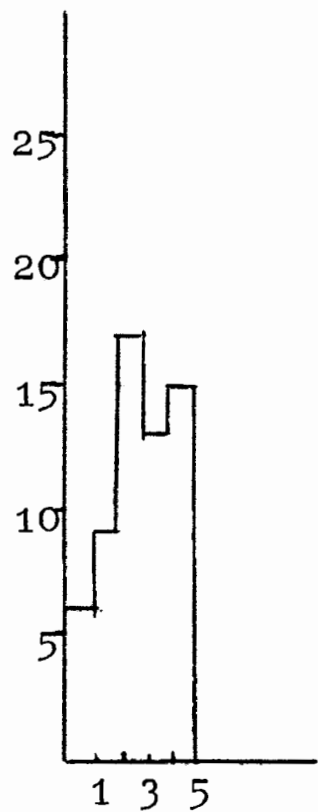

Intervention 2 (strengths)

Mean : 3.37

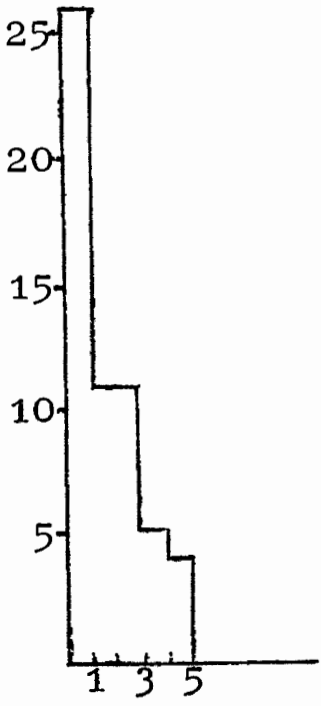

Intervention 3 (medication)

Mean: 2.02

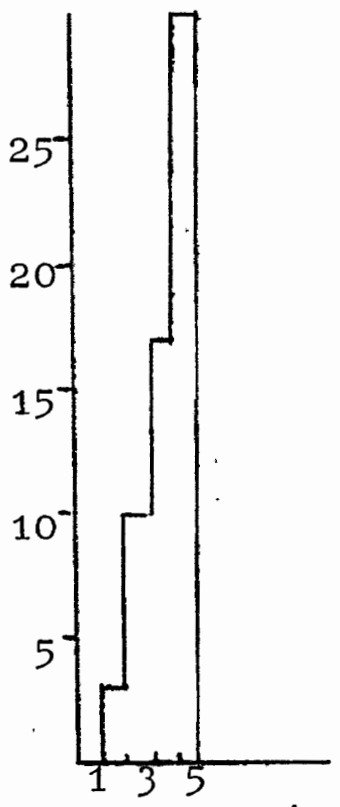

Intervention 4 (appropriate anger)

Mean: 4.23

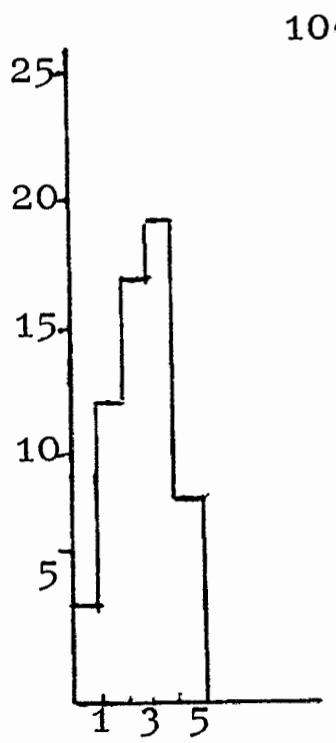

Intervention 5 (community)

Mean : 3.25

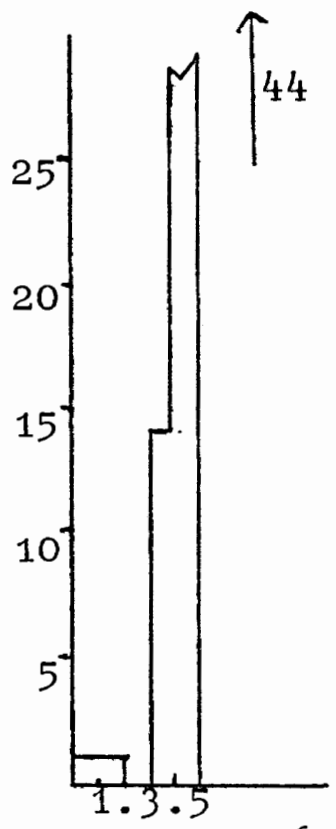

Intervention 6

(self awareness)

Mean 4.65

Figure 2. Pattern of response to Case 1 in Part 2 (Frances, age 46). 


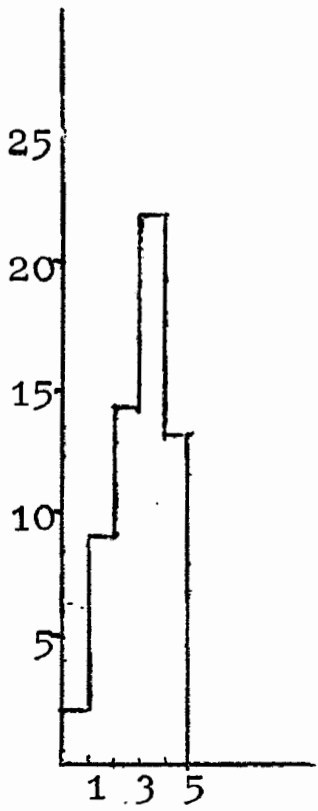

Intervention 2 (acting out)

Mean: 3.58

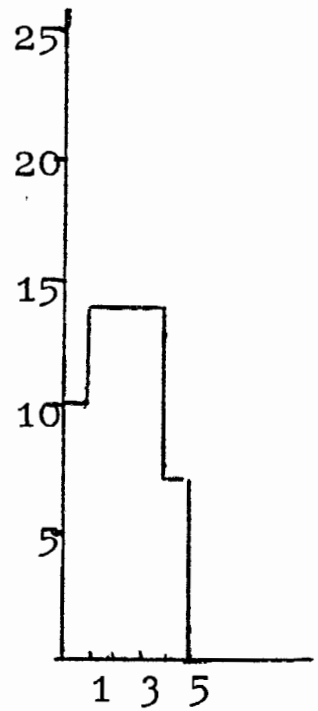

Intervention 1 (social pressure)

Mean: 2.87

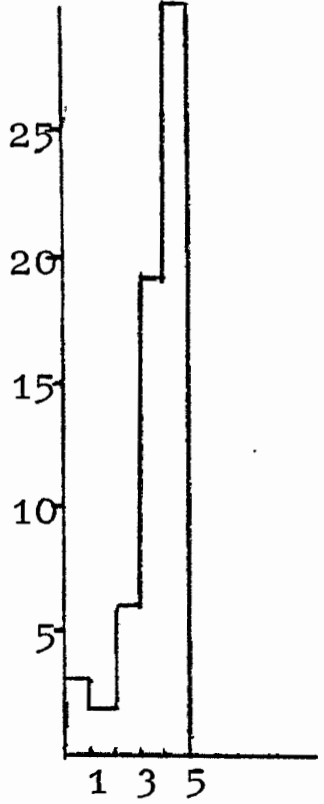

Intervention 3 (responsibility)

Mean: 4.18

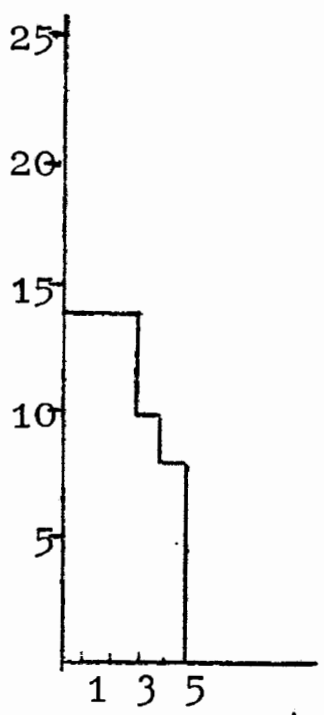

Intervention 4 (anger at limited options) Mean: 2.73

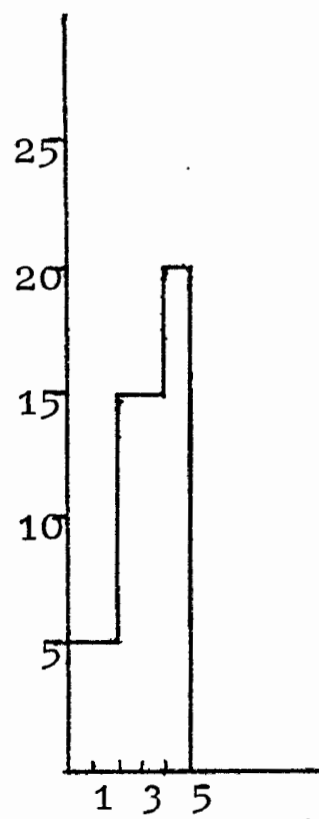

Intervention 6 (empathy)

Mean: 3.67

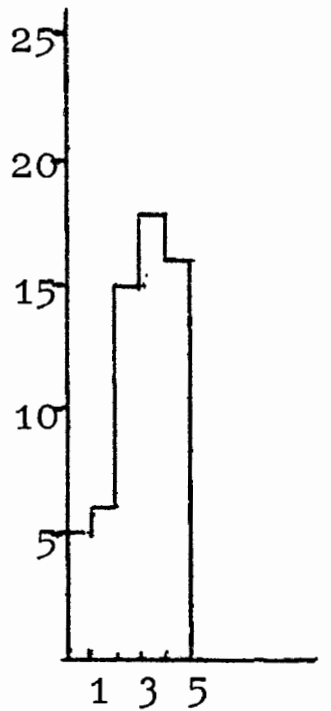

Intervention 5

(non-traditional)

Mean: 3.57

Figure 4. Pattern of response to Case 2 in Part 2 (Ellen, age 15). 


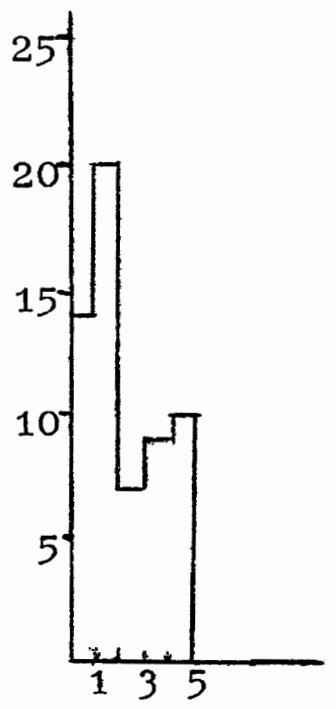

Intervention 1 (conflict)

Mean: 2.68

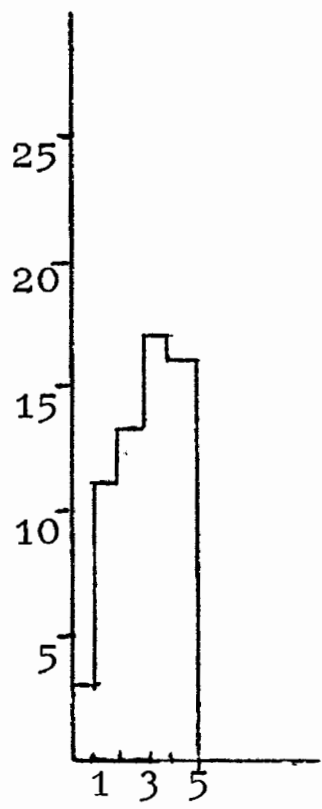

Intervention 2 (assertiveness)

Mean: 3.53

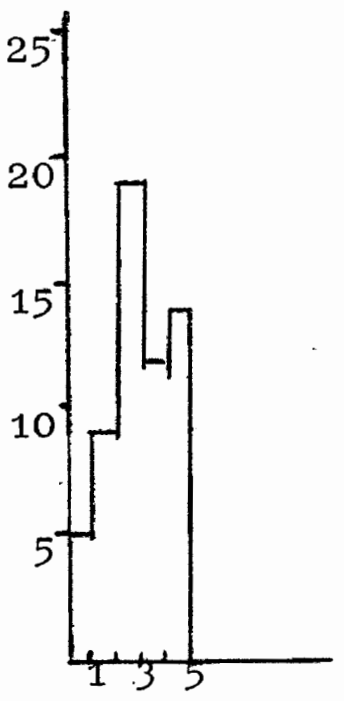

Intervention 3 (mother-wife)

Mean: 3.38

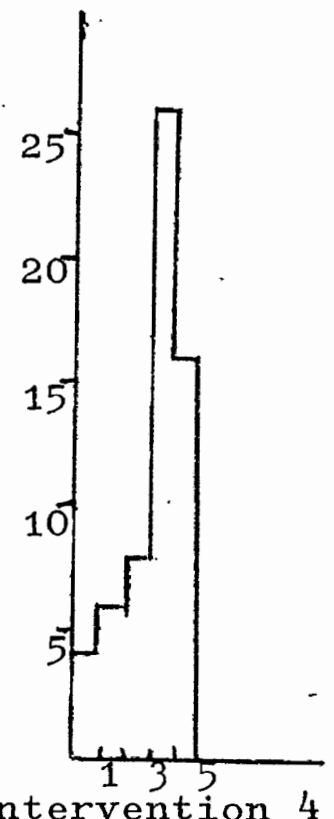

(role awareness)

Mean: 3.77

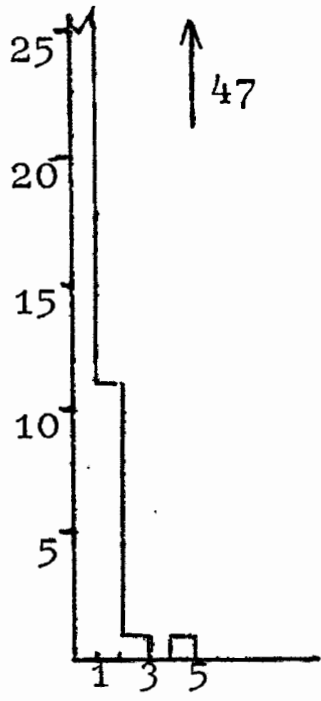

Intervention 5 (traditional)

Mean: 1.28

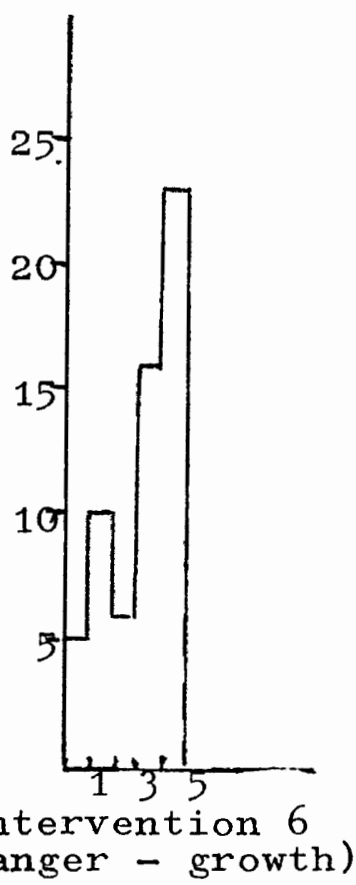

Me an: 3.70

Figure 4. Pattern of response to Case 3 in Part 2 (Alice, age 23). 
noted above, this alone of the traditional interventions was not considered to be acceptable to feminists; in fact, it was included just because it is a classic example of the approach which they oppose most vehemently. The rejection of this option accounts for much of the difference between mean feminist and traditional scores. (If scores on this intervention are excluded and an averaged mean calculated on the basis of the remaining eight scores, the traditional averaged mean, 3.24, compares with the feminist averaged mean, 3.60).

Influence of Stage of Life

Major differences in scores relating to feminist intervention strategies are those among the means of each of the three cases. Feminist interventions are most likely in the case of Frances (Case 1) and least likely in the case of Ellen (Case 2). Averaged mean feminist scores for each of the three cases are presented in Table III, and contrasted with traditional scores. Interestingly, there is a tendency for traditional scores to vary inversely with feminist scores. In addition, the mean scores for each of the feminist interventions are presented and compared for each of the three cases in Figure 5. Comparison by mean for each intervention is more accurate (and will be further explored below). 
TABLE III

MEAN SCORES BY CASES

\begin{tabular}{l|c|c}
\hline & $\begin{array}{c}\text { Average Score- } \\
\text { Feminist Items }\end{array}$ & $\begin{array}{c}\text { Average Score } \\
\text { Traditional Items }\end{array}$ \\
\hline $\begin{array}{l}\text { Case 1 } \\
\text { (Frances) }\end{array}$ & 4.08 & 2.79 \\
$\begin{array}{l}\text { Case 2 } \\
\text { (Ellen) }\end{array}$ & 3.06 & 3.81 \\
$\begin{array}{l}\text { Case 3 } \\
\text { Alice) }\end{array}$ & 3.66 & $2.44^{*}$ \\
\hline
\end{tabular}
is 3.03 .

*Excluding intervention 5, this value

Differences Related to Type of Intervention

A more detailed approach to the responses in this section gives a more complex, but also more accurate picture. Means computed and cited above are useful in illustrating trends, but they do not reflect independent data, and may be misleading for this reason.

In the case of Frances (see Figure 2), clearly most social workers sampled reject the traditional use of medication, and would focus on self-awareness, "encouraging her to begin the process of identifying her own wants and needs - differentiated from relationships with children and husband -- to refashion a meaningful role and identity." This is a feminist focus that fits 


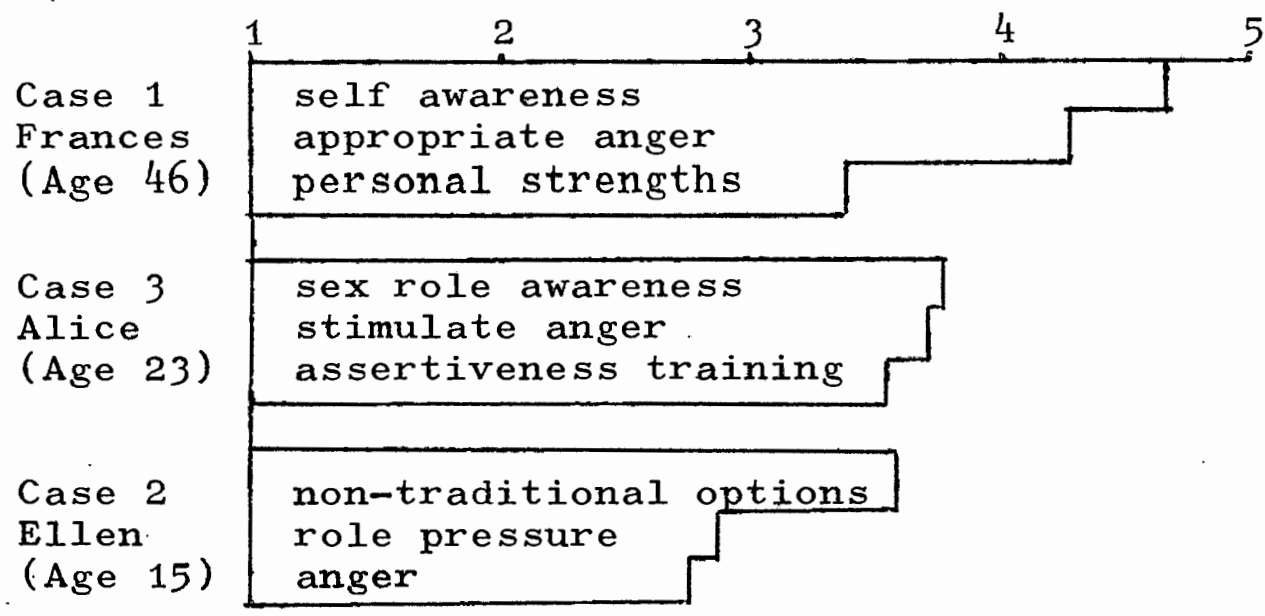

Figure 5. Comparison of mean responses by case and intervention strategy.

well with gestalt and other current therapeutic emphasis on self-awareness. A second feminist focus, recognizing that the "symptom" of anger was an appropriate response to a difficult situation, was also extensively supported by social workers. There was, however, broad disagreement in the field on the advisability of using the other feminist option (validating Frances' strengths), or the two remaining traditional ones (working through anger and community volunteer work).

In the case of Ellen, no feminist interventions received extensive support. Most favored, however, was exploring the implications of non-traditional role options with Ellen. Least favored, interestingly, was recognizing that Ellen's "symptom" of anger was an appropriate response to a difficult situation. Helping Ellen to understand and deal with social pressure to adopt a traditional role 
would be a significant element of a feminist response to Ellen's situation, seen as part of the exploration of nontraditional role options, in that helping her to deal with some of the opposition she would face in doing non-traditional things would follow naturally. That this was not as widely supported as intervention 5 may be due to respondents' seeing this as taking a more active role, while they interpreted intervention 5 as part of a passive role (i.e., merely letting Ellen know, when appropriate, that non-traditional options were acceptable, or in validating her demands for such options). In addition, however, some respondents appeared to have been confused by the wording of intervention 1 , interpreting it as meaning that Ellen should comply with peer and adult pressure (when margin notes warranted, the respondent's real preference was corrected in tabulating the results presented here).

Intervention strategies that received extensive support were all traditional. Social workers in the sample were especially concerned to help Ellen "evaluate and accept her own responsibility for the situations she finds unsatisfactory" (mean score for this was 4.18, in the "likely" zone). There was also support for discussing consequences of acting out behavior and empathic listening to help her through her adolescent identity 
crisis.

Alice's case presents the most classic feminist case. In this case, as in the case of Frances, awareness was often supported (this time relating to sex role passivity). As in the cases of both Frances and Ellen, facilitating awareness was more widely supported than facilitating anger. Respondents were less likely to indicate that they would facilitate Alice's "awareness of anger at being assigned to an inferior sex role" in order to use it as a means to growth. Respondents were, however, more likely to see anger as appropriate for Alice than for Ellen, although they were less likely to see it as appropriate for Alice than for Frances. (Interestingly enough, the anger, in each case, relates to the same sex role, but is experienced at different points in the cycle).

Finally, there was broad variation in respondents' indications of how likely they would be to teach Alice assertiveness, or do the traditional work with unresolved conflict with parental figures and improvement of current family relationships. As noted above, social workers in this sample would be very unlikely to encourage Alice to adopt a traditional role in order to solve her problems (mean for this intervention, intervention 5, was 1.28 ). 


\section{COMMTTMENT AND INTERVENTION STRATEGIES}

The relationship between how likely social workers are to employ feminist interventions and their degree of commitment| to feminism has (at least) two aspects. First is the simple correlation between degree of committment (as measured by agreement with feminist beliefs, Part 3, and by involvement in feminist activities, Part 4), and the likelihood of feminist responses in Part $2 \mathrm{~F}$ for all respondents in the sample group. Second, is showing that social workers who report themselves active in the women's movement, particularly as it relates to mental health and other social welfare issues, are likely to choose feminist interventions.

Measures of Correlation

In the first instance, correlation calculations were made to determine the relation between scores on Part 3 and Part 4 with Part 2F. The correlation found to be most representative is that between Part 3 and Part 2F (although the relationship between scores on both these scales and scores from Part 4 is also interesting and will be presented below) Part 3 represents both the equal rights concerns and the interest in redefining women's role in the family. As will be shown below, the latter is very closely related to the likeli- 
hood of choosing feminist interventions.

The correlation between commitment and Part $2 \mathrm{~F}$ is not linear. Calculating the linear correlation ratio for the relation between scores on Part 3 and Part $2 F$ results in a Pearson product-moment correlation ( $r$ ) value of 0.29 (that is, only $8 \%, r^{2}$, of the variation in scores of Part $2 F$ appears to be explained by variation in scores of Part 3). On the other hand, the joint frequency table, presented as Figure 6, shows more clearly than a scatter diagram, the pattern of correlation of the data (a J-scatter). Clearly, respondents are unlikely to have high scores (more than $33 ; 32.37$ is the mean) on Part $2 F$ if they have low scores (49 and under; 49.08 is the mean) on Part 3. A high score on Part 3 is a necessary, but not a sufficient condition for a high score on Part $2 F$. The correlation ratio $\left(\eta^{2}\right)$ measures this type of correlation more accurately than the Pearsonian $r$, and is 0.3275 . Thus, $33 \%$ of the variation in scores on Part $2 F$ is explained by variation in scores on Part 3.

Correlation between Part $2 F$ and Part 4 is less close. The joint frequency diagram is presented below as Figure 7 . The correlation ratio $\left(\eta^{2}\right)$ is $0.2526 ; 25 \%$ of the variation in scores on Part $2 F$ is explained by variation in scores on Part 4. Frequently, respondents stated they were active in working for women's rights, 


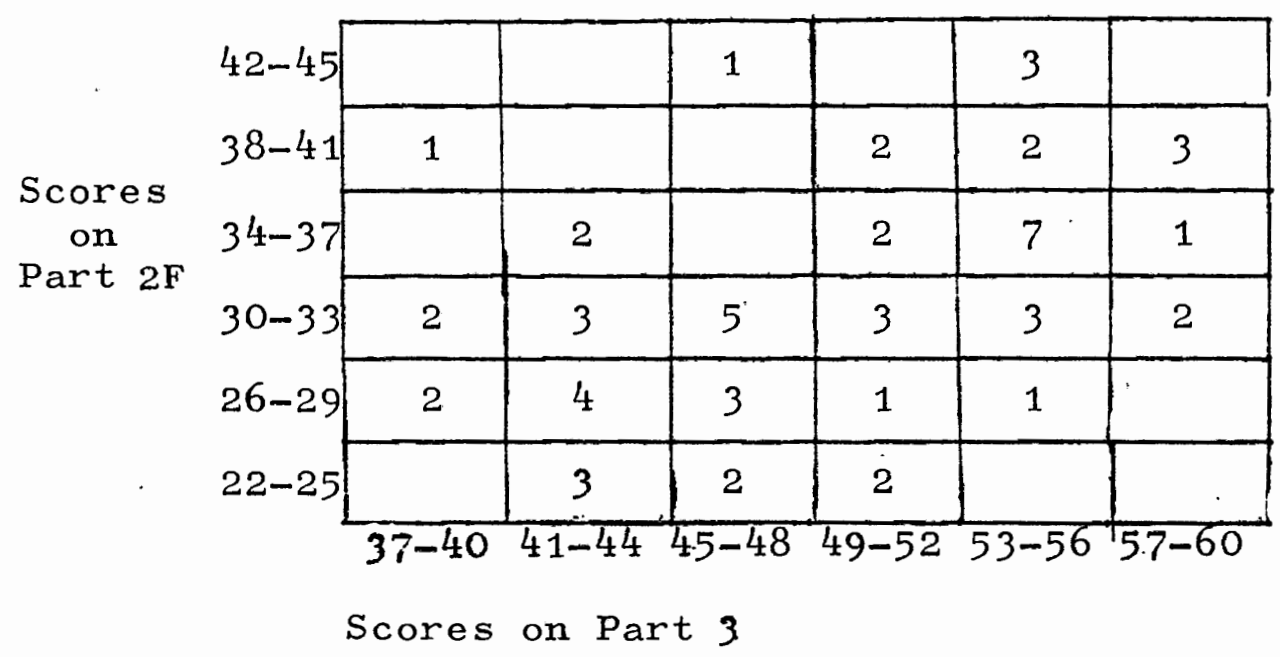

Figure 6. Joint Frequency Table for the correlation of scores on Part 3 with scores on Part 2F.

but less concerned about other demands. For example, one respondent noted participation as "speaker in support of Planned Parenthood and the Equal Rights Amendment in the Community (ERA, Planned Parenthood, yes; N.o.W., no)." This respondent had a score of 5 on Part 4 (quite high; mean for the sample group is 2.28), but a score of 48 on Part 3, due to low scores on items relating to women's traditional role in the family. Thus, as it was constructed (and as this respondent noted on the questionnaire, as it happened), Part 4 did not distinguish between involvement in obtaining merely equal rights, or a new definition of women's role. As indicated in the review of literature chapter, the distinction is an important one.

Interestingly, correlation between Parts 3 and 4 is high, and the pattern of correlation is again a $J-$ 


\begin{tabular}{|c|c|c|c|c|c|c|c|c|}
\hline \multirow{3}{*}{$\begin{array}{l}\text { Scores } \\
\text { on }\end{array}$} & $42-45$ & & & 2 & & 2 & & 1 \\
\hline & $38-41$ & & 3 & 1 & 3 & & & 1 \\
\hline & $34-37$ & & 4 & 1 & & 1 & 3 & 2 \\
\hline \multirow{4}{*}{ Part $2 F$} & $30-33$ & 4 & 3 & 6 & 2 & 1 & 2 & \\
\hline & $26-29$ & 5 & 5 & & 1 & & 1 & \\
\hline & $22-25$ & 2 & & 1 & 3 & 1 & & \\
\hline & & 0 & 1 & 2 & 3 & 4 & 5 & 6. \\
\hline
\end{tabular}

Figure 7. Joint Frequency Table for the correlation of scores on Part 4 with scores on Part $2 F$.

scatter, like the pattern for the relationship of scores on Part 2F and Part 3. A high score on Part 3 tends to be necessary, though not a sufficient condition, for a high score on Part 4. The Joint Frequency Table is presented below. Calculation of the correlation ratio $\left(\eta^{2}\right)$ shows that $61 \%$ of the variation in involvement is explained by variation in beliefs. (Part 3 ).

Correlation was also measured by computer analysis. A form of multiple regression analysis called sub-program analysis was performed on the data gathered in the questionnaire (cf. Kim and Kohout, pages 320-367 in Statistical Programs for the Social Sciences, 1975). Included as variables were seven of the interventions which had been identified as pivotal by an earlier factor rotation. Since the sub-program regression form of 


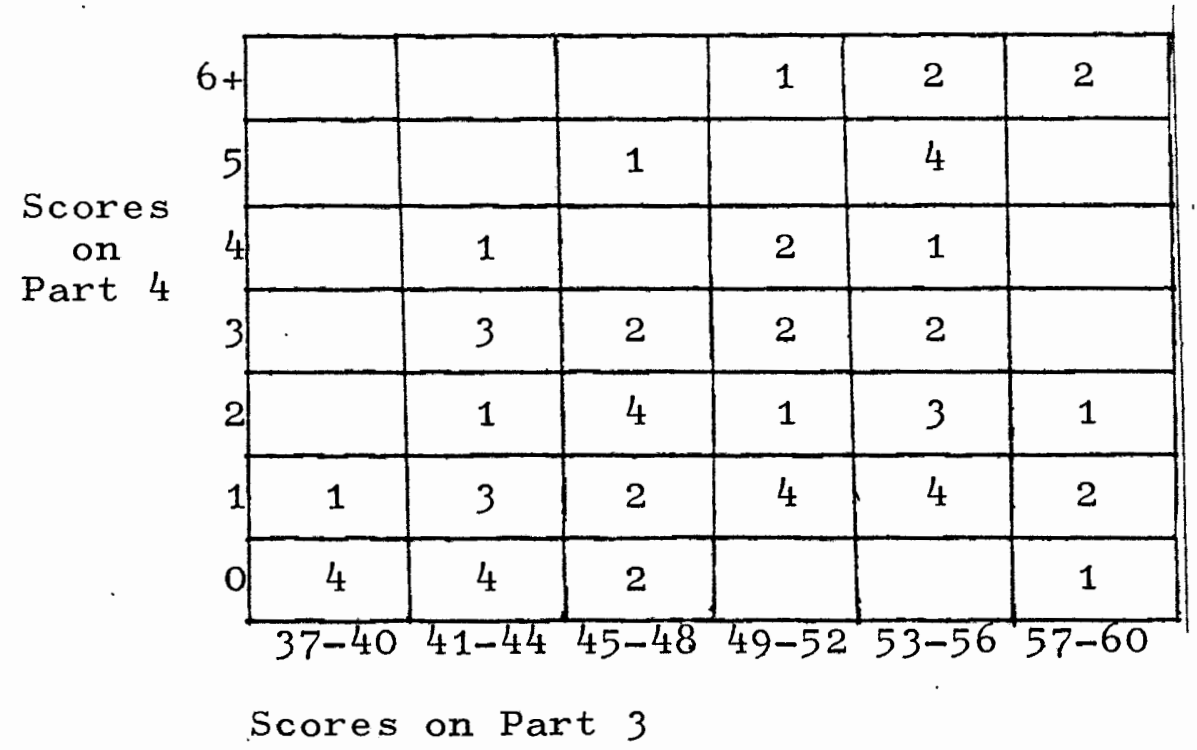

Figure 8. Joint Frequency Table for the correlation of scores on Part 3 with scores on Part 4.

multiple regression analysis is used to find the best linear measure of correlation, significant results wexe meager. As illustrated above, Part 3 and Part 4 do not have a very strong linear correlation with items from Part 2. Only five correlations obtained by this method reached significance; two relate to the demographic variables, and will be discussed in that section. Of the three remaining significant correlations, all involve Case 3 (Alice). The second intervention, teaching as- . sertiveness is positively correlated with scores on Part 3. Likewise, intervention 1 is inversely related to high scores on Part 3; the factor rotation indicated that respondents who chose intervention 2 rejected intervention 1 (a validation of the test items in Part 2 , 
since intervention 1 was identified as traditional and intervention 2 as feminist). The second significant item is the positive correlation of intervention. 6, helping Alice become aware of her anger, with high scores on Part 3. The factor rotation had indicated that respondents who tended to choose intervention 6 also tended to choose intervention 4, which dealt with helping Alice to become aware of passivity as part of the sex role she was taught (since both these feminist interventions are positively correlated with Part 3 scores, this is another indication that the test items in Part 2 are valid). The third significant linear correlation to emerge from the computer analysis, interestingly, was of preference for intervention 3 (improving Alice's relationships with husband and children), in positive correlation with scores on Part 4. This is somewhat disturbing, given the near-universal opposition of feminist writers to emphasizing a woman's involvement as mother and wife to the detriment of a view of her as a person. On the other hand, as shown in Figure 6 above, high feminist scores on Part 2 do correlate with high involvement scores $\left(\eta^{2}=0.25\right)$, so that this finding may represent a less important trend within the whole. People with high relationship needs may be the ones who are more active in social movements, and more likely to deal with relationship problems when working with clients. 
Three Groups of Feminists

A number of respondents indicated particularly extensive and personal involvement in the women's movement as part of their answer to the questions posed in Part 4. These respondents had all participated in at least four activities, and described what these activities were. On the basis of these descriptions, the first two of three groups can be differentiated.

The first of these groups, Group 1, was composed of ten respondents. The mean score for this group on Part 4 was 5.4. Two were men. Six had obtained their last degree in the $1970^{\prime} \mathrm{s}$, three in the 1960's. The modal age range was from 35 to 50. They reported that they had been active in ways that related to women's social role:

...helped to get a women's center going in a small California college.

...believe myself to be a feminist and to do feminist, egalitarian psychotherapy.

....volunteer time in settings offering.services to women, i.e. health clinic, shelter

home for battered women.

...organized and ran assertion training groups, women's rap groups.

The second group, Group 2, contained seven respondents, was also very active (mean score on Part 4 was 4.4).

There was one man in this group. More had obtained their last degree in the 1960's (4, or 57\%), than in the 1970's (43\%). Modal age range was 35 to 50. Practice orientation was mixed. These respondents reported they had been 
active mainly in political areas, and mainly for equal employment rights for women. The following comments are representative:

Aggressive affirmative action in job recruitment and hiring; rewriting job descriptions to insure equal pay for equal work, and equal pay for equal talent.

...filed civil rights complaint and federal suit.

...speaker in support of Planned Parenthood and the Equal Rights Amendment in the community (ERA and Planned Parenthood, yes; N.O.W., no).

It is the differences in the mean scores for the two groups on Part $2 F$ and Part 3 that is so interesting. The scores are presented in Table IV, with the scores for Group 3, to be described below.

\section{TABLE IV}

SCORES ON PART $2 F$ AND ON PART 3 FOR THE THREE GROUPS OF FEMINIST RESPONDEN'TS

\begin{tabular}{|c|c|c|}
\hline & $\begin{array}{l}\text { Mean } \\
\text { Total Score } \\
\text { Part } 2 F\end{array}$ & $\begin{array}{c}\text { Mean } \\
\text { Total Score } \\
\text { Part } 3\end{array}$ \\
\hline$\underset{(N=10)}{\text { Group }} 1$ & $\begin{array}{c}38.3 \\
(\text { range } 33-45)\end{array}$ & $\begin{array}{c}54.2 \\
(\text { range } 50-59)\end{array}$ \\
\hline$\underset{(N=7)}{\text { Group }} 2$ & $\begin{array}{c}29.4 \\
\text { (range } 23-45)\end{array}$ & $\begin{array}{c}50.6 \\
(\text { range } 42-57)\end{array}$ \\
\hline $\begin{array}{l}\text { Group } 3 \\
(\mathrm{~N}=8)\end{array}$ & $\begin{array}{c}37 \cdot 9 \\
\text { (range } 36-40)\end{array}$ & $\begin{array}{c}51.5 \\
\text { (range } 38-57 \text { ) }\end{array}$ \\
\hline
\end{tabular}

As noted above, these results are compatible with conventional analysis of the women's movement which 
separates it into two parts: one section is mainly concerned with legal equality while the other section (or rather other sections) are concerned with redefinition of women's social role as well. Thus, Group 1, which by self report was interested in the social conditions of women, outside of the employment question, has a higher mean score on Part 3, the composite rights and social conditions scale. This group also scores higher on the feminist section of Part 2 (seven members of this group report themselves specifically involved in some aspect of feminist-oriented therapy; they were the only respondents who so identified themselves), and is more than one standard deviation to the right of the mean for the sample group.

It is worth noting, as a check on the validity of the cases and interventions constructed for Part 2 , that the scores of Group 1 on Part $2 F$ are significantly higher than the scores of a traditional group. For comparison with Group 1, a traditional group was isolated by taking all respondents who had a score more than one standard deviation to the left of the mean on the feminist beliefs section (Part 3). When the mean score of this traditional group on Part $2 F$ is compared to the mean score of Group 1 on Part 2F; using a t test, the higher scores of Group 1 are significant at the 0.01 level. Group 2, when contrasted with Group 1, is somewhat 
less active, and has a lower mean score on Part 3, although the mean for the Group is still above the mean for the sample group (49.08). Interestingly, the mean score on the feminist section of Part 2 is below that of the sample group (whose mean is 32.37). It is about six tenths of a standard deviation to the left of the mean .

Thus, it is clear that, among all social worker respondents who report themselves to be very involved with the feminist movement, there are two distinct groups.

A third group can be distinguished. It is not characterized by high involvement with the women's movement, but by high scores on Part 2F. Members of Group 1 and Group 3 constitute all respondents with high scores on Part 2F. The mean score for Group 3 on Part 4 was 1.6, below the sample average. Mean score on Part 3 , however, was above the sample average. Half the respondents in this group are men. The modal age range of the group is under 35 (although $25 \%$ are over 50). They tend to have received their last degree in the 1970 's (50\%) and also to be less oriented toward psychodynamic practice theories than the sample group $(63 \%$ did not check a Freudian or Psychodyanmic orientation: see discussion of practice orientation effects below). In Table IV, the mean scores of Group 3 respondents are compared to those of Groups 1 and 2. Clearly this group of respondents 
has a feminist commitment and ascribes to feminist principles in therapeutic intervention, although no respondent in this group indicated (in Part 4) that work with these principles was considered a form of activism in the women's movement.

While members of Group 3 tend to be younger, to have received their last degree more recently and to be non-Freudian in practice orientation more frequently, these differences are not significant. In addition, there are no significant differences in their pattern of response to the feminist items in Part 2 . Thus, there are two groups very likely to use feminist interventions: one group, which is highly involved in the women's movement in its concerns about women's social role, and a second group, moderately involved in the movement. Both groups, relative to the sample group as a whole, hold more feminist beliefs, are young, recent graduates, and less oriented twoards psychodyanmic theories.

\section{DEMOGRAPHIC ASSOCIATIONS}

Respondents were asked to give some demographic information about themselves. This information was compared to the response to Part $2 F$ and to the responses to the feminist beliefs section, Part 3 . 
Age

Respondents were asked to indicate whether they were 35 and under, 36 to 50, or 51 and older. Results are summarized in Table $\mathrm{V}$. When responses to Part $2 \mathrm{~F}$ and to Part 3 were compared by age, association did not reach significance.

TABLE V

AGE OF RESPONDENTS

\begin{tabular}{l|c|c}
\hline & Number & Percent \\
\hline 35 and under & 19 & $32 \%$ \\
$36-50$ & 26 & $43 \%$ \\
51 and over & 15 & $25 \%$ \\
\hline
\end{tabular}

$\underline{\text { Sex }}$

Slightly more women (58\%) than men responded to the questionnaire. Differences in response related to sex were interesting (particularly for Part 3, where they were significant at the relatively gross level of $0.1)$, but not significant. Related to participation in the women's movement (as measured by Part 4), there was significant (0.01) differentiation by sex; this, however, is hardly surprizing. Table VI shows the mean scores for all parts of the questionnaire according to age, and within age ranges, by sex, compared with the sample mean. 
TABLE VI MEAN SCORES ON PART 2F, PART 3 AND PART 4
BY AGE AND SEX

\begin{tabular}{l|c|c|c}
\hline & $\begin{array}{c}\text { Mean } \\
\text { Total Score } \\
\text { Part 2F }\end{array}$ & $\begin{array}{c}\text { Mean } \\
\text { Total Score } \\
\text { Part 3 }\end{array}$ & $\begin{array}{c}\text { Mean } \\
\text { Total Score } \\
\text { Part 4 }\end{array}$ \\
\hline 35 and under & 33.42 & 51.47 & 2.05 \\
Women & 33.54 & 52.00 & 2.00 \\
$36-50$ & 33.25 & 50.75 & 2.13 \\
Women & 31.70 & 47.75 & 2.83 \\
Men & 33.58 & 50.75 & 4.41 \\
50 and over & 29.83 & 44.75 & 1.25 \\
Women & 32.45 & 41.80 & 2.30 \\
Men & 32.36 & 49.45 & 2.60 \\
Sample Group & 32.75 & 36.50 & 1.50 \\
(as a whole) & 32.37 & 49.08 & 2.28 \\
\hline
\end{tabular}

\section{City Size}

The size of the city in which respondents practice is not significantly related to responses to Part $2 F$ or to Part 3 . The response pattern to Part $2 F$ illustrates the spread of responses by city. size (see Table VII). Thus, while a number of residents of smaller towns in Oregon do not choose a high number of feminist interventions, a number do (they are either low or high), and, in contrast, residents of the Portland area (the 
, TABLE VII

RESPONSES TO PART 2F

RELATED TO CITY SIZE

\begin{tabular}{|c|c|c|c|}
\hline \multirow{2}{*}{$\begin{array}{l}\text { City } \\
\text { Size }\end{array}$} & \multicolumn{3}{|c|}{ Mean Total Score on Part $2 F$} \\
\hline & $\begin{array}{c}\text { Low } \\
(23-30)\end{array}$ & $\begin{array}{l}\text { Middle } \\
(31-37)\end{array}$ & $\begin{array}{l}\text { High } \\
(38-45)\end{array}$ \\
\hline $\begin{array}{l}25,000 \\
\text { and under }\end{array}$ & 5 & 1 & 3 \\
\hline $\begin{array}{l}25,000 \\
\text { to } 75,000\end{array}$ & 1 & 1 & 3 \\
\hline $\begin{array}{l}75,000 \\
\text { to } 150,000\end{array}$ & 5 & 2 & 1 \\
\hline $\begin{array}{l}150,000 \\
\text { and over }\end{array}$ & 15 & 18 & 5 \\
\hline
\end{tabular}

only city in Oregon over 150,000 population) tended to choose a more modest number of feminist interventions than had been expected.

Date of Last Degree

The date of last degree obtained was associated with responses to Part $2 F$ and to Part 3 at significant levels. The association with Part $2 F$ was significant at the 0.01 level; that with Part 3 was not significant at the 0.01 level, but was significant at 0.02 . Table VIII below shows that the major differences occur in respondents who had received degrees in the 1940's and 
TABLE VIII

DATE OF LAST DEGREE RELATED TO SCORES ON PART 2F AND PART 3

\begin{tabular}{|c|c|c|c|c|c|c|}
\hline \multirow{3}{*}{$\begin{array}{l}\text { Date } \\
\text { of } \\
\text { Last } \\
\text { De- } \\
\text { gree }\end{array}$} & \multicolumn{6}{|c|}{ Mean Total Scores } \\
\hline & \multicolumn{3}{|c|}{ Part 2F } & \multicolumn{3}{|c|}{ Part 3} \\
\hline & $\underset{(23-30)}{\text { Low }}$ & $\begin{array}{c}\text { Middle } \\
(31-37)\end{array}$ & $\begin{array}{c}\text { High } \\
(38-45)\end{array}$ & $\begin{array}{c}\text { Low } \\
(37-44)\end{array}$ & $\begin{array}{l}\text { Middle } \\
(45-52)\end{array}$ & $\begin{array}{l}\text { High } \\
(53-60)\end{array}$ \\
\hline $\begin{array}{r}1940- \\
1959\end{array}$ & 5 & 3 & 1 & 6 & 2 & 1 \\
\hline $\begin{array}{r}1960- \\
1964\end{array}$ & 4 & 2 & 1 & 4 & 2 & 1 \\
\hline $\begin{array}{r}1965- \\
1969\end{array}$ & 7 & 3 & 4 & 4 & 4 & 6 \\
\hline $\begin{array}{r}1970- \\
1974\end{array}$ & 4 & 7 & 2 & 2 & 7 & 4 \\
\hline $\begin{array}{r}1975- \\
1978\end{array}$ & 5 & 5 & 5 & 1 & 5 & 9 \\
\hline
\end{tabular}

$1950^{\prime} \mathrm{s}$, who are (as might be expected) more conservative with respect to these issues, but that the real change in support of feminist beliefs and interventions occurred mainly in the 1970's graduates, and particularly among the most recently graduated group.

One significant linear correlation isolated by the computer program run on the data (see description above) was an association between year of graduation and a tendency to support items 1, 2 and 4 of Case 1 (Frances) in Part 2. These items related to working tlirough anger 
(traditional intervention 1), validating Frances' abilib. (feminist intervention 2) and recognizing her anger as legitimate (intervention 4 ). This may be due to the fact that attention to the special situation of older people is relatively recent in the social work curriculum, and through being integrated with the course work fairly recently, has been more influenced by feminist concerns.

It is also interesting (see section on practice orientation below) that there is a significant association between practice orientation and date last degree was obtained.

TABLE IX

PRACTICE ORIENTATION RELATED TO DATE OF LAST DEGREE

\begin{tabular}{|c|c|c|c|c|}
\hline \multirow{2}{*}{$\begin{array}{l}\text { Practice } \\
\text { Orientation }\end{array}$} & \multicolumn{4}{|c|}{ Date of Last Degree } \\
\hline & $\begin{array}{r}1940- \\
1949\end{array}$ & $\begin{array}{r}1950- \\
1959\end{array}$ & $\begin{array}{r}1960- \\
1969\end{array}$ & $\begin{array}{r}1970- \\
1978\end{array}$ \\
\hline $\begin{array}{l}\text { Group I } \\
\text { (Psychodynamic) }\end{array}$ & 3 & 4 & 9 & 2 \\
\hline $\begin{array}{l}\text { Group II } \\
\text { (Psychodynamic } \\
\text { and Humanist) }\end{array}$ & 0 & 1 & 6 & 10 \\
\hline $\begin{array}{l}\text { Group III } \\
\text { (Humanist) }\end{array}$ & 0 & 0 & 2 & 9 \\
\hline $\begin{array}{l}\text { Group IV } \\
\text { (Miscellaneous) }\end{array}$ & 0 & 1 & 4 & 6 \\
\hline
\end{tabular}


Since recent graduates are so heavily represented in the sample group, their contribution to the sample means is an important factor.

\section{$\underline{\text { School Attended }}$}

In almost every case, the last degree obtained was an M.S.W., or equivalent degree, from a school of social work. Other degrees were one Juris Doctor, two M.S.S.A. degrees, and two B.A. degrees. Overall, $38 \%$ of all respondents had been graduated from the School of Social Work at Portland State University. Counting only graduates in the years since the school was organized, and had its first graduating class, $53 \%$ of the respondents are graduates of Portland State. Responses to Part $2 F$ were not significantly associated with whether the respondent had attende Portland State or another school (in the same time period); there was, however, a trend for Portland State graduates to choose fewer feminist interventions than graduates of other schools of the same period (significant only at 0.1 ).

Practice Setting

Respondents were asked to indicate whether they worked in a public agency, private agency, or were in private practice. Further, they were asked to indicate if the agency in which they worked was an "alternative" agency. No respondents work in alternative agencies, as 
defined by the author (see Design section above). Two respondents checked this, but, from other information supplied, it was determined that these agencies, while different from the norm for social workers, were not alternative agencies. Of the 57 respondents who furnished information, $43 \%$ work in public agencies, $35 \%$ work in private agencies and $21 \%$ are in private practice. Four respondents indicated they work half time in an agency, half time in their own practice; this has been taken into account in the figures above. The pattern of responses to Part $2 F$ and to Part 3 was not significantly correlated with practice setting. Interestingly, practice setting was associated with size of city: most social workers in smaller towns work in public agencies.

\section{Ethnic Background}

All respondents checked that they are caucasian.

Practice Orientation

All practice orientations offered were checked by at least one respondent. A number of respondents checked more than six practice orientations: 35\% (in fact, $12 \%$ checked more than 10). Only $12 \%$ checked only one orientation (which was most likely to be "social casework" or "eclectic"). The remaining $48 \%$ checked from two to six options. It seems clear that many respondents consider using a "practice orientation" as tantamount to using a 
method or technique. Rather than a metaphysical statement about the basis of personality and personal change, it would|seem that these practice orientations represent for the respondents something more like therapeutic skills. Response patterns are shown in Table $X$ below. About $20 \%$ of respondents wrote in practice orientations, in addition to the ones checked. Most frequently, these were Reality Therapy, Existentialist (including Logotherapy), and social administration ( 3 ) .

TABLE $\mathrm{X}$

DISTRIBUTION OF PRACTICE ORIENTATIONS

\begin{tabular}{|c|c|c|c|}
\hline Orientation & Percent & Orientation & cent \\
\hline Adlerian & $5 \%$ & Jungian & $3 \%$ \\
\hline Assertive Training & $32 \%$ & Learning Theory & $22 \%$ \\
\hline Behaviorism & $23 \%$ & Primal & $5 \%$ \\
\hline Bioenergetics & $2 \%$ & Psychodynamic & $32 \%$ \\
\hline Co-counseling & $20 \%$ & Radical Therapy & $3 \%$ \\
\hline Eclectic & $62 \%$ & Reichian & $3 \%$ \\
\hline Family Therapy & $60 \%$ & Relaxation Training & $12 \%$ \\
\hline Freudian & $38 \%$ & Rogerian & $13 \%$ \\
\hline Gestalt & $30 \%$ & Social Casework & $65 \%$ \\
\hline Humanistic & $37 \%$ & Transactional Analysis & $30 \%$ \\
\hline
\end{tabular}

The respondents were divided into four groups 
(roughly equal before the more psychodynamically oriented non-respondent group was added). Group I (19 respondents or $32 \%$ ) represented the respondents who had checked psychodynamic and related orientations, but not humanist orientations. Group II (18 respondents or 31\%) was composed of respondents who checked humanist and psychodynamic orientations. Group III ( 11 respondents or $31 \%$ ) was respondents who checked humanist orientations, but not psychodynamic orientations. There was no other significant grouping to be made (the existentialists, including Rogerians, were insufficiently distinguished from psychodyanmic practitioners; there were very few behaviorists). The fourth group (11 respondents, or 19\%) was composed of respondents who did not fit into any of the other groups (for example, they checked only social casework or eclectic; there was not enough information about them), although they clearly were not heavily committed to either a psychodynamic or humanist view. Because so little was known about members of the fourth group, this group was not considered in calculations of association reported below.

The association between practice orientation (grouped as explained) with the number of feminist responses on Part 2 is significant at the 0.01 level. The correlation ratio $\left(\eta^{2}\right)$ for this association is 0.21 ; this means that $21 \%$ of the variation in scores on Part 
2 is explained by variation in practice orientation. Table XI shows the pattern of response by the first three practice orientation groups.

TABLE XI

RELATION BETWEEN PRACTICE ORIENTATION AND SCORES ON PART 2F

\begin{tabular}{l|c|c|c}
\hline \multirow{2}{*}{$\begin{array}{l}\text { Practice } \\
\text { Orientation }\end{array}$} & \multicolumn{2}{|c}{ Mean Total Scores on Part 2F } \\
\cline { 2 - 4 } & $\begin{array}{c}\text { Low } \\
(23-30)\end{array}$ & $\begin{array}{c}\text { Middle } \\
(31-37)\end{array}$ & $\begin{array}{c}\text { High } \\
(38-45)\end{array}$ \\
\hline $\begin{array}{l}\text { Group I } \\
\text { (Psychodyanmic) }\end{array}$ & 13 & 5 & 1 \\
$\begin{array}{l}\text { Group II } \\
\text { (Psychodynamic } \\
\text { and Humanist) }\end{array}$ & 9 & 5 & 4 \\
$\begin{array}{l}\text { Group III } \\
\text { (Humanist) }\end{array}$ & 1 & 5 & 5 \\
\hline
\end{tabular}

As noted above, practice orientation and date of last degree obtained are related.

Thus the demographic variables indicate that respondents are more likely to choose feminist interventions as described in Part $2 F$, when they are recent graduates of schools of social work, and adhere to a humanist practice orientation. Their age, place of work, degree of urbanization and sex are all hardly associated, if associated at all, with the tendency to choose feminist interventions. 


\section{CHAPTER V}

\section{DISCUSSION}

Results of the questionnaire show that feminism is beginning to have an effect on social workers as individual citizens, if not in their professional practice. The degree of individual commitment to feminism and its relationship to using feminist interventions in professional practice are discussed in the first part of this section. The second part involves an examination of the way feminism has begun to affect social work practice.

\section{DIFFERENCE BETWEEN FEMINIST COMMITMENT AND PRACTICE}

Results of the questionnaire suggest that social workers hold many feminist beliefs. The results suggest that, in oregon, there is a consensus of support for feminist beliefs in terms of equal rights for women in employment. In addition, results suggest that social workers favor -- though less strongly -- redefining women's role in the family. While intellectual agreement with feminist beliefs is the most striking evidence of social work receptivity to feminism, some action -- particularly verbal support of their beliefs - is being 
taken by the large majority. In comparison with other groups surveyed using this scale, the response was more favorable to feminism. Thus it can be said that social workers in Oregon show a relatively significant committment to feminism in their personal lives.

In relating personal commitment to feminism to the likelihood of adopting feminist interventions in professional practice, it is clear that social workers in Oregon are less likely to use feminist interventions than to hold feminist beliefs. In contrast to the tendency to be in the position of agreeing with feminist beliefs as a group, the sample group was just slightly more than neutral about using feminist interventions in practice.

Reasons for this difference are not addressed in this study directly, but some speculation is tentatively supported by results of the demographic survey and by the identification of at least two groups of feminists among respondents.

One influence on the decreased likelihood of using feminist interventions in practice may be the countervailing values inherent in practice orientation. The more psychodynamically oriented social workers are less likely to use feminist interventions in practice. This indicates that it may be more difficult for social workers to integrate feminism and this type of practice orien- 
tation. More recent graduates, who are more likely to have been exposed to feminist concerns and the beginnings of academic effort to integrate these systematically with a practice orientation are more likely to use feminist interventions.

Further, the existence of a group of feminists who were active in pursuing equal rights for women, but did not use feminist interventions in practice, suggests that there may be general ideological orientations in the political sphere that inhibit the adoption of feminist interventions.

Beyond this, few observations can be supported at al1. Worthy of consideration, however, is the widespread tendency to believe, and even give "lip service" to what seems to be a good idea at the moment, without being committed enough to take the (inevitable) risks of putting it into practice. Numerous sociological studies have demonstrated the connection between belief and action: most find a higher incidence of belief than of action, and are yet unclear about the reasons for the difference (Kenniston, 1967: 108-137). The results of this study, indicating a difference between personal beliefs and professional actions, might be another instance of this widespread tendency.

Results of the study do show that, when the commitment to feminist beliefs is relatively higher (in the 
highest 50-60 range of Part 3), there is a tendency to adopt feminist interventions in practice. Scores in this highest range seem to be a necessary, though not a sufficient condition for a significant tendency to adopt feminist interventions.

This association of feminist beliefs and practice seems to suggest that, although there is still a discrepancy between belief and practice, as belief becomes very strong and comprehensive, it is more likely to be associated with attempts to actualize the belief in practice.

It is important to note that while practice orientation had a significant influence on the tendency to adopt feminist interventions, the correlation with feminist beliefs was stronger than that with practice orientation (0.3275 as compared with 0.21$)$.

This finding suggests that a significant factor in gaining greater acceptance of feminist interventions in practice is degree of commitment| to feminist beliefs. This is a political factor in the sense that political refers to the success (or lack of $i t$ ) of the feminist movement in convincing large numbers of people that its analysis of the social conditions of women -- including the relationship to mental health and other social services - is correct. This implies a concurrent influence on central government policies, which will in turn affect more people, but it is the degree of influence on social 
workers (and, doubtless, their potential client groups) that this study finds to be most important.

\section{PATTERN OF INFLUENCE ON PRACTICE}

Results show that the feminist influence on social work practice is just beginning. Feminist interventions have been more likely to be adopted in two areas: when they are most readily assimilable into traditional styles and standards of intervention, and when they conflict least with women's traditional role responsibilities.

Adoption Limited by Traditionally Prescribed Methods

In giving special help to women who have been adversely affected by conforming to the female role, whether they can see this for themselves or not, results are mixed. In the review of literature, three principle strategies of change emerged: becoming aware of personal rights and needs, coming to terms with long suppressed anger at unequal social treatment, and solidarity with other women.

First, as a group, social workers surveyed were most likely to adopt an intervention strategy that is not too discordant with the classic prescriptions. Thus, they were more likely to favor increasing a woman's selfawareness and self definition than they were to consider facilitating her anger at her social condition. Self 
awareness was overwhelmingly accepted as a therapeutic strategy for Frances, the older woman (Case 1). Helping Alice (23) become aware of her passivity was similarly, the most favored intervention in Case 3. An awarenessrelated issue in Case 2 -- helping Ellen recognize and deal with peer pressure on her to adopt feminine behavior -- was not supported however, presumably because its social content was more overt (and perhaps because Ellen is a rebellious adolescent; see below). Second, facilitating and legitimizing awareness of anger has been an important feminist strategy for promoting personal change. Respondents in the two groups who scored high on feminist intervention strategies (the active and the less active) both were as likely to choose facilitating anger as facilitating self awareness. This suggests that they regard these as coordinate and related strategies. In the sample group as a whole, however, there was distinctly less support for strategies related to facilitating and legitimizing anger. In the case of Frances (Case 1) this was still a preferred strategy, but less utilized than awareness; there was minimal receptivity to this in the case of Alice, and in Ellen's case it was rejected as a strategy by the majority.

The third major feminist strategy for personal change identified in the literature review is realizing that other women share the same problem and that, by 
working together, the problem can be overcome. While this idea is implicated to some degree in the idea that a woman's anger is legitimate, this is most directly dealt with in work with groups, which was not approached in this study.

In addition, it is clear that social workers are only beginning to validate the strengths of women that are not generally recognized in this culture. For exam-. ple, few would emphasize to Frances their appreciation of her competence at mothering (even when, in the intervention offered, this was expressed as "facilitating the growth of others," Jean Baker Miller's term), now that this skill may no longer be socially needed.

Adoption Limited by Traditional Role Responsibilities

Social workers show a willingness to be flexible in their definition of the proper role for a woman. For example, they would tend to support a woman's attempt to combine marriage and work, if this was what she wanted. This was evidenced in their rejection of the idea (presented as intervention 5 in Case 3) that Alice's anxiety was due to her wanting to work outside the home. According to the literature, some years ago, Alice's wanting to work outside the home (particularly when she was the mother of young children) would have been perceived as evidence of masculine protest or competitiveness with men 
and thus discouraged by the psychoanalytically orthodox social worker. A second reflection of this increased willingness to accept a woman's desire to explore alternatives is in the slight tendency to support Ellen's search for non-traditional options (the mean score on this intervention was 3.57 , just past the neutral midpoint in the direction of acceptance).

The finding that raises the most interesting speculations is the marked difference in the willingness of social workers to choose feminist interventions depending on the stage of life of their clients. This difference seems to be related to the degree to which the current social system depends on performance of the (traditional) role. Frances, at 46, has run the course: her family is successfully raised and gone. She can be self-aware, she can even be legitimately angry. What is interesting is that, at 15, Ellen's anger, which is raised at the same social role, is not legitimate, but rather should be cooled out by traditional methods of defusing anger (empathic listening, attributing responsibility for the situation to her, and though less so, stigmatizing her with the label "acting out"). Both Frances and Ellen are reacting to the constraints of the female role, despite their difference in age. Evidently, it is important that Ellen accept and go through with it, unless she is able to be very clear about what she wants (the questionnaire results 
indicate that social workers will validate role transcendence when a client is able to do this on her own, but will not work to stimulate the desire for role transcendence if it is not presented). It is incongruous that social workers would validate Frances' anger at the results of taking on the female role, when they are unwilling to tackle the prevention issue of helping Ellen to avoid such an unhealthy situation. Presumably, thirty years later, they would validate Ellen's anger, if she did take on the female role in the meantime. In Alice's case, there seems to be a hybrid situation. Alice, at 23, has clearly accepted the female role as part of her identity, like Frances, and, like Frances she is suffering as a result: the passivity that is part of this role is, in fact, a major constituent of her problem. On the other hand, unlike Frances, she still has a family to raise. Perhaps this is the reason that the tendency to work with Alice towards awareness of her situation, and towards anger at unjust treatment is more muted than in Frances' case.

In comparison with Ellen, however, Alice is a pliant client. She has, in fact, accepted the main contours of the role; she need merely change some aspects of it in order to get on with her job (and this, it seems is what she is likely to be helped to do).

Two alternative explanations for this pattern of 
results seem possible, but neither seems really to fit the cases presented. The first involves the social work maxim to "start where the client is." This would conceivably be related to the choice of feminist interventions if the female role is considered to be merely a life style option: the social worker would only deal with feminist issues with a client who needed to raise them. In the case of Alice, the client has evidently chosen a traditional role, and the social worker is therefore obligated to work with that, according to this maxim. Alice, however, despite her passivity, is asking for a non-traditional option, over her husband's objections. Moreover, social workers showed more tendency to use feminist responses with Frances, who made no demands for a non-traditional role. Ellen, also, clearly was looking for a non-traditional option, and was the least likely to receive feminist responses. Thus, the response seems not to depend on "where the client is" except in the sense of where she is in the stage of life.

In any case, feminists assert (and they assert that empirical studies prove) that the female role is inherently threatening to a woman's mental health. Thus, helping a woman move to a non-traditional role option would be part of good therapeutic practice, independent of the client's asking for help in this or not. It is the same thing as saying that, if a therapist believes a client 
needs more self-awareness, he or she will help the client move as far in this direction as the client can go, regardless of whether the client expresses a need to do this or not.

The only other explanation for this pattern besides the interpretation that it reflects pressure to conform to the current definitions of necessary social roles is that social workers consider Ellen (and, to a lesser extent, Alice) to be in a more pathological state than Frances, and therefore, are inclined to give less 1attitude to her expression of preferences and emotions. This does not seem supported by the cases themselves. As noted by the faculty members who examined the cases in Part 2, before it was mailed out as part of the questionnaire, all cases represent developmental crises (rather than severe pathology) and depressive symptomatology. In the case of Ellen, there is hostility and fighting with other girls, but it questionable wether this overt expression of anger is more pathological in actual fact than the self-punitive pattern characteristic of both Alice and Frances.

If this is considered more serious for the reason that Ellen's hostility is overtly expressed, this is more than a clue that issues of social control are involved in this case, more than in the others, and this, in turn would support the interpretation that the pat- 
tern of results is related to social pressure, as it affects Ellen, Alice, and Frances in a differentiated way -

Thus, although social workers show some notable receptivity to feminist influences in their practice, the tug of the tendency to see women in traditional ways is still marked. In the differentiated response to Ellen, Alice, and Frances is the meta-system impositionof the requirements of the traditional female role.

The two groups who were identified as being most likely to choose feminist responses also showed some difference in treatment of Ellen's case (see Table XII). Although there was no significant difference in their mean response to Alice and Frances, they were slightly less likely to choose a feminist response in the case of Ellen. This may indicate that feminism has not yet defined how it relates to the needs of children and adolescents adequately, and that this lack of definition may reflect another form of social oppression: as described by Myrdal, children, as well as women and blacks, are distinguished easily from the larger society, and subjected to a system of deprivations. 
TABLE XII

COMPARISON OF MEAN SCORES ON CASES IN PART 2F FOR GROUP 1, GROUP 3 AND

THE SAMPLE GROUP

\begin{tabular}{l|c|c|c}
\hline & \multicolumn{3}{|c|}{ Mean Average Scores on Part 2F } \\
\cline { 2 - 4 } & $\begin{array}{r}\text { Case 1 } \\
\text { (Frances })\end{array}$ & $\begin{array}{c}\text { Case 2 } \\
(\text { Ellen })\end{array}$ & $\begin{array}{c}\text { Case 3 } \\
\text { (Alice) }\end{array}$ \\
\hline $\begin{array}{l}\text { Group 1 } \\
(N=10)\end{array}$ & 4.1 & 3.9 & 4.6 \\
$\begin{array}{l}\text { Group 3 } \\
(N=8)\end{array}$ & 4.6 & 3.8 & 4.2 \\
$\begin{array}{l}\text { Sample } \\
(N=60)\end{array}$ & 4.08 & 3.06 & 3.66 \\
\hline
\end{tabular}




\section{CHAPTER VI}

\section{CONCLUSIONS}

This study appears to represent the pattern of feminist responses at one point in a process of transition. From a time when social work and other helping professions were not seen as helpful by feminists, there is now at least the beginning of a movement towards acceptance of the feminist analysis. In this regard, the major findings of this study are, first, that social workers are receptive to feminist beliefs, but show considerably less tendency to use feminist interventions in their practice. Second, the most important influences on the tendency to adopt feminist interventions identified in this study are commitment to feminism, practice orientation and time since last degree.

Limited Acceptance of Feminist Interventions

While acceptance of feminist beliefs is widespread, the movement to accept feminist interventions in practice is far behind. This movement, however, is most clearly evident in the areas of practice that can be most easily assimilated to it: dropping role prescriptions for those 
who wish to reject them, or for those who have, quite literally, outlived the role, and utilizing established awareness techniques in a feminist direction. Utilizing feminist interventions in the case of women who are of an age to be involved by traditional female role prescriptions -- unless they indicate a desire for a nontraditional role (and sometimes not even then) -- is not common among social workers. New feminist types of intervention strategies -- such as stimulating anger at unjust. social conditions to help the person grow to transcend them, or showing appreciation for skills the person may have that are not highly valued by the society -- are not common either.

That social work could adopt more feminist intervention strategies is indicated by the response pattern of those who had high scores on Part 2F. These respondents utilized both awareness techniques and facilitation of anger at the social role. They also made fewer stage of life distinctions than did the sample group as a whole. (Work in analyzing and dealing with the problmes of adolescents is just beginning within the feminist movement; perhaps as this is more carefully articulated within the movement there will be a greater possibility for change in this area as well). 
Influences in Adoption of Feminist Interventions

Impetus towards greater acceptance of the feminist analysis of what interventions will be helpful to women seems to have at least two sources: the broader feminist movement itself, and development away from strict psychodynamic analysis, particularly among more recent social work graduates.

The change in belief systems in a feminist direction is the most pronounced effect of the feminist movement, and this seems to be a necessary precondition for change in practice, although other influencing factors, unspecified in this study, intervene at this point. Still the only social workers who had a significantly feminist practice orientation were ones who also had extensive feminist beliefs and some involvement with the movement.

As noted in the review of literature, social work as a profession can be expected to be interested in social reforms if they have a solid empirical base to recommend them, and if they are not too far removed from what most workers (and powerful client groups) would accept. The importance of this overtly political test for the acceptance of reforms in the field is confirmed by this study. It is interesting to speculate about the group of feminist social workers concerned mainly with job rights issues, who scored lower than the sample mean on Part $2 \mathrm{~F}$. 
Certainly it indicates that if the feminist movement succeeds only in its equal rights concerns, increasing acceptance of feminist practice approaches will be less likely to occur. But the reason for this group's being less supportive of feminist interventions in practice than the sample group is unclear. Evidently, they are at least as likely (and, doubtless, more likely) than other social workers who do not share their feminist beliefs to be aware of the implications feminist theory has for practice. Perhaps, however, they have been able to succeed in the field themselves, and fail to recognize the barriers other women confront. Or, perhaps, they ascribe to a different general ideological position than the other feminist groups, a position which emphasizes individual capabilities and responsibility.

There is also influence from two other sources: the recent development of practice theories that permit a coherent reappraisal of the classic psychoanalyitc concepts relating to women. These theories are often humanist or related to a social systems or social psychological perspective. They are approaches which seriously work at incorporating viewpoints like this expressed by Perls, et al.:

...historical and cultural factors cannot be considered as complicating or modifying conditions of a simpler biophysical situation, but are intrinsic in the way the problem is presented to us (1951: 228). 
These perspectives are relatively recent additions to the social work curriculum. The connection of greater receptivity to feminist practice approaches among more recent graduates, who also tend to adopt such theories would seem to confirm this influence.

Movement away from psychodynamic explanation will not, in itself, strengthen the feminist influence on social work practice, of course. In the review of the literature relating to the Parsonian systems analysis of the family, there were clearly a number of ideas that feminists oppose. It is, rather, in the context of feminist political concern, as it has been mobilized by the feminist movement, that developing systems concepts and new humanist theories have been modified to incorporate ideas congruent with the feminist analysis.

Questions for Further Study

Further research might perhaps be focused on the other factors that influence adoption of feminist intervention strategies, besides conversion to feminist beliefs. It is clear that the conversion is a necessary but not sufficient concomitant of the adoption of feminist intervention strategies, and the strongest indicator identified in this study of the tendency to use feminism in practice. What other factors are involved, however, is not immediately apparent. Research might attempt to 
clarify the differences between the feminists concerned about job rights (often called "conservative") and those (often called "radical" or "political") concerned about women's social role. How these differences account for the great discrepancy in tendency to utilize feminist interventions should be further explored. In any case, in future research, a careful and systematic attempt should be made to distinguish between these two groups because the differences between them may be so significant. Another research focus might include a study of the differences between the two groups who had high scores on Part 2F, considering both their attitudes toward practice and toward the feminist movement in order to isolate other factors that influence the adoption of feminist intervention strategies.

Implications for Theories of Social Change

Fundamentally, for the author, the questions for further study raised by this work relate to the larger question of the mechanics of the process by which a change in belief and practice systems comes about in society. These processes are as yet little understood, and even the most solidly based recent theories (such as Thomas Kuhn's theory (1970), which is compatible with the evidence of this research) are widely debated. This study clearly illustrates one small section of the pro- 
cess of social change but, in the evidence that the momentum is mainly political, gives only gross indication of how this section studied relates to the whole process. To elaborate and articulate this connection would, of course require -- conservatively speaking -- many studies.

Thus, in answer to the original question of what the results of pressure by the resurgent feminist movement have been in the field of social work, it appears that feminism is widely accepted as an ideology among Oregon social workers, but only a small group of social workers engage in practice which is significantly influenced by the feminist analysis. Should feminism, in its social and cultural aspects, continue as a political force, there may be more change in social work practice due to feminist influence. If, on the other hand, feminism as a political movement has lost its momentum, feminist influence on social work may remain limited to the pattern sketched out in this study until there is another feminist push for change. It appears from this study that it is the political future that will tell whether the practice pattern here described will solidify as a plateau of considerable proportions, or become just a point in an ongoing movement of change. 


\section{BIBLIOGRAPHY}

Abarbane1, Gail. "Helping Victims of Rape." Social Work $21(1976), 478-482$.

Abbott, Sidney, and Barbara Love. "Is Women's Liberation a Lesbian Plot?" In Woman in Sexist Society. Ed. Vivian Gornick and Barbara $K$ Moran. New York: New American Library (Signet), 1971, pp. 601-621.

Ange 1, Jerome, ed. The Radical Therapist. New York: Ballantine Books, 1971.

Allen, Pamela. "Free Space." In Radical Feminism. Ed. Anne Koedt, Ellen Levine, and Anita Rapone. New York: New York Time Company (Quadrangle Books), 1973, pp. 271-279.

Allport, Gordon W. The Nature of Prejudice. Reading, Mass.: Addison-Wesley, 1954.

Alsbrook, Larry. "Marital Communication and Sexism." Social Casework $57(1976), 517-522$.

Babladelis, Georgia. "Editorial." Psychology of Women Quarterly 1 (1976), 3, 4.

Bardwick, Judith M. "The Sex Hormones, the Central Nervous System and Affect Variability in Humans." In Women in Therapy. Ed. Violet Franks and Vasanti Burtle. New York: Brunner/Mazel, 1974, pp. 27-50.

, and Elizabeth Douvan. "Ambivalence: The Socialization of Women." In Woman in Sexist Society. Ed. Vivian Gornick and Barbara K. Moran. New York: New American Library (Signet), 1971, pp. 225-241.

- Elizabeth Douvan, Matina S. Horner, and David Gutman. Feminine Personality and Conflict. Belmont, Calif.: Brooks Cole, 1970.

Bart, Pauline. "Depression in Middle-Aged Women." In Woman in Sexist Society. Ed. Vivian Gornick and Barbara K. Moran. New York: New American Library (Signet), 1971, pp. 163-186. 
- "Ideologies and Utopias of Psychotherapy." In The Sociology of Psychotherapy. Ed. Paul W. Roman and Harrison M. Trice. New York: Jason Aronson, 1974, pp. 9-57.

Bayes, Marjorie, Lynn Whisnat and Lynn Ann Wilk. "The Mental Health Center and the Women's Liberation Group: An Intergroup Encounter." Psychiatry 40 (1977), 66-78.

Beauvoir, Simone de. The Second Sex. Trans. and Ed. H. M. Parshley. New York: Random House (Vintage), 1974.

Bem, Sandra L. and Daryl J. Bem. "Case Study of a Nonconscious Ideology: Training Woman to Know Her Place." In Female Psychology: The Emerging Self. Ed. Sue Cox. Chicago: Science Research Associates, 1976, pp. 180-191.

Berlin, Sharon B. "Better Work With Women Clients." Social Work, 21 (1976), 492-497.

Bernard, Jessie. The Future of Marriage. New York: World, 1972 .

-c- Women, Wives, Mothers: Values and Options. Chicago: Aldine, 1975.

Bernard, Shirley. "Aggression in Women." In The Radical Therapist. Ed. Jerome Angel. New York: Ballantine, 1971, pp. 188-191.

Billingsley, Donna. "Sex Role Stereotypes and Clinical Judgments: Negative Bias in Psychotherapy." ERIC ED 136137 .

Bleir, Ruth H. "Brain, Body and Behavior." In Beyond Intellectual Sexism. Ed. Joan I. Roberts. New York: David McKay, 1976, pp. 64-73.

Borenzweig, Herman. "Social Work and Psychoanalytic Theory: A Historical Analysis." Social Work, 16 (1971), 7-16.

Brenner, Charles. An Elementary Textbook of Psychoanalysis. Garden City, N.Y.: Doubleday Anchor, 1957.

Briar, Scott. "The Casework Predicament." Social Work $13(1968), 5-11$. 
Brockway, Barbara Stevens. "Assertiveness Training for Professional Women." Social Work 21 (1976), 498505 .

Brodsky, Annette M. "The Consciousness Raising Group as a Model for Therapy with Women." Psychotherapy: Theory, Research and Practice 10 (1973), 24-29.

Broverman, Inge K., Donald M. Broverman, Frank E. Clarkson, Paul S. Rosenkrantz and Susan R. Vogel. "Sex Role Stereotypes and Clinical Judgments of Mental Health." In Woman: Dependent or Independent Variable. Ed. Rhoda Kesler Unger and Florence L. Denmark. New York: Psychological Dimensions, 1975, pp. 164-176.

Brooks, Keith. "Freudianism is Not a Basis for a Marxist Psychology." In Radical Psychology. Ed. Phil Brown. New York: Harper and Row (Harper Colophon), 1973, pp. 315-374.

Brown, Phil, ed. Radical Psychology. New York: Harper and Row (Harper Colophon), 1973.

- - - Toward a Marxist Psychology. New York: Harper and Row (Harper Colophon), 1974.

Brown, Phyllis and Eileen T. Nickerson. "Effectiveness of a Brief Intervention Strategy in Changing Attitudes Toward Women." Seventh Annual Convention of the $\mathrm{Na}$ tional Association of School Psychologists, Atlanta, Georgia. 18-19 January 1975. ERIC ED 123511.

Brownmiller, Susan. Against Our Will. New York: Bantam, 1976 .

Bul1, Jenny. "High School homen: Oppression and Liberation." In And Jill Came Tumbling After: Sexism In American Education. Ed. Judith Stacey, Susan Béreaud and Jean Daniels. New York: Dell (Laurel) 1974, pp. 213-220.

Burgess, Ernst and Paul Wallin. Engagement and Marriage. New York: Lippincott, 1953.

Butler, Pamela. "Assertiveness Training: Teaching Women Not to Discriminate Against Themselves." Psychotherapy: Theory, Research and Practice 13 (1976) 56-60. 
Castillejo, Irene Claremont de. Knowing Women. New York: Putnam, 1973.

Chafetz, Janet Saltzman. "Women in Social Work." Social Work 17 (1972), 12-18.

- _ Patricia Sampson, Paula Beck and Joyce West. "A Study of Homosexual Women." Social Work 19 (1974), $714-722$.

Chase, Karen. "Seeing Sexism: A Look at Feminist Therapy." State and Mind 6, No. 2 (1977), 19-22.

Chesler, Phyllis. Women and Madness. New York: Avon, 1972 .

Chodorow, Nancy. "Being and Doing." In Woman in Sexist Society. Ed. Vivian Gornick and Barbara K. Moran. New York: New American Library (Signet), 1971, pp. 259-291.

- . . Family Structure and Feminine Personality." In Women, Culture and Society. Ed. Michelle Zimbalist Rosaldo and Louise Lamphere. Stanford, Calif.: Stanford University Press, 1974, pp. 43-66.

-___-_. "Femininity, Feminism and Freud." The Psychoanalytic Psychology of Sigmund Freud Symposium of Pathfinders in Human Personality Series of the Division of Developmental Studies, University of Oregon, 21 October 1976.

Cox, Sue. Female Psychology. Chicago: Science Research Associates, 1976 .

Cummings, Mary and Judy Smith. "Consciousness Raising for the Counselors: the Development of a Counselor Referral File." Frontiers 1, No. 3 (1976), 34-46.

David, Deborah S. and Robert Brannon, eds. The 49\% Majority. Reading, Mass.: Addison-Wesley, 1976.

Davis, Martha Sue. "Women's Liberation Groups as a Primary Preventive Mental Health Strategy." Community Mental Health Journal 13 (1977), 219-228.

Dejanikus, Tacie and Fran Pollner. "Feminist Counseling." Rough Times 4 , No. 2 (1974), 10-12.

Dempewolff, Judith Ann. "Feminism and Its Correlates." Diss. University of Cincinatti, 1972. 
Donahue, Thomas J. "Research on Counselor Discrimination Against.Female Clients." Tenth Anniversary Meeting of the Michigan Personnel and Guidance Association, Detroit, Michigan. 2-4 November 1975. ERIC ED 124 848 .

Eastman, Paula Costa. "Consciousness Raising as a Resocialization Process for Women." Smith College Studies in Social Work 43 (1973), 153-183.

Edwards, Gwenyth, Dale Cohen and Marla Zanov. "Feminist Therapy Conference, 1975." Rough Times 4, No. 7 $(1975), 18,19$.

Englehard, Patricia Auer, Katheryn Otto Jones and Richard $\mathrm{J}$. Stiggins. "Trends in Counselor Attitudes About Women's Roles." Journal of Counseling Psychology $23(1976), 365-372$.

Etheridge, Carolyn F. "Equality in the Family." Interna tional Journal of Women's Studies 1 (1978), 7282 .

Faunce, Patricia Spencer and Susan Phipps-Yonas. "Women's Liberation and Human Sexual Relations." International Journal of Women's Studies 1 (1978), 8395.

Firestone, Shulamith. The Dialectic of Sex. New York: William Morrow, 1970.

Fodor, Ira Goldstein. "The Phobic Syndrome in Women." In Women in Therapy. Ed. Violet Franks and Vasanti Burtle. New York: Brunner/Mazel, 1974, pp. 132-168.

Follingstad, Diane R., Elizabeth A. Robinson and Marta Pugh. "Effects of Consciousness Raising Groups on Measures of Feminism, Self Esteem and Social Desirability." Journal of Counseling Psychology 24 $(1977), 223-2 \overline{30}$

Foster, Barb and Maggie Reed. "Sexism in the Helping Relationship." Workshop, Portland Oregon. 31 March 1978 .

Franks, Violet and Vasanti Burtle, eds. Women in Therapy. New York: Brunner/Mazel, 1974. 
Freeman, Jo. "The Building of the Gilded Cage." In . Radical Feminism. Ed. Anne Koedt, Ellen Levine and Anita Rapone. New York: New York Times Company (Quadrangle Books), 1973, pp. 127-150.

The Politics of Women's Liberation, New York: David McKay, 1975.

- "Social Construction of the Second Sex." In Female Psychology. Ed. Sue Cox. Chicago: Science Research Associates, 1976, pp. 136-151.

Freire, Paulo. Pedagogy of the Oppressed. New York: Seabury Press, 1970 .

Friedan, Betty. The Feminine Mystique. New York: Norton, 1963 .

Freud, Sigmund. "Consequences of the Anatomical Distinction Between the Sexes." In Women and Analysis, Ed. Jean Strouse. New York: Dell (Laurel), pp. 27-38. Jean Strouse. New York: Dell $\frac{\text { Women and Analysis. }}{\text { (Laurel), pp. 53-72. }}$

- - Femininity." In Women and Analysis. Ed. Jean Strouse. New York: De11 (Laure1), pp. 91-115.

Galper, Jefrey H. The Politics of Social Services. Englewood Cliffs, N.J.: Prentice Hall, 1975.

Glaser, Kristin. "Women's Self Help Groups as an Alternative to Therapy." Psychotherapy:-Theory, Research and Practice 13 (1976), 77-81.

Goffman, Erving. Stigma. Englewood Cliffs, N.J.: Prentice Hall (Spectrum), 1963.

Goldschmidt, J., M.M. Gergen, K. Quigley and K.J. Gergen. "The Women's Liberation Movement." Journal of Personality $42(1974), 601-617$.

Gornick, Vivian and Barbara K. Moran, eds. Woman in Se ist Society. New York: New American Library (Signet), 19.71.

Hacker, Helen. "Women as a Minority Group." In Female Psychology. Ed. Sue Cox. Chicago: Science Research Associates, 1976, pp. 156-170. 
Hamilton, Gordon. Theory and Practice of Social Casework, 2nd ed., rev. New York: Columbia University Press, 1951.

Hammen, Constance L. and Stephanie Dale Peters. "Differential Responses to Male and Female Depressive Reactions." Journal of Consuting and Clinical Psychology 45 (1977), 994-1001.

Hammer, Signe. Women: Body and Culture. New York: Harper and Row (Perennial Library), 1975.

Harris, Linda Hall and Margaret Exner Lucas. "Sex Role Stereotyping." Social Work 21 (1976), 386-389.

Henley, Nancy and Jo Freeman. The Sexual Politics of Interpersonal Behavior." In Female Psychology. Ed. Sue Cox. Chicago: Science Research Associates, 1976, pp. 171-179.

Hermes, Jeanette, "On Radical Therapy," In Going Crazy. Ed. Hendrik M. Ruitenbeek. New York: Bantam, 1972, pp. 23-40.

Hoffman, Frances Lee. "Foundations of Feminist Social Theory." Diss. University of Oregon, 1976.

Hole, Judith and Ellen Levine. Rebirth of Feminism. New York: New York Times Book Company (Quadrangle Books), 1971.

Holroyd, Jean. "Psychotherapy and Women's Liberation." The Counseling Psychologist 6. No. 2 (1976) pp. $22-28$.

Horney, Karen. "The Flight from. Womanhood." In Psychoanalysis and Women. Ed. Jean Baker Miller. Baltimore, Md.: Penguin: 1973, pp. 5-20.

- "The Problem of Feminine Masochism." Psychoanalysis and Women. Ed. Jean Baker Miller. Baltimore, Md.: Penguin, 1973, pp. 21-38.

Hubbard, Susan Dickes. "Social Pressures of Feminine Sexuality." Frontiers 1, No. 3 (1976), 31-33.

Huber Joan. "Sociology." Signs 1 (1976), 685-699.

Hyde, Janet S. and B.G. Rosenberg. Half the Human Experience. Lexington, Mass.: Heath, 1976. 
Jakubowski, Patricia. "Helping Women Develop Assertiveness Skills." Eighty-fourth Annual Conference of the American Psychological Association, Washington, D.C. 3-7 September 1976. ERIC ED 137679.

Johnson, Marilyn. "An Approach to Feminist Therapy." Psychotherapy: Theory, Research and Practice 13 $(1976), 72-76$.

Kaschak, Ellyn. "Sociotherapy." Psychotherapy: Theory, Research and Practice $13(1976), 6-63$.

Kelly, Jeffrey A. and Judith Worell. "New Formulations of Sex Roles and Androgyny: A Critical Review." Journal of Consulting and Clinical Psychology 45 (1977), 1101-1115.

Kenniston, Kenneth. "The Sources of Student Discontent." Journal of Social Issues $23(1967), 108-137$.

Kenworthy, Joy Anne, Corinne Koufacos and Julia Sherman. "Women and Therapy: A Survey on Internship Programs." Psychology of Women Quarterly 1 (1976), 125-137.

Kim, Jae-On and Frank J. Kohout. "Multiple Regression Analysis: Sub-Program Regression." In Statisstical Programs for the Social Sciences, 2nd ed., Ed. Norman H. Nie, C. Hadlai Hull, Jean G. Jenkins, Karlin Steinbrenner, and Dale H. Bent. New York: McGraw Hill, 1975, pp. 320-367.

Kirsh, Barbara. "Consciousness Raising Groups as Therapy for Women." In Women in Therapy. Ed. Violet Franks and Vasanti Burtle. New York: Brunner/Mazel, 1974, pp. 326-354.

Klapper, Zelda S. "The Impact of the Women's Liberation Movement on Child Development Books." In The Women's Movement. Ed. Helen Wortis and Clara Rabinowitz. New York: AMS Press, 1972, pp. 21-26.

Klein, Viola. "The Stereotype of Femininity." In Woman: Dependent or Independent Variable. Ed. Rhoda Kesler Unger and Florence L. Denmark. New York: Psychological Dimensions, 1975, pp. 19-30.

Koedt, Anne. "The Myth of the Vaginal Orgasm." In Radical Feminism. Ed. Anne Koedt, Ellen Levine and Anita Rapone. New York: New York Times Company (Quadrangle Books), 1973, pp. 198-207. 
- Ellen Levine and Anita Rapone, eds. Radical Feminism. New York: New York Times Company (Quadrangle Books), 1973.

Kravetz, Diane F. "Consciousness Raising Groups and Group Psychotherapy: Alternative Mental Health Resources for Women." Psychotherapy: Theory, Research and Practice $13(1976), 66-71$.

Work $21(1976), 421-426$.

"Women and Social Workers: Common Victims of Sexism." In Beyond Intellectual Sexism. Ed. Joan I. Roberts. New York: David McKay, 1976, pp. 160-170.

Kronsky, Betty J. "Feminism and Psychotherapy." Journal of Contemporary Psychotherapy 3, No. 2 (1971), pp. 89-98.

Kuhn, Thomas S., The Structure of Scientific Revolutions, 2nd ed. Chicago: University of Chicago Press, 1970.

Laing, R.D. The Politics of Experience. New York: Ballantine, 1967 .

Family. Baltimore, Md.: Penguin, 1964 .

Laws, Judith Long. "A Feminist Review of Marital Adjustment Literature." Journal of Marriage and the Family 33 (1971), T83-516.

Lazarus, Arnold A. "Women in Behavior Therapy." In Women in Therapy. Ed. Violet Franks and Vasanti Burtle. New York: Brunner/ Maze1, 1974, pp. 217-229.

Lerman, Hannah. "What Happens in Feminist Therapy." Frontiers 1 , No. $3(1976), 17-22$.

Lewis, Melvin. Clinical Aspects of Child Development. Philadelphia: Lea and Febiger, 1971.

Lindsey, Karen. "On the Need to Develop a Feminist Therapy." Rough Times 4, No. 3 (1974), 2, 3 .

Liss, Lora. "Development and Demise of a Women's Center." Meeting of the Society for the Study ot Social Problems, Montreal, Canada. August 1974: ERIC ED 124 460 . 
Maccoby, Eleanor Emmons and Carol Nagy Jacklin. "Summary and Commentary from The Psychology of Sex Differences." In Female Psychology. Ed. Sue Cox. Chicago: Science Research Associates, 1976, pp. 104-121.

Mander, Anica Vesel and Ann Kent Rush. Feminism as Therapy. New York: Random House; Berkeley: Bookworks, 1974.

Marecek, Jeanne. "Dimensions of Feminist Therapy." Eightythird Annual Convention of the American Psychological Association, Chicago, Illinois. 30 August2 September, 1975. ERIC ED 119062.

- - "Power and Women's Psychological Disorders." Eighty-third Annual Convention of the American Psychological Association, Chicago, Illinois. 30 August - 2 September, 1975. ERIC 124856.

- Cond and Christine Frash. "Locus of Control and College Women's Role Expectations." Journal of Counseling Psychology 24, No. 2 (1977), 132-136.

Masters, William H. and Virginia E. Johnson. Human Sexual Inadequacy. Boston: Little Brown, 1970. 1966.

Mausner, Bernard and Barbara Coles. "Avoidance of Success Among Women." International Journal of Women's Studies 1 (1978), 30-49.

Mead, Margaret. "Conclusion from Sex and Temperament in Three Primitive Societies." In Female Psychology. Ed. Sue Cox. Chicago: Science Research Associates, 1976, pp. 63-71.

Mednick, Martha Shuck and Hilda J. Weissman. "The Psychology of Women -- Selected Topics." In Female Psychology. Ed. Sue Cox. Chicago: Science Research Associates, 1976, pp. 122-135.

Meyer, Carol H. "Direct Services in New and Old Contexts." In Shaping the New Social Work. Ed. Alfred J. Kahn. New York: Columbia University Press, 1973, pp. 2654.

- - Social Work Practice, lan (The Free Press), 1976.

2nd ed. New York: McMil- 
Millex, Jean Baker. "New Issues, New Approaches." In Psychoanalysis and Women. Ed. Jean Baker Miller. Baltimore, Md.: Penguin, 1973, pp. 375-406.

Md.: Penguin, 1973.

Beacon, 1976 .

- - , and Ira Mothner. "Psychological Consequences of Sexual Inequality." American Journal

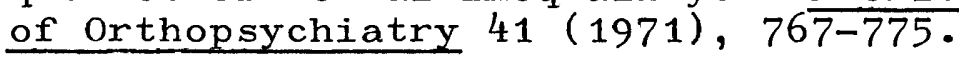

Miller, Nadine. "Letter to Her Psychiatrist." In The Radical Therapist. Ed. Jerome Angel. New York: Ballantine, 1971, pp. 139-143.

Millet, Kate. Sexual Politics. Garden City, N.Y.: Doubleday, 1970 .

Mitche11, Juliet. Psychoanalysis and Feminism. New York: Random House (Vintage), 1975.

- Women's Estate. New York: Pantheon, 1972.

Montana Assertiveness Training Collective for Women. "The Personal is Political." State and Mind 6, No, 2 $(1977), 22-25$.

Morgan, Robin, ed. Sisterhood is Powerful. New York: Random House, $19 \overline{70 .}$

Moulton, Ruth. "Some Effects of the New Feminism." American Journal of Psychiatry 34 (1977), 1-6.

"A Survey and Reevaluation of the Concept of Penis Envy." In Psychoanalysis and Women. Ed. Jean Baker Miller. Baltimore, Md.: Penguin, 1973, pp. 240-258.

Mueller, Karen and Margie Whittaker Leidig. "Women's Anger and Feminist Therapy." Frontiers 1, No. 3 $(1976), 23-30$.

Mueller, John H., Karl F, Schuessler and Herbert L. Costner. Statistical Reasoning in Sociology, 2nd ed. Boston: Hought n Mifflin, 1970 . 
Mundy, Jean. "Women in Rage." In Woman: Dependent or Independent Variable. Ed. Rhoda Kesler Unger and Florence . Denmark. New York: Psychological Dimensions, 1975, pp. 196-210.

Myrdal, Gunnar. An American Dilemma. New York: Harper, 1944.

Neil, Georgia and Carol Woolfe. "Assertive Training." Rough Times 5, No. 2 (1976), pp. 10, 11.

Nickerson, Eileen T. "Intervention Strategies for Modifying Sex Role Stereotypes." Seventh Annual Convention of the National Association of School Psychologists, Atlanta, Georgia. 18-19 January 1975. ERIC ED 123513 .

Oakley, Ann. "Sexuality." In Female Psychology. Ed. Sue Cox. Chicago: Science Research Associates, 1976 , pp. 264-279.

Orasami, Judity and Rosamond Gianutsos. "A Case Study of Sexism and Elitism in an Introductory Psychology Textbook." Rough Times 4, No. 2 (1974), pp. 8,9.

Ortner, Sherry B. "Is Female to Male as Nature is to Culture?" In Women, Culture and Society. Ed. Michelle Zimbalist Rosaldo and Louise Lamphere. Stanford, Calif.: Stanford University Press, 1974, pp. 67-87.

Parlee, Mary Brown. "Psychology." Signs 1 (1975), pp. 119139 .

Perls, Frederick, Ralph E. Hefferline and Paul Goodman. Gestalt Therapy. New York: Dell (Delta), 1951.

Phelps, Stanlee and Nancy Austin. The Assertive Woman. San Luis Obispo, Calif.: Impact, 1975.

Pincus, Allen and Anne Minahan. Social Work Practice. Itasca, Ill.: Peacock, $197 \overline{3 .}$

Pincus, Cynthis, Nathalie Redding and Roberta Lawrence, "A Professional Counseling Service for Women." Social Work $19(1974)$, pp. 187-195.

Pogue, Elissa and Cercie Miller. "The Elizabeth Stone House." Rough Times 5, No. 2 (1976), pp. 2-4. 
Pollock, Mordeca Jane. "Changing the Role of Women." In The Women's Movement. Ed. Helen Wortis and Clara Rabinowitz. New York: AMS Press, 1972, pp. $10-20$.

Powe11, Barbara. "The Empty Nest, Employment and Psychiatric Symptoms in College Educated Women." Psychology of Women Quarterly 2 (1977), 35-43.

Radov, Carol G., Barbara R. Masnick and Barbara B. Hauser. "Issues in Feminist Therapy." Social Work 22 (1977), 507-509.

Redstockings Sister. "Brainwashing and Women." In The Radical Therapist. Ed. Jerome Angel. New York: Ballantine, 1971, pp. 121-126.

Reuther, Rosemary. New Woman/New Earth. New York: Seabury Press (Crossroad), 1975.

Rice, Jay K. and David G. Rice. "Implications of the Women's Liberation Movement for Psychotherapy." The American Journal of Psychiatry 130 (1973), 191-196.

Roberts, Joan I., ed. Beyond Intellectual Sexism. New York: David Mc

Rosaldo, Michelle Zimbalist and Louise Lamphere, eds. Women, Culture and Society. Stanford, Calif.: Stanford University Press, 1974.

Rossi, Alice S. "Equality Between the Sexes." In The New Feminism in Twentieth Century America. Ed. June Sochen. Lexington, Mass.: D.C. Heath, 1971, pp. $79-87$.

Ruitenbeek, Hendrick M. Going Crazy. New York: Bantam, 1972 .

Rush, Ann Kent. Getting Clear. New York: Random House; Berkeley, Calif.: The Bookworks, 1973.

- "What is Feminist Therapy?" In Feminism as Therapy. Ed. Anica Vesel Mander and Ann Kent Rush. New York: Random House; Berkeley: The Bookworks, 1974, pp. 37-59.

Schneidt, May. "Challenging AT." Quest 4 (1977), 76-84. 
Schnitzer, Phoebe Kazdin. "The Motive to Avoid Success." Psychology of Women Quarterly 1 (1977), 273-282.

Schur, Edwin M. Labeling Deviant Behavior. New York: Harper and Row (Monograph), 1971 .

Schwartz, Mary C. "Importance of the Sex of Worker and Client." Social Work 19 (1974), 177-184.

Schuyler, Marcella. "Battered Wives." Social Work 21 $(1976), 480-491$.

Scotch, C. Bernard. "Sex Status in Social Work." Social Work 16 (1971), 5-11.

Seligman, Martin E.P. Helplessness. San Francisco: W.H. Freeman, 1975 .

Sennett, Richard and Jonathan Cobb. The Hidden Injuries of Class. New York: Random House (Vintage), 1972.

Shainess, Natalie. "Images of Women." Journal of Psychotherapy $23(1969), 77-97$.

Sherfey, Mary Jane. "A Theory on Female Sexuality." In Psychology of Women. Ed. Sue Cox. Chicago: Science Research Associates, 1976, pp. 278-283.

Sherman, Julia A. On the Psychology of Women. Springfield, I1l.: Charles G. Thomas, 1971.

Silverman, Daniel. "First Do No More Harm." American Journal of Orthopsychiatry 47 (1977), 91-96.

Sochen, June. Movers and Shakers. New York: New York Times Book Co. (Quadrangle), 1973.

America. Lexington, Mass.: D.C. Heath, 1971.

Stacey, Judith, Susan Béreaud and Jean Daniels. And Jill Came Tumbling After. New York: Dell (Laure 1 ), 1974.

Steiner, Claude M. Scripts People Live. New York: Bantam, 1975.

Steinman, Anne and Leonard H. Alshan. "Role Change." Eighty-fourth Convention of the American Psychological Association, Washington, D.C. 3-7 September 1976. ERIC ED 137633 . 
Stevens, Barbara. "The Psychotherapist and Women's Liberation." Social Work 16 (1971), 12-18.

Strouse, Jean, ed. Women and Analysis.. New York: Dell (Laure1), $197 \overline{4 .}$

Tanner, Leslie B. Voices from Women's Liberation. New York: New American Library (Signet), 1970.

Tarvis, Carol Ann. "The Unliberated Liberals." Diss. University of Michegan, 1971.

Tennov, Dorothy Psychotherapy: The Hazardous Cure. New York: Abelard-Schurman, 1975.

Thomas, Susan Amelia. Moving Towards Integration. Thesis. Portland State University, 1975.

Thompson, Clara. "Cultural Pressures in the Psychology of Women." In Psychoanalysis and Women. Ed. Jean Baker Miller. Baltimore, Md.: Penguin, 1975, pp. 69-84.

- - "Penis Envy in Women." In Psychoanalysis and Women. Ed. Jean Baker Miller. Baltimore, Md.: Penguin, 1973, pp. 52-57.

- Nome Effects of the Derogatory Attitude Towards Female Sexuality." In Psychoanalysis and Women. Ed. Jean Baker Miller. Baltimore, Md.: Penguin, 1973, pp. 58-68.

Tinker, Bonnie. "The Bradley/Angle House." Class Meeting of SW 553, School of Social Work, Portland State University, Portland, Oregon. 5 December, 1976.

Torrey, Jane W. "It Takes All Kinds (To Make a Movement)." International Journal of Women's Studies 1 (1977), 167-177.

Turkel, Ann Ruth. "A Woman Analyst's Practice and Feminism." American Journal of Psychoanalysis 36 (1976), $119-126$.

Unger, Rhoda Kesler and Florence L. Denmark. Woman: Dependent or Independent Variable. New York: Psychological Dimensions, 1975.

Walstedt, Joyce Jennings. "Beyond Freud." Frontiers 1, No. 3 (1976), 1-9. 
Wandrei, Karin. "Lesbians in Therapy." Rough Times 4, No. $8(1975), 2-4$.

Webbink, Pat. "Growing Women." State and Mind 5, No. 4 $(1976), 8$.

Weissman, Myrna M. "Depressed Women:" Eighth Symposium on fective Psychotherapy of the Texas Research Institute of Mental Sciences, Houston, Texas. 19-21 November 1975. ERIC ED 127510.

Weisstein, Naomi. "Psychology Constructs the Female." In Woman in Sexist Society.. Ed. Vivian Gornick and Barbara K. Moran. New York: New American Library (Signet), 1971, pp. 207-224.

Wetzel, Janice Wood. "Interaction of Feminism and Social Work in America." Social Casework 57 (1976), 227236 .

\section{Frontiers 1, No. 3(1976), 10-16.}

White, Martha S. "Psychological and Social Barriers to Women in Science." Science 170 (1970), 413-416.

Williams, Elizabeth Friar. Notes of a Feminist Therapist. New York: Dell (Laure I), 1976.

Williams, Juanita H. Psychology of Women. New York: Norton, 1977 .

Williams, Martha, Liz Ho and Lucy Fielder. "Career Patterns." Social Work 19 (1974), 463-466.

Wolman, Carol S. "Therapy Groups for Women." American Journal of Psychiatry 133 (1976), 274-278.

Women and Therapy Project at Goddard-Cambridge Graduate School for Social Change. "Feminist Therapy Conference." State and Mind 5 No. 3 (1976), 19-21.

Women in Mental Health Project. "Women to Women Services." Social Policy $7(1976), 21-27$.

Wortis, Helen and Clara Rabinowitz. The Woman's Movement. New York: AMS Press, 1972.

Wyckoff, Hogie. "Radical Psychiatry in Women's Groups." In The Radical Therapist. Ed. Jerome Ange1. New York: Ballantine, 1971, pp. 181-187. 
"Sex Role Scripting in Men and Women and Banal Scripts of Women." In Scripts People Live. Claude M. Steiner. New York: Bantam, 1975, pp. 196-234.

-- Solving Women's Problems. New York: Grove Press, 1977 .

Yates, Gayle Graham. What Women Want. Cambridge, Mass.: Harvard University Press, 1975.

Young, Alma T., Barbara Berkman and Helen Rehr. "Women Who Seek Abortions." Social Work 18 (1973), 60 . 
APPENDIX 
February 15,1978

Dear Member of N.A.S.W.:

As a student in Portland State's Master's in Social Work program, I have decided to do research on issues in social work treatment in Oregon. The N.A.S.W. Oregon Chapter has agreed to give its active cooperation with this project.

You have been selected as part of a random sample of N.A.S.W. members in an effort to get reliable information about the views and treatment strategies of oregon social workers. I would appreciate your taking the time to fill out the enclosed questionnaire. It probably will require about 15 minutes.

The questionnaire is in four parts. You will find that part two is a group of case descriptions: please respond to them as you would in actual practice. You will note the questionnaire you receive is coded. The code is to facilitate follow-up and will not be used to identify individual responses. Data analysis will be in terms of the sample group. Furthermore, the questionnaires will be destroyed as soon as the necessary data are abstracted from them.

If you would be interested in the results of this survey and my own conclusions, please fill out the form below and enclose it with your questionnaire (or mail separately if you want to avoid identifying your questionnaire).

Please return this form by March 1,1978 .

I hope that you will take the time to respond.

Sincerely,

Elizabeth Miller

I would like to receive a copy of the results of the survey, and

a summary of the research conclusions.

Mailing Label:

Name

Street Address

City, State, Zip 
Code :

Part One

Age: Please check one

under $35 \longrightarrow 36-50 \longrightarrow 51$ and over

Sex: Please check one

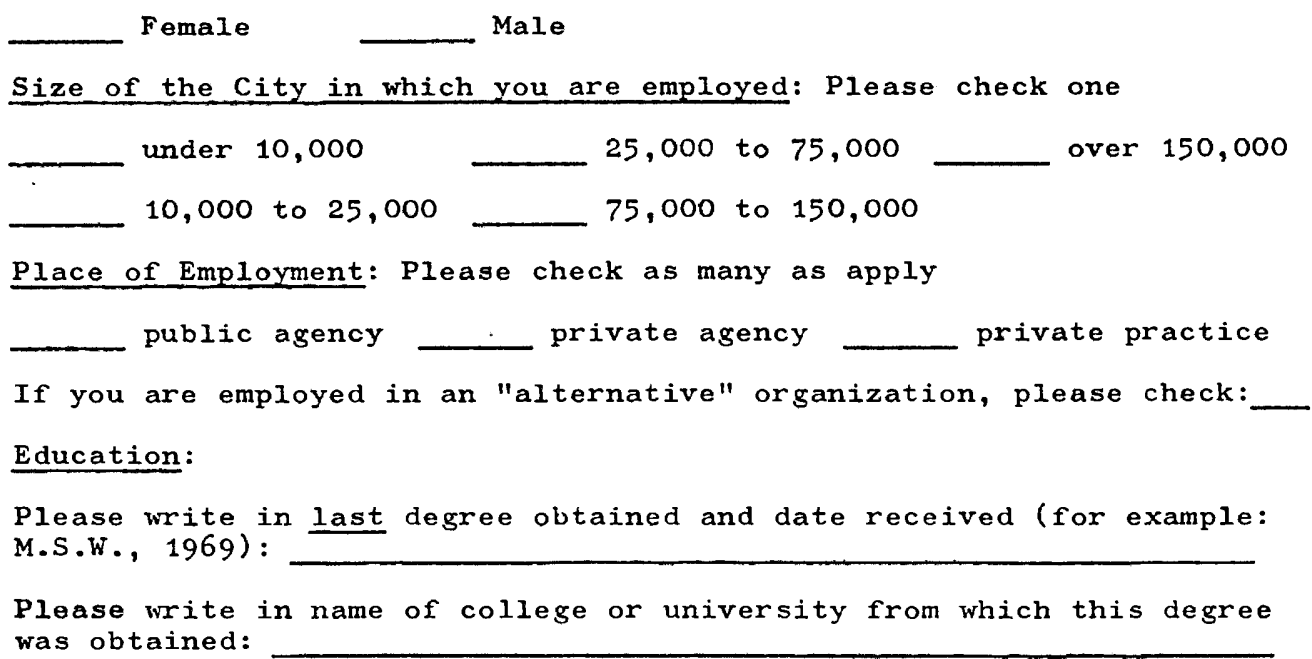

Ethnic Background: Please check one

$\begin{array}{ll}\text { Afro-American } & \text { Spanish Surname } \\ \text { American Indian } & \text { Caucasian } \\ \text { Oriental American } & \text { Other (Specify: }\end{array}$

Practice Orientation: Please check all that apply

- Adlerian
Assertive Training
Behaviorism
Bioenergetics
Co-counseling
Eclectic
Family Therapy
Freudian
Gestalt
Humanistic
Other ISnorifv:

Jungian Learning Theory Primal Psychodyanmic Radical Therapy Reichian Relaxation Training Rogerian Social Casework Transactional Analysis 
Part Two

Below are three case descriptions followed by a list of possible interventions. Please indicate how likely you would be to employ each of these interventions on the five-point scale, from very likely to very unlikely. The range of interventions listed is not meant to be comprehensive, nor does the order in which they appear indicate a sequential treatment plan.

\section{Case 1}

Frances Grant, 46, says her daughter told her to go talk to someone, which is the reason she made an appointment to see you. Frances says that since the youngest of her three children left home, she has been feeling tired, at loose ends, and it's getting worse. She says she hears herself complaining all the time to her husband, her neighbors, and her children (when she can get hold of them). She gets so sick of herself that sometimes she cries. Her daughter tells her she should get a job, she says, but she has no skills. She adds that, lately, she has been having dreams about her children -- in which each one meets some catastrophic end. This is deeply disturbing to her; now she's even afraid to go to sleep.

During the course of your treatment of Frances, how likely would you be to use any of the following interventions? Please indicate your response by circling one of the numbers on the fire-point scale.

1. Working through her anger toward her children (and, ideally, also exploring the character of her relationship to them before they left home)

$$
\text { Very unlikely }
$$

2. Encouraging Frances to reconsider and re-value the skills she may have developed as a mother in facilitating the growth of other people

$$
\text { Very unlikely }
$$

3. Using anti-depressant medication (or, if more appropriate, hormone replacement therapy) to ease her transition through menopause

$$
\text { Very unlikely Very likely }
$$

4. Helping Frances to recognize her anger and fear as an appropriate response to the unanticipated situation of no longer being needed as a mother

$$
\text { Very unlikely }
$$

5. Encouraging Frances to keep busy by increasing her involvement in community activities

$$
\text { Very unlikely }
$$

6. Encouraging her to begin the process of identifying her own wants and needs - differentiated from relationships with children and husband - to refashion a meaningful role and identity Very unlikely Very likely 
Case 2

Ellen is 15, in the ninth grade, and has been referred to you by one of her teachers. The teacher. gives you a history of non-cooperation with school authorities, frequent fights with girls her own age, and an apparent lack of interest in boys. Ellen herself relates a long list. of grievances against significant adults and her peers. She says they call her crazy, but she says they are the ones that are really crazy. She is impatient with school, and finds the work boring. She speaks scathingly about pollution, romantically about the environment, and being alone with nature, and, somewhat anxiously, confides to you her dream of becoming an environmental engineer to do something about the problem. When you ask her what problems you could work on together, she pauses, and states that no one will be her friend, and she finds this confusing.

During the course of your treatment of Ellen, how likely would you be to use any of the following interventions? Please indicate your response by circling one of the numbers on the five point scale.

1. Help Ellen to identify and deal with social pressures from adults and peers to adopt feminine interests and behaviors Very unlikely

2. Discuss with Ellen the consequences of her acting out behavior Very unlikely Very likely $1+3-2-3$

3. Help Ellen learn to evaluate and accept her own responsibility for the situations she finds unsatisfactory Very unlikely Very likely

4. Support and clarify Ellen's anger that the options that appear to be open to her are inadequate for her needs Very unlikely $\quad$ Very likely:

5. Explore with Ellen the implications of the idea that, in principle, all career roles and sexual orientations are open to her Very unlikely Very likely

6. Use empathic listening to help her through her adolescent "identity crisis" Very unlikely 


\section{Case 3}

Alice Long is a twenty-three year old mother of two (Liza, 21/2 years, and Bobby, 6 months), who has asked you for help in dealing with a recent depression. She has had "bad periods" before, but this, she says, is worse: she sleeps, cries a lot, and reads romantic novels "to take my mind off it." She feels she doesn't have any friends left and is not sure "what I did wrong." She states that "I can't seem to do anything right" as far as her husband, Dale, is concerned, and gives quite a list of her (unsuccessful) efforts to gain his approval. Although she held a job as a file clerk for a year before Bobby's birth, she did not make independent decisions about spending money, nor did she open her own bank account, for fear of offending Dale still further. She says, shyly, that she'd really like to go back to work, but Dale thinks Bobby is too young to be without her. Alice volunteers that whe has thought of leaving Dale, but wonders if she might not feel even more depressed alone with the two kids in an apartment. Dale, she says, would never come in with her for counseling and, besides, she would rather have the time with you all to herself.

In the course of your treatment of Alice, how likely would you be to use any of the following interventions? Please indicate your response by circling one of the numbers on the five-point scale.

1. Helping Alice deal with unresolved conflicts with parental figures

$$
\text { Very unlikely } 2-3 \text { - Very likely }
$$

2. Working out a program of assertiveness training

$$
\text { Very unlikely }
$$

3. Focusing on improving Alice's skills as a mother and her relationship with Dale

$$
\text { Very unlikely }
$$

4. Helping Alice to realize that while pleasing others and submissiveness are part of the sex role she was taught, these behaviors involve a loss of her own power

$$
\text { Very unlikely }
$$

5. Stimulating her awareness that the world of work may be too much for her, causing her inferiority feelings, and that she would be more fulfilled caring for her young children Very unlikely Very likely

6. Facilitating her awareness of anger at being assigned to an inferior sex role, and helping her channel it into effective action for growth

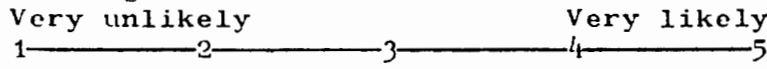




\section{Part Three}

Please indicate the extent of your agreement or disagreement with the following propositions by circling a number on the five-point scale.

1. There should be legislative restrictions on abortion.

$$
\text { Disagree strongly } 3
$$

2. Community day-care centers should be established nationally.

Disagree strongly Agree strongly

3. Men and women should be paid equally for equal work.

$$
\text { Disagree Strongly } 3-3-4
$$

4. Motherhood is the most fulfilling role for women. Disagree strongly Agree strongly

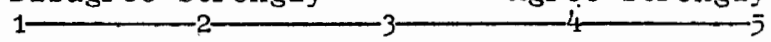

5. It is important for me to be physically attractive to the opposite sex.

Disagree strongly Agree strongly

6. Women should not be able to obtain an abortion merely on request. Disagree strongly

7. I would place my children in a day-care center. Disagree strongly Agree strongly $1 \longrightarrow 2-3-2-3$

8. There are circumstances in which women should be paid less than men for equal work.

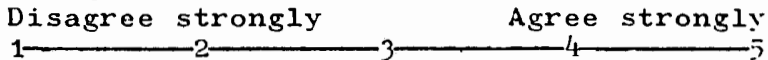

9. There are some jobs for which women are emotionally unfit. Disagree strongly Agree strongly

10. A woman's career should always be secondary to her husband's. Disagree strongly Agree strongly $1 \longrightarrow 2-3-4$

11. The wife should not always have primary responsibility for household duties.

$$
\text { Disagree strongly Agree strongly: }
$$

12. The mother should have primary responsibility for care and nurturance of children.

$$
\text { Disagree strongly Agree strongly }
$$




\section{Part Four}

Please check if you have ever done any of the following in support of the Women's Movement.

gave a financial donation

rendered verbal support

attended meetings

distributed literature

demonstrated

organized any of the above activities

participated in any other way: please indicate

Would you please check to be sure that you have answered all of the questions. Thank you. 